\title{
Conjugated Polymers with Repeated Sequences of Group 16 Heterocycles Synthesized through Catalyst- Transfer Polycondensation
}

Chia-Hua Tsai, ${ }^{\dagger}$ Andria Fortney, ${ }^{\dagger}$ Yunyan Qiu, Roberto R. Gil, David Yaron, Tomasz Kowalewski and Kevin J. T. Noonan

Department of Chemistry, Carnegie Mellon University, 4400 Fifth Avenue, Pittsburgh, Pennsylvania, 15213, United States.

Corresponding authors: noonan@andrew.cmu.edu, 1-412-268-3128

tomek@andrew.cmu.edu,1-412-268-5927

yaron@andrew.cmu.edu, 1-412-268-1351

\section{Table of Contents}

Materials and Methods

S6-S1 1

Experimental Procedures

S12-S27

Scheme S1. Synthesis of monomer 1

5'-bromo-3,4'-dihexyl-2,2'-bithiophene (1)

Scheme S2. Synthesis of monomer 2

(4-hexylselenophen-2-yl)trimethylstannane

S12-S13

3-hexyl-2-(4-hexylselenophen-2-yl)thiophene (A)

2-(5-bromo-4-hexylselenophen-2-yl)-3-hexylthiophene (2)

Scheme S3. Synthesis of monomer 3

3,4'-dihexyl-5'-(4-hexylselenophen-2-yl)-2,2'-bithiophene (B)

5'-(5-bromo-4-hexylselenophen-2-yl)-3,4'-dihexyl-2,2'-bithiophene (3) ....S 16-S17

Scheme S4. Synthesis of monomer 4

2-(3,4'-dihexyl-[2,2'-biselenophen]-5-yl)-3-hexylthiophene (C). S18

2-(5'-bromo-3,4'-dihexyl-[2,2'-biselenophen]-5-yl)-3-hexylthiophene (4). 
Scheme S5. Synthesis of monomer 5 S20

3-hexyl-2-(4-hexyl-5-(4-hexylselenophen-2-yl)thiophen-2-yl)furan (D)....S20-S21

2-(5-(5-bromo-4-hexylselenophen-2-yl)-4-hexylthiophen-2-yl)-3-hexylfuran (5)

S21-S22

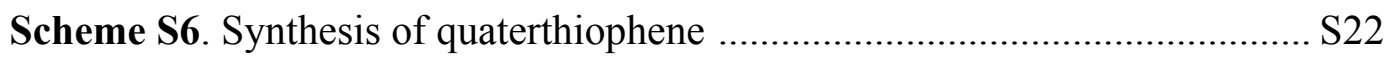

5"'-bromo-3,4',4",4"'-tetrahexyl-2,2':5',2":5",2"'-quaterthiophene .............. S22-S23

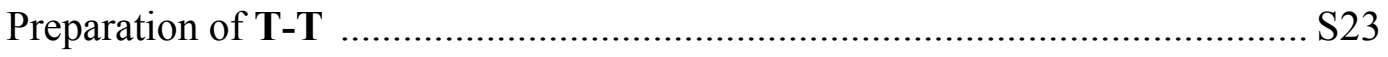

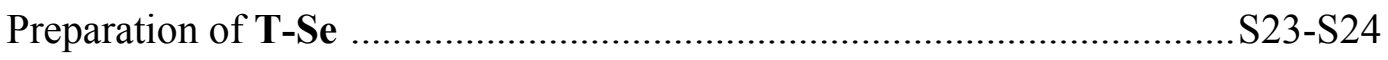

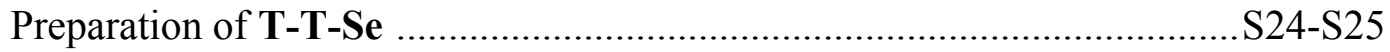

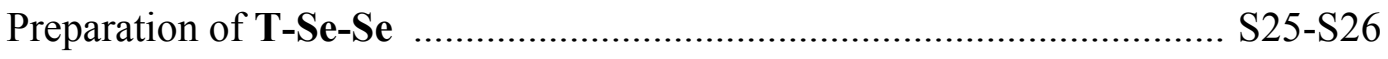

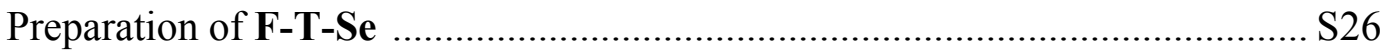

Preparation of P3HT using quaterthiophene …………………………...... S27

Procedure for Obtaining $M_{\mathrm{n}}$ versus Conversion Plot …………………………....S27-S29

Table S1. $M_{\mathrm{n}}$ versus Conversion Data for T-T ………………………......... S28

Figure S1. $M_{\mathrm{n}}$ versus Conversion Plot for T-T ………………………….... S28

Table S2. $M_{\mathrm{n}}$ versus Conversion Data for T-Se …………............................... S29

Figure S2. $M_{\mathrm{n}}$ versus Conversion Plot for T-Se ............................................ S29

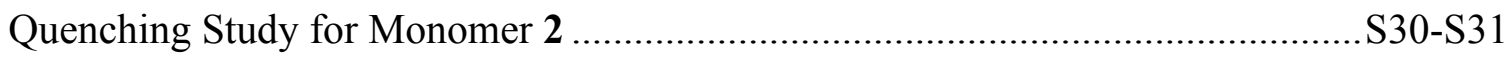

Figure S3. ${ }^{1} \mathrm{H}$ NMR Spectrum …………………….................................. $\mathrm{S} 30$

Figure S4. GC-MS Chromatogram ................................................................ S31

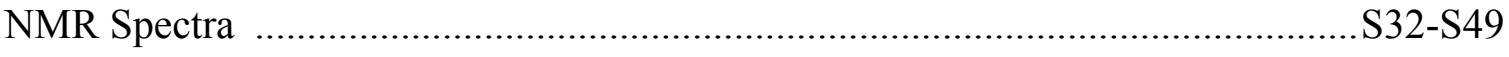

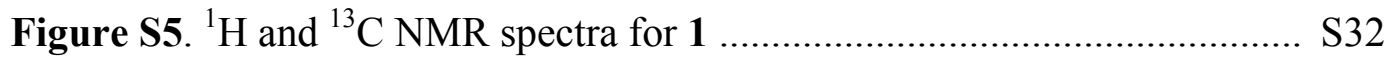


Figure S6. ${ }^{1} \mathrm{H}$ and ${ }^{13} \mathrm{C}$ NMR spectra for (4-hexylselenophen-2-

yl)trimethylstannane

Figure S7. ${ }^{1} \mathrm{H}$ and ${ }^{13} \mathrm{C}$ NMR spectra for compound $\mathbf{A}$ S34

Figure S8. ${ }^{1} \mathrm{H}$ and ${ }^{13} \mathrm{C}$ NMR spectra for compound 2 S35

Figure S9. ${ }^{1} \mathrm{H}$ and ${ }^{13} \mathrm{C}$ NMR spectra for compound $\mathbf{B}$ S36

Figure S10. ${ }^{1} \mathrm{H}$ and ${ }^{13} \mathrm{C}$ NMR spectra for compound 3 S37

Figure S11. ${ }^{1} \mathrm{H}$ and ${ }^{13} \mathrm{C}$ NMR spectra for compound $\mathbf{C}$ S38

Figure S12. ${ }^{1} \mathrm{H}$ and ${ }^{13} \mathrm{C}$ NMR spectra for compound 4 S39

Figure S13. ${ }^{1} \mathrm{H}$ and ${ }^{13} \mathrm{C}$ NMR spectra for compound $\mathbf{D}$ $\mathrm{S} 40$

Figure S14. ${ }^{1} \mathrm{H}$ and ${ }^{13} \mathrm{C}$ NMR spectra for compound 5 S41

Figure S15. ${ }^{1} \mathrm{H}$ and ${ }^{13} \mathrm{C}$ NMR spectra for T-T S42

Figure S16. ${ }^{1} \mathrm{H}$ and ${ }^{13} \mathrm{C}$ NMR spectra for T-Se S43

Figure S17. Long range COSY spectrum of T-Se S44

Figure S18. High resolution coupled HSQC of T-Se S44

Figure S19. ${ }^{1} \mathrm{H}$ and ${ }^{13} \mathrm{C}$ NMR spectra for T-T-Se S45

Figure S20. ${ }^{1} \mathrm{H}$ and ${ }^{13} \mathrm{C}$ NMR spectra for T-Se-Se S46

Figure S21. ${ }^{1} \mathrm{H}$ and ${ }^{13} \mathrm{C}$ NMR spectra for F-T-Se S47

Figure S22. High resolution coupled HSQC of Compound 5 S48

Figure S23. Long range COSY spectrum of F-T-Se S49

Figure S24. High resolution coupled HSQC of F-T-Se S49 GPC traces $\mathrm{S} 50-\mathrm{S} 60$

Figure S25. GPC Chromatogram of T-T (M/Cat. = 25) in Table 1 S50

Figure S26. GPC Chromatogram of T-T $(\mathrm{M} / \mathrm{Cat} .=50)$ in Table 1 S51 
Figure S27. GPC Chromatogram of T-T $(\mathrm{M} / \mathrm{Cat} .=100)$ in Table 1............... S52

Figure S28. GPC Chromatogram of T-Se $(\mathrm{M} /$ Cat. $=25)$ in Table 1 ................ S53

Figure S29. GPC Chromatogram of T-Se $(\mathrm{M} / \mathrm{Cat} .=50)$ in Table 1 ............... S54

Figure S30. GPC Chromatogram of T-Se $(\mathrm{M} /$ Cat. $=100)$ in Table 1 .............. S55

Figure S31. GPC Chromatogram of T-T-Se $(\mathrm{M} / \mathrm{Cat} .=50)$ in Table 1 ............ S56

Figure S32. GPC Chromatogram of T-Se-Se $(\mathrm{M} /$ Cat. $=50)$ in Table $1 \ldots \ldots \ldots . .$. S57

Figure S33. GPC Chromatogram of F-T-Se (M/Cat. $=50)$ in Table 1 ............ S58

Figure S34. GPC Chromatogram of F-T-Se (M/Cat. = 100) in Table 1 ........... S59

Figure S35. GPC Chromatogram of P3HT using tetramer $(\mathrm{M} / \mathrm{Cat} .=25) \ldots \ldots . . \mathrm{S} 60$

AFM images S61-S63

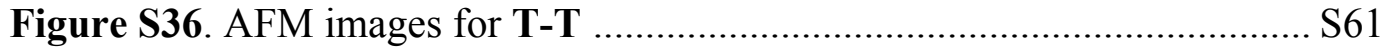

Figure S37. AFM images for T-T-Se .................................................... S61

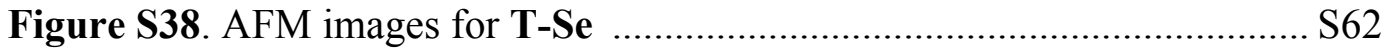

Figure S39. AFM images for T-Se-Se ................................................. S62

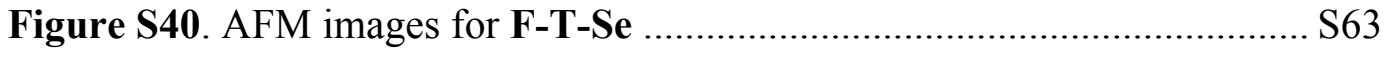

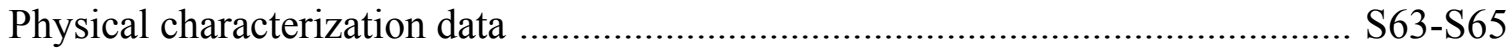

Table S3. Physical characterization data for all polymers ........................... S63

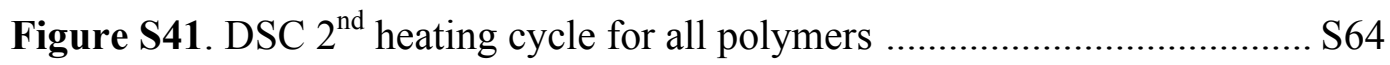

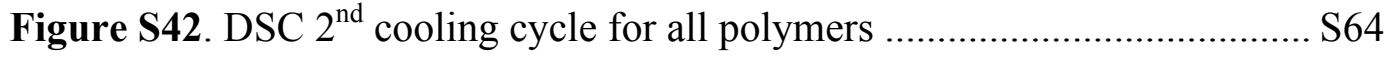

Figure S43. $\Delta \mathrm{H} / \mathrm{Ring}(\mathrm{J} / \mathrm{mol})$ vs. Se Content $\left(\mathrm{X}_{\mathrm{i}}\right.$ Selenophene Rings)......... S65

Figure S44. Thermal degradation analysis of all polymers .......................... S65

Cyclic Voltammetry Data for all polymers................................................... S65-S68

Table S4. Oxidation and Reduction Average Values .................................. S65 
Figure S45. Cyclic Voltammogram for T-T S66

Figure S46. Cyclic Voltammogram for T-Se S66

Figure S47. Cyclic Voltammogram for T-T-Se S67

Figure S48. Cyclic Voltammogram for T-Se-Se S67

Figure S49. Cyclic Voltammogram for F-T-Se S68

DFT Computation and Analysis S69-S75

Figure S50. Predicted twisting energy for oligomers S71

Table S5. Predicted curvature in alternating copolymers of F, T and Se....... S72

Figure S51. Correlation between exciton model and TDDFT S74

References S76 
Materials and Methods. All synthetic manipulations were carried out using standard Schlenk techniques under a nitrogen atmosphere or in an mBraun glovebox under an atmosphere of purified nitrogen. All solvents for reactions (dichloromethane, diethyl ether, tetrahydrofuran, toluene) were purchased from commercial sources, degassed with argon, and dried using a JC Meyer solvent system prior to use. 1,4-dioxane was purchased from Acros and distilled before use. Solvents used in work-up procedures and column chromatography were purchased from commercial sources and used as received. All other chemicals were used as received from commercial sources except $\mathrm{N}$ bromosuccinimide (NBS), which was recrystallized from hot water prior to use. 3hexylselenophene ${ }^{1}$ and 2-bromo-3-hexylfuran ${ }^{2}$ were prepared according to literature procedures. $\mathrm{CDCl}_{3}$ was dried using $\mathrm{P}_{2} \mathrm{O}_{5}$ and distilled prior to use. TMPMgCl$\cdot \mathrm{LiCl}$ was titrated against benzoic acid using fluorene as the indicator.

Polymer samples were precipitated and washed with methanol for GPC analysis (Table 1). Polymer samples analyzed by UV-vis spectroscopy, atomic force microscopy (AFM), differential scanning calorimetry (DSC), thermogravimetric analysis (TGA) and X-ray scattering were further purified by reprecipitation and subsequent washes with methanol, acetone and hexanes. A short path, basic aluminum oxide column with $\mathrm{CHCl}_{3}$ as the eluent was employed as the final step of purification. The samples selected for these analyses were: T-T with $M_{\mathrm{n}}=36,100, \oslash=1.16$, T-Se with $M_{\mathrm{n}}=39,800, Ð=1.18$, T-TSe with $M_{\mathrm{n}}=32,100, \nexists=1.23$, T-Se-Se with $M_{\mathrm{n}}=39,000, \oslash=1.16$ and F-T-Se with $M_{\mathrm{n}}$ $=23,100, Ð=1.22$.

NMR Analysis. All NMR experiments were collected at $300 \mathrm{~K}$ on a two-channel Bruker Avance III NMR instrument equipped with a Broad Band Inverse (BBI) probe, operating 
at $500 \mathrm{MHz}$ for ${ }^{1} \mathrm{H}\left(126 \mathrm{MHz}\right.$ for $\left.{ }^{13} \mathrm{C}\right)$. The ${ }^{1} \mathrm{H}$ NMR spectra are referenced to residual protio solvents (7.26 for $\mathrm{CHCl}_{3}$ ) and the ${ }^{13} \mathrm{C}$ NMR spectra are referenced to $\mathrm{CDCl}_{3}(77.23$ ppm). The F2 proton-coupled HSQC was performed using the recently published PerfectHSQC pulse program. ${ }^{3}$ The 2D NMR analysis of the T-Se polymer $\left(M_{\mathrm{n}}=15,000, \nexists=\right.$ 1.16) was used to help identify end groups in the other thiophene-selenophene copolymers. The 2D NMR analysis of F-T-Se $\left(M_{\mathrm{n}}=23,100, \nexists=1.22\right)$ was facilitated by analysis of compound 5 using coupled HSQC experiments.

Mass Spectrometry. High Resolution Mass Spectrometry (HRMS) was performed in the School of Chemical Sciences Mass Spectrometry Laboratory at the University of Illinois, Urbana-Champaign.

Gel-Permeation Chromatography. GPC traces were obtained using a Waters Instrument equipped with a 717 plus autosampler, a Waters 2414 refractive index (RI) detector and two SDV columns (Porosity 1000 and $100000 \AA$; Polymer Standard Services) with THF as the eluent (flow rate $1 \mathrm{~mL} / \mathrm{min}, 40{ }^{\circ} \mathrm{C}$ ). Molecular weights were determined by applying a 10-point calibration based on polystyrene standards (Polystyrene, ReadyCal Kit, Polymer Standard Services). All polymer aliquots subjected to GPC were prepared by quenching $\sim 0.2 \mathrm{~mL}$ of the polymer solution with $\sim 1.0 \mathrm{~mL}$ of 6 $\mathrm{M}$ methanolic $\mathrm{HCl}$. The precipitate was filtered and washed with methanol only. The resultant polymer was dissolved in $\sim 1 \mathrm{~mL}$ of THF, filtered through a $0.22 \mu \mathrm{m}$ syringe filter and analyzed.

GC-MS Analysis. GC-MS analysis was performed on a Hewlett-Packard Agilent 68905973 GC-MS workstation. The GC column was a Hewlett-Packard fused silica capillary column cross-linked with 5\% phenylmethylsiloxane. Helium was used as the carrier gas. 
The following conditions were used for all GC-MS analyses: injector temperature, $250{ }^{\circ} \mathrm{C}$; initial temperature, $70{ }^{\circ} \mathrm{C}$; temperature ramp, $10{ }^{\circ} \mathrm{C} / \mathrm{min}$; final temperature, $280{ }^{\circ} \mathrm{C}$. All polymer aliquots subjected to GC-MS were prepared by quenching $\sim 0.2 \mathrm{~mL}$ of the polymer solution with $\sim 1.0 \mathrm{~mL}$ of acidic methanol $(\mathrm{HCl}$ :methanol, 1:200 $\mathrm{v} / \mathrm{v}$ ). Then the solution was diluted with $1 \mathrm{~mL}$ of diethyl ether in a $20 \mathrm{~mL}$ scintillation vial. 0.2 $\mathrm{mL}$ of this resultant solution was filtered through a $0.22 \mu \mathrm{m}$ PTFE syringe filter into a 2 $\mathrm{mL}$ vial and diethyl ether was added to fill the vial. Conversion was calculated by comparison of the nonadecane internal standard to the monomer.

UV-vis Spectroscopy. UV-vis spectra of all polymers were recorded on a Varian Cary 5000 spectrophotometer. Prior to recording the spectra for all polymers, a $100 \%$ transmittance sample was taken of a "blank", either $\mathrm{CHCl}_{3}$ (solution) or cleaned glass substrate (solid-state). This "blank" was then run a second time as sample zero, to ensure a zero baseline. The blank was then set in the program as the baseline correction/background subtraction to all future recorded spectra. No further baseline corrections were performed prior to analysis.

Solution measurements were conducted in $\mathrm{CHCl}_{3}$ at $\sim 0.0075 \mathrm{mg} / \mathrm{mL}$ concentration. In the dark, under a dry nitrogen environment in a glovebox, thin film samples were prepared from a spin-coating process. Glass cover slips $(22 \times 22 \mathrm{~mm})$ were cleaned by spraying with fresh acetone, isopropanol and dried under a jet of filtered, dry nitrogen. $5 \mathrm{mg} / \mathrm{mL}$ solutions of T-T, T-Se, T-T-Se, T-Se-Se and F-T-Se in dry toluene were heated to $80^{\circ} \mathrm{C}$ in glass vials for $10 \mathrm{~min}$, filtered through a $0.22 \mu \mathrm{m}$ PTFE syringe filter using a glass syringe, and re-heated for $5 \mathrm{~min}$ prior to spin-casting from hot solutions. The spin-coating conditions consisted of three cycles, a 400 RPM spreading 
cycle for $5 \mathrm{~s}$, a 1000 RPM main cycle for $30 \mathrm{~s}$ and a 2000 RPM wicking cycle for $15 \mathrm{~s}$. The films were annealed at $150^{\circ} \mathrm{C}$ for $1 \mathrm{~h}$ under a nitrogen environment.

Electrochemical Analysis. For cyclic voltammetry, a three electrode system comprised of a silver wire pseudo-reference, a coiled platinum counter electrode, and a $1 \mathrm{~mm}^{2}$ platinum-disk working electrode was employed and was controlled with a $\mathrm{CH}$ Instruments Model 600C Series Electrochemical Analyzer/Workstation. A solution of the polymer $(0.5 \mathrm{mg} / \mathrm{mL}$ in toluene) was drop cast onto the working electrode. The electrode was immersed in anhydrous acetonitrile with $0.1 \mathrm{M}$ tetra-butylammonium hexafluorophosphate (Fluka, electrochemical grade). Potentials were scanned at $0.10 \mathrm{~V} / \mathrm{s}$ under a constant argon purge and were referenced to SCE via a ferrocene internal standard $\left(\mathrm{Fc} / \mathrm{Fc}^{+}\right)$. Considering the oxidation potential of ferrocene is $+0.40 \mathrm{~V}$ versus SCE in acetonitrile and the SCE electrode is $-4.7 \mathrm{eV}$ from vacuum, ${ }^{4}$ the HOMO and LUMO energy levels were estimated according to:

$\mathrm{E}_{\mathrm{HOMO}}=-\left(\mathrm{E}_{[\text {onset, ox vs. Fc/Fc }}^{+}+5.1\right)(\mathrm{eV}) \quad \mathrm{E}_{\mathrm{LUMO}}=-\left(\mathrm{E}_{[\text {onset, red vs. Fc/Fc }}^{+}+5.1\right)(\mathrm{eV})$.

Differential Scanning Calorimetry. DSC experiments were performed on a Seiko SSC/5200 SII DSC220C system. Experiments were carried out under a nitrogen environment with a heating rate of $10{ }^{\circ} \mathrm{C} / \mathrm{min}$ and a cooling rate of $-10{ }^{\circ} \mathrm{C} / \mathrm{min}$ within a range of $30^{\circ} \mathrm{C}$ to $270{ }^{\circ} \mathrm{C}$ for a duration of three cycles.

Thermogravimetric Analysis. TGA experiments were performed using a Perkin Elmer TGA 4000. Experiments were carried out under a nitrogen environment with a heating rate of $10{ }^{\circ} \mathrm{C} / \mathrm{min}$ within a range of $30^{\circ} \mathrm{C}$ to $500{ }^{\circ} \mathrm{C}$ and a successive heating rate of $20^{\circ} \mathrm{C} /$ min within a range of $500{ }^{\circ} \mathrm{C}$ to $800{ }^{\circ} \mathrm{C}$. 
Atomic Force Microscopy. Ultra-thin films were prepared for T-T, T-Se, T-T-Se and T-Se-Se samples to better visualize single layer nanofibrillar morphologies. Due to the light sensitivity of the F-T-Se sample, a thicker film was prepared for AFM imaging. The wafers were cleaned by spraying with fresh acetone and isopropanol and dried under a jet of filtered, dry nitrogen, followed by UV/Ozone treatment at $120{ }^{\circ} \mathrm{C}$ for $45 \mathrm{~min}$, followed by an incubation period of 45 min until cooled to $42{ }^{\circ} \mathrm{C}$ (Novascan PSD-UVT). The wafers were then placed under vacuum (10 mTorr) for $90 \mathrm{~min}$.

The F-T-Se sample was prepared under a dry nitrogen environment in a glovebox, whereas the T-T, T-Se, T-T-Se and T-Se-Se samples were prepared under ambient conditions. These samples were prepared from $0.1 \mathrm{mg} / \mathrm{mL}$ solutions in anhydrous $\mathrm{CHCl}_{3}$, whereas the F-T-Se sample was prepared from a $1 \mathrm{mg} / \mathrm{mL}$ solution in anhydrous $\mathrm{CHCl}_{3}$, on $2 \times 2 \mathrm{~cm}$ silicon wafers with native oxide. The solutions were heated to $50^{\circ} \mathrm{C}$ in glass vials for $30 \mathrm{~min}$, filtered through a $0.22 \mu \mathrm{m}$ PTFE syringe filter using a glass syringe, and re-heated for $5 \mathrm{~min}$ prior to drop-casting hot solutions onto the wafers. The as-treated wafers were placed in a petri dish, lined with $1 \mathrm{~mL}$ of chloroform; completely covered with a minimum amount of solution, and allowed to dry slowly by solvent-vapor annealing. The as-obtained films were imaged with a Bruker Dimension V hybrid AFM in tapping mode.

Grazing-Incidence Wide Angle X-Ray Scattering. The wafers were cleaned by spraying with fresh hexanes, acetone and isopropanol and dried under a jet of filtered, dry nitrogen, followed by UV/Ozone treatment at $120{ }^{\circ} \mathrm{C}$ for $45 \mathrm{~min}$, followed by an incubation period of 45 min until cooled to $42{ }^{\circ} \mathrm{C}$ (Novascan PSD-UVT). The wafers were then placed under vacuum (10 mTorr) for $90 \mathrm{~min}$. 
The F-T-Se sample was prepared under a dry nitrogen environment in a glovebox, whereas the T-T, T-Se, T-T-Se and T-Se-Se samples were prepared under ambient conditions. All samples were prepared from $2 \mathrm{mg} / \mathrm{mL}$ solutions in anhydrous $\mathrm{CHCl}_{3}$ on $2 \times 2 \mathrm{~cm}$ silicon wafers with native oxide. The solutions were heated to $50{ }^{\circ} \mathrm{C}$ in glass vials for $30 \mathrm{~min}$, filtered through a $0.22 \mu \mathrm{m}$ PTFE syringe filter using a glass syringe, and re-heated for $5 \mathrm{~min}$ prior to drop-casting hot solutions onto the wafers. The as-treated wafers were placed in a petri dish, lined with $1 \mathrm{~mL}$ of chloroform; completely covered with a minimum amount of solution, and allowed to dry slowly by solvent-vapor annealing. The films were then annealed at $150{ }^{\circ} \mathrm{C}$ for $30 \mathrm{~min}$ prior to measurement.

GIWAXS measurements were taken at the Cornell High Energy Synchrotron Source (CHESS) D1 $(\lambda=1.162 \mathrm{~nm})$ station. A wide bandpass $(1.47 \%)$ doublebounce multilayer monochromator supplied an intense beam of $10.1 \mathrm{keV}$ photons. GIWAXS intensities were recorded with an area detector (Medoptics) with a resolution of $47.19 \mu \mathrm{m}$ per pixel and a total area of about $50 \mathrm{~mm}$ by $50 \mathrm{~mm}$ at a distance of $10.62 \mathrm{~cm}$ from the thin film sample. The sample was mounted on a sample goniometer, in order to control the incident angle and the sample azimuth. An accurate calibration of the incident angle was performed in situ by measuring the X-ray reflectivity from the sample using an ion chamber. The measurements were calibrated using a ceria standard. The intense scattering close to the direct beam was blocked with a 1.5 -mm-wide tantalum rod. Exposures times under these conditions ranged from $0.1 \mathrm{~s}$ to $3 \mathrm{~s}$ depending on the contrast and sample quality. The $2 \mathrm{D}$ - scattering profiles were background subtracted and post-processed to take into account the missing wedge of Ewald sphere inherent to GIWAXS geometry. ${ }^{5}$ 


\section{Experimental Procedures}

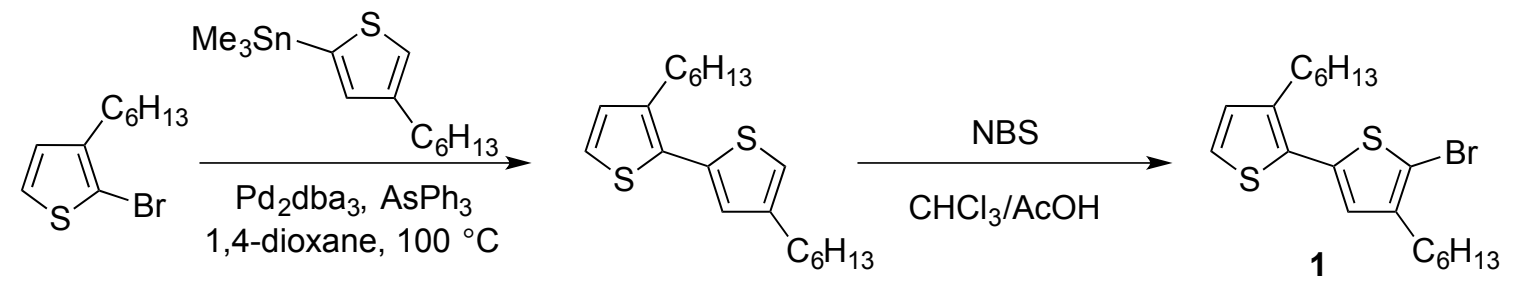

Scheme S1. Synthesis of monomer 1.

5'-bromo-3,4'-dihexyl-2,2'-bithiophene (1). This compound was prepared according to a literature procedure. ${ }^{6}$ The ${ }^{1} \mathrm{H}$ NMR spectrum was compared to a previous report. ${ }^{7}$ HR-EIMS $(\mathrm{m} / \mathrm{z})$ :

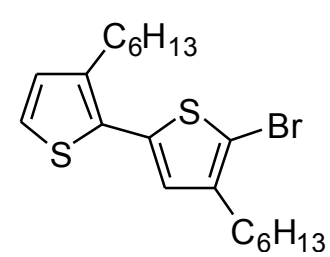
$[\mathrm{M}]^{+}$calculated for $\mathrm{C}_{20} \mathrm{H}_{29} \mathrm{BrS}_{2}$ : 412.0894; found 412.0886.

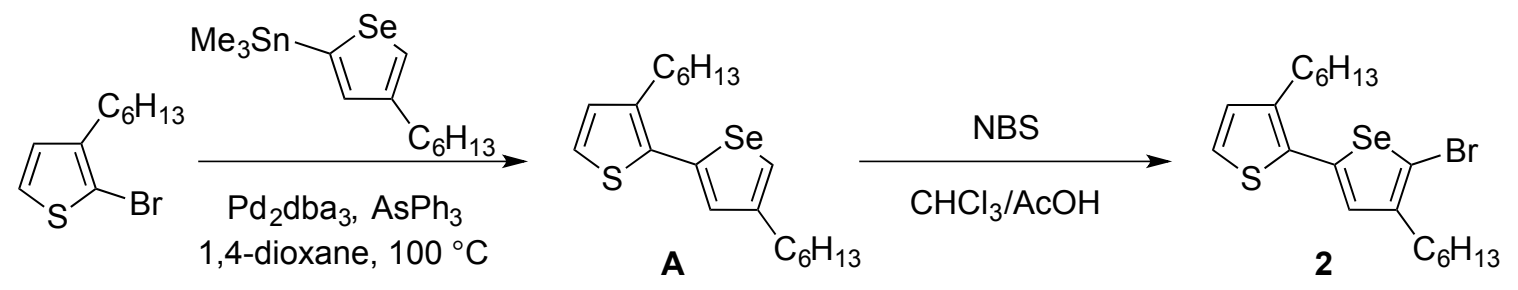

Scheme S2. Synthesis of monomer 2.

(4-hexylselenophen-2-yl)trimethylstannane. An oven-dried $100 \mathrm{~mL}$ Schlenk flask equipped with a magnetic stir bar was evacuated and

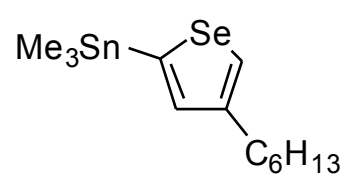
backfilled with $\mathrm{N}_{2}$. The flask was charged with $60 \mathrm{~mL}$ of dry THF and 3hexylselenophene $(3.0 \mathrm{~g}, 13.9 \mathrm{mmol})$. The reaction mixture was cooled to $-78{ }^{\circ} \mathrm{C}$ using a dry-ice acetone bath. Approximately 1.2 equivalents of lithium diisopropylamide $(1.0 \mathrm{M}$ 
in THF/hexane, $16.7 \mathrm{~mL}, 16.7 \mathrm{mmol}$ ) was added to the cold solution dropwise using a syringe. The reaction mixture was stirred at $-78{ }^{\circ} \mathrm{C}$ for $1 \mathrm{~h}$ and then warmed to room temperature and stirred for $1 \mathrm{~h}$. The reaction vessel was cooled to $-78^{\circ} \mathrm{C}$ and trimethyltin chloride (3.33 g, $16.7 \mathrm{mmol}$ ) was dissolved in a minimal amount of THF and added to the solution by syringe after which, the cold bath was removed and the reaction mixture was warmed to room temperature and stirred overnight. The mixture was combined with saturated aqueous $\mathrm{NH}_{4} \mathrm{Cl}(50 \mathrm{~mL})$, transferred to a separatory funnel and the organic and aqueous phases were separated. The organic phase was washed 3 more times with water $(3 \times 50 \mathrm{~mL})$, dried over $\mathrm{Na}_{2} \mathrm{SO}_{4}$ and concentrated using rotary evaporation. The crude material was purified by distillation at $110{ }^{\circ} \mathrm{C}$ in vacuo to afford $4.50 \mathrm{~g}$ of (4hexylselenophen-2-yl)trimethylstannane as a colorless oil (86\% yield). Note: tin satellites are visible and used in integration of the signals but not assigned in this spectrum. ${ }^{1} \mathrm{H}$ $\operatorname{NMR}\left(500 \mathrm{MHz}, \mathrm{CDCl}_{3}\right) \delta 7.82(\mathrm{~d}, J=1.0 \mathrm{~Hz}, 1 \mathrm{H}), 7.36(\mathrm{~d}, J=1.0 \mathrm{~Hz}, 1 \mathrm{H}), 2.67-2.58$ $(\mathrm{m}, 2 \mathrm{H}), 1.69-1.58(\mathrm{~m}, 2 \mathrm{H}), 1.40-1.26(\mathrm{~m}, 6 \mathrm{H}), 0.95-0.84(\mathrm{~m}, 3 \mathrm{H}), 0.36(\mathrm{~s}, 9 \mathrm{H}) .{ }^{13} \mathrm{C}$ NMR (126 MHz, $\left.\mathrm{CDCl}_{3}\right) \delta 147.0,144.4,140.3,129.3,31.9,31.8,30.8,29.4,22.9,14.3$, -7.7. HR-EIMS (m/z): [M] calculated for $\mathrm{C}_{13} \mathrm{H}_{24} \mathrm{SeSn:} 380.0065$; found 380.0066 .

3-hexyl-2-(4-hexylselenophen-2-yl)thiophene (A). An oven-dried $250 \mathrm{~mL}$ 3-necked flask equipped with a magnetic stir bar was charged with $\mathrm{Pd}_{2} \mathrm{dba}_{3}(0.98 \mathrm{~g}, 1.07 \mathrm{mmol})$ and $\mathrm{AsPh}_{3}(2.61 \mathrm{~g}, 8.52$

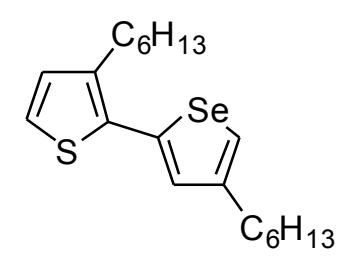
mmol). 1,4-Dioxane $(200 \mathrm{~mL})$ was added to the flask by syringe and the mixture was stirred for $10 \mathrm{~min}$. 2-bromo-3-hexylthiophene was added $(5.80 \mathrm{~g}, 23.5 \mathrm{mmol})$ and the mixture was stirred for $5 \mathrm{~min}$. Finally (4-hexylselenophen-2-yl)trimethylstannane ( $8.05 \mathrm{~g}$, 
$21.3 \mathrm{mmol}$ ) was added by syringe. The flask was subsequently immersed in an oil bath at $100{ }^{\circ} \mathrm{C}$ and stirred overnight. Upon completion, the reaction mixture was cooled to room temperature and concentrated using rotary evaporation. The remaining residue was loaded onto silica gel and purified using column chromatography, eluting with hexanes $\left(R_{\mathrm{f}}=0.66\right)$ to afford $5.83 \mathrm{~g}$ of 3-hexyl-2-(4-hexylselenophen-2-yl)thiophene as a light yellow oil (72\% yield). A small impurity was visible in the ${ }^{1} \mathrm{H}$ and ${ }^{13} \mathrm{C}$ that was removed in the subsequent bromination. ${ }^{1} \mathrm{H} \mathrm{NMR}\left(500 \mathrm{MHz}, \mathrm{CDCl}_{3}\right) \delta 7.50(\mathrm{~d}, J=1.3 \mathrm{~Hz}, 1 \mathrm{H})$, $7.14(\mathrm{~d}, J=1.4 \mathrm{~Hz}, 1 \mathrm{H}), 7.13(\mathrm{~d}, J=5.2 \mathrm{~Hz}, 1 \mathrm{H}), 6.92(\mathrm{~d}, J=5.2 \mathrm{~Hz}, 1 \mathrm{H}), 2.76-2.71$ (m, 2H), $2.61-2.55(\mathrm{~m}, 2 \mathrm{H}), 1.69-1.56(\mathrm{~m}, 4 \mathrm{H}), 1.44-1.21(\mathrm{~m}, 12 \mathrm{H}), 0.96-0.83(\mathrm{~m}$, 6H). ${ }^{13} \mathrm{C}$ NMR $\left(126 \mathrm{MHz}, \mathrm{CDCl}_{3}\right) \delta 145.7,140.4,139.3,133.6,130.23$ and $130.18(2$ overlapping signals), 124.6, 123.6, 32.4, 31.92 and 31.89 (2 overlapping signals), 30.9, $30.5,29.5,29.4,29.2,22.9,14.32,14.30$ (2 overlapping signals). Note: only 11 of the 12 possible signals from the hexyl chains are visible due to similarities between chemical environments. HR-EIMS (m/z): $[\mathrm{M}]^{+}$calculated for $\mathrm{C}_{20} \mathrm{H}_{30} \mathrm{SSe}$ : 382.1233; found 382.1246.

2-(5-bromo-4-hexylselenophen-2-yl)-3-hexylthiophene (2). A 100 $\mathrm{mL}$ round bottom flask equipped with a magnetic stir bar was charged with A (1.75 g, $4.59 \mathrm{mmol})$, acetic acid (35 mL) and

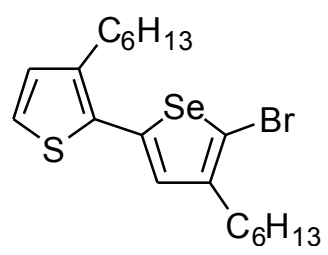
chloroform $(35 \mathrm{~mL})$. The flask was covered with aluminum foil and immersed in an ice bath and $\mathrm{N}$-bromosuccinimide $(0.82 \mathrm{~g}, 4.61 \mathrm{mmol})$, was added in small portions over a period of $5 \mathrm{~min}$. Upon complete addition of the NBS, the ice bath was removed and the reaction mixture was stirred overnight. The mixture was poured into water, and the 
organic phase was extracted and washed with saturated $\mathrm{NaHCO}_{3}$ solution and water $(3 \times$ $50 \mathrm{~mL}$ ). The organic extract was dried over $\mathrm{Na}_{2} \mathrm{SO}_{4}$ and filtered. Removal of the solvent by rotary evaporation furnished the crude product, which was purified by chromatography on silica gel, eluting with hexanes $\left(R_{\mathrm{f}}=0.76\right)$ to afford $1.63 \mathrm{~g}$ of 2-(5bromo-4-hexylselenophen-2-yl)-3-hexylthiophene as a light yellow oil (77\% yield). ${ }^{1} \mathrm{H}$ NMR $\left(500 \mathrm{MHz}, \mathrm{CDCl}_{3}\right) \delta 7.15(\mathrm{~d}, J=5.2 \mathrm{~Hz}, 1 \mathrm{H}), 6.95(\mathrm{~s}, 1 \mathrm{H}), 6.91(\mathrm{~d}, J=5.2 \mathrm{~Hz}$, 1H), $2.71-2.66(\mathrm{~m}, 2 \mathrm{H}), 2.57-2.51(\mathrm{~m}, 2 \mathrm{H}), 1.65-1.55(\mathrm{~m}, 4 \mathrm{H}), 1.41-1.25(\mathrm{~m}, 12 \mathrm{H})$, $0.94-0.85(\mathrm{~m}, 6 \mathrm{H}) .{ }^{13} \mathrm{C}$ NMR $\left(126 \mathrm{MHz}, \mathrm{CDCl}_{3}\right) \delta 144.8,140.3,139.9,132.7,130.2$, 129.6, 124.1, 111.5, 31.87 and 31.86 (2 overlapping signals), 31.1, 31.0, 29.8, 29.4, 29.1, 22.84 and 22.83 (2 overlapping signals), 14.31 and 14.29 (2 overlapping signals). Note: only 11 of the 12 possible signals from the hexyl chains are visible due to similarities between chemical environments. HR-EIMS (m/z): [M] $]^{+}$calculated for $\mathrm{C}_{20} \mathrm{H}_{29} \mathrm{SSeBr}$ : 460.0339; found 460.0340.

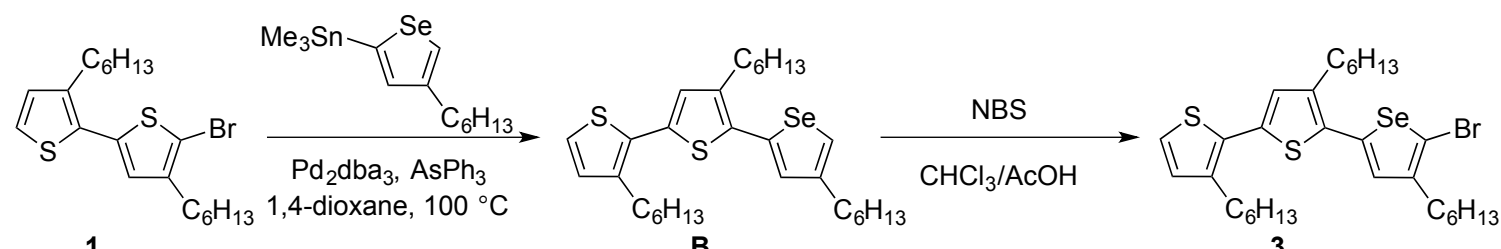

Scheme S3. Synthesis of monomer 3.

3,4'-dihexyl-5'-(4-hexylselenophen-2-yl)-2,2'-bithiophene

(B). An oven-dried $50 \mathrm{~mL} 3$-necked flask equipped with a magnetic stir bar was charged with $\operatorname{Pd}_{2} \mathrm{dba}_{3}(0.11 \mathrm{~g}, 0.12 \mathrm{mmol})$ and<smiles>CCCCCCc1ccsc1-c1cc(CCCCC)c(-c2cc(CC)c[se]2)s1</smiles>
$\mathrm{AsPh}_{3}(0.30 \mathrm{~g}, 0.98 \mathrm{mmol}) .1$,4-Dioxane $(20 \mathrm{~mL})$ was added to the flask by syringe and 
the mixture was stirred for $10 \mathrm{~min}$. Compound 1 was then added (1.00 g, $2.42 \mathrm{mmol})$ and the mixture was stirred for another $5 \mathrm{~min}$. Finally (4-hexylselenophen-2yl)trimethylstannane (0.96 $\mathrm{g}, 2.54 \mathrm{mmol})$ was added by syringe. The flask was subsequently immersed in an oil bath at $100^{\circ} \mathrm{C}$ and stirred overnight. Upon completion, the reaction mixture was cooled to room temperature and concentrated using rotary evaporation. The residue was loaded onto silica gel and purified using column chromatography, eluting with hexanes $\left(R_{\mathrm{f}}=0.62\right)$ to afford $1.05 \mathrm{~g}$ of $3,4^{\prime}$-dihexyl-5'-(4hexylselenophen-2-yl)-2,2'-bithiophene as a yellow oil (79\% yield). A small impurity was visible in the ${ }^{1} \mathrm{H}$ and ${ }^{13} \mathrm{C}$ that was removed in the subsequent bromination. ${ }^{1} \mathrm{H}$ NMR $\left(500 \mathrm{MHz}, \mathrm{CDCl}_{3}\right) \delta 7.51(\mathrm{~s}, 1 \mathrm{H}), 7.21-7.13(\mathrm{~m}, 2 \mathrm{H}), 6.96-6.89(\mathrm{~m}, 2 \mathrm{H}), 2.78(\mathrm{t}, J=$ $7.9 \mathrm{~Hz}, 2 \mathrm{H}), 2.73(\mathrm{t}, J=7.9 \mathrm{~Hz}, 2 \mathrm{H}), 2.58(\mathrm{t}, J=7.7 \mathrm{~Hz}, 2 \mathrm{H}), 1.74-1.56(\mathrm{~m}, 6 \mathrm{H}), 1.48-$ $1.21(\mathrm{~m}, 18 \mathrm{H}), 0.96-0.82(\mathrm{~m}, 9 \mathrm{H}) .{ }^{13} \mathrm{C} \mathrm{NMR}\left(126 \mathrm{MHz}, \mathrm{CDCl}_{3}\right) \delta 145.7,139.9,139.8$, $139.5,134.1,133.4,130.8,130.3,130.0,128.9,124.6,123.7,32.4,31.92$ and $31.90(2$ overlapping signals), 30.9, 30.8, 30.5, 29.6 and 29.51 and 29.48 (2 overlapping signals), $29.4,29.2,22.9,14.32$ and 14.30 (2 overlapping signals). Note: only 14 of the 18 possible signals from the hexyl chains are visible due to similarities between chemical environments. HR-EIMS (m/z): $[\mathrm{M}]^{+}$calculated for $\mathrm{C}_{30} \mathrm{H}_{44} \mathrm{~S}_{2} \mathrm{Se}$ : 548.2050; found 548.2050.

5'-(5-bromo-4-hexylselenophen-2-yl)-3,4'-dihexyl-2,2'-

bithiophene (3). A $100 \mathrm{~mL}$ round bottom flask equipped with a magnetic stir bar was charged with $\mathbf{B}(0.69 \mathrm{~g}, 1.26$

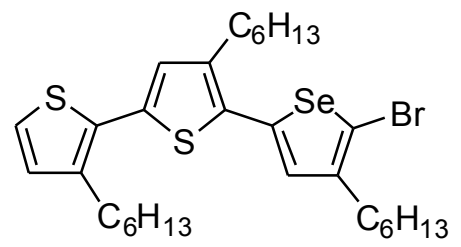
mmol), acetic acid $(12 \mathrm{~mL})$ and chloroform $(12 \mathrm{~mL})$. The flask was covered with 
aluminum foil and immersed in an ice bath and N-bromosuccinimide (0.22 g, $1.24 \mathrm{mmol})$, was added in small portions over a period of $5 \mathrm{~min}$. Upon complete addition of the NBS, the ice bath was removed and the reaction mixture was stirred overnight. The mixture was poured into water, and the organic phase was extracted and washed with saturated $\mathrm{NaHCO}_{3}$ solution and water $(3 \times 50 \mathrm{~mL})$. The organic extract was dried over $\mathrm{Na}_{2} \mathrm{SO}_{4}$ and filtered. Removal of the solvent by rotary evaporation furnished the crude product which was purified by chromatography on silica gel, eluting with hexanes $\left(R_{\mathrm{f}}=0.71\right)$ to afford $0.62 \mathrm{~g}$ of 5'-(5-bromo-4-hexylselenophen-2-yl)-3,4'-dihexyl-2,2'-bithiophene as a yellow oil (79\% yield). ${ }^{1} \mathrm{H}$ NMR $\left(500 \mathrm{MHz}, \mathrm{CDCl}_{3}\right) \delta 7.16(\mathrm{~d}, J=5.2 \mathrm{~Hz}, 1 \mathrm{H}), 6.97(\mathrm{~s}, 1 \mathrm{H})$, $6.92(\mathrm{~d}, J=5.2 \mathrm{~Hz}, 1 \mathrm{H}), 6.91(\mathrm{~s}, 1 \mathrm{H}), 2.80-2.73(\mathrm{~m}, 2 \mathrm{H}), 2.71-2.64(\mathrm{~m}, 2 \mathrm{H}), 2.58-$ $2.51(\mathrm{~m}, 2 \mathrm{H}), 1.70-1.55(\mathrm{~m}, 6 \mathrm{H}), 1.44-1.24(\mathrm{~m}, 18 \mathrm{H}), 0.95-0.83(\mathrm{~m}, 9 \mathrm{H}) .{ }^{13} \mathrm{C} \mathrm{NMR}$ $\left(126 \mathrm{MHz}, \mathrm{CDCl}_{3}\right) \delta 144.9,140.1,140.0,139.9,134.6,132.5,130.5,130.3,129.3,128.9$, 123.9, 111.5, 31.88 and 31.87 (2 overlapping signals), 31.1, 30.9, 30.8, 29.8, 29.6, 29.51 and 29.47 (2 overlapping signals), 29.4, 29.2, 22.9, 22.8, 14.31 and 14.30 (2 overlapping signals). Note: only 15 of the 18 possible signals from the hexyl chains are visible due to similarities between chemical environments. HR-EIMS $(\mathrm{m} / \mathrm{z}):[\mathrm{M}]^{+}$calculated for $\mathrm{C}_{30} \mathrm{H}_{43} \mathrm{~S}_{2} \mathrm{SeBr}$ : 626.1155; found 626.1149.

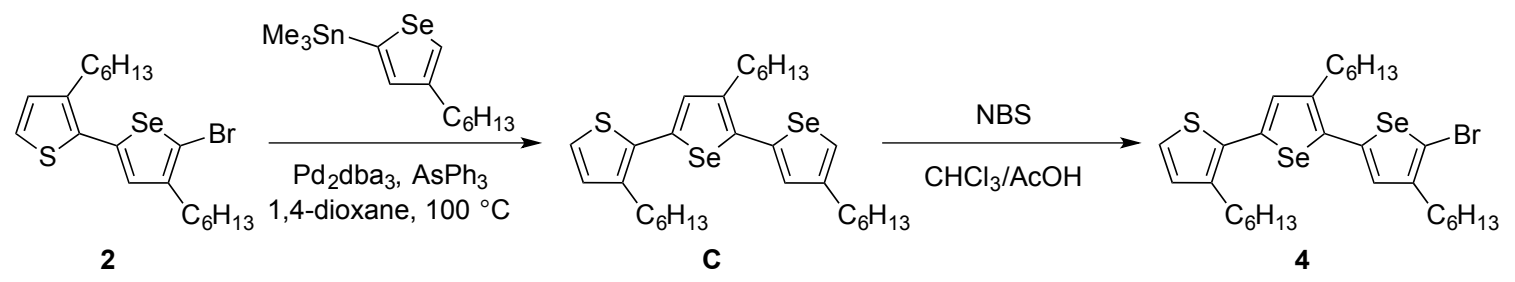

Scheme S4. Synthesis of monomer 4. 
(C). An oven-dried $100 \mathrm{~mL}$ 3-necked flask equipped with a magnetic stir bar was charged with $\mathrm{Pd}_{2} \mathrm{dba}_{3}(0.10 \mathrm{~g}, 0.11$

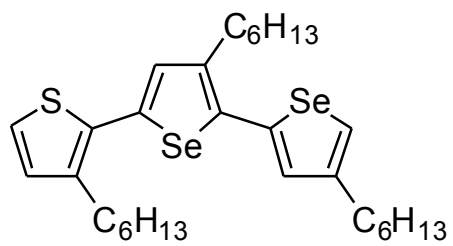
mmol) and $\mathrm{AsPh}_{3}(0.27 \mathrm{~g}, 0.88 \mathrm{mmol})$. 1,4-Dioxane $(20 \mathrm{~mL})$ was added to the flask by syringe and the mixture was stirred for $10 \mathrm{~min}$. Compound 2 was added (1.00 g, 2.17 mmol) and the mixture was stirred for 5 min. Finally (4-hexylselenophen-2yl)trimethylstannane $(0.86 \mathrm{~g}, 2.28 \mathrm{mmol})$ was added by syringe. The flask was subsequently immersed in an oil bath at $100{ }^{\circ} \mathrm{C}$ and stirred overnight. Upon completion, the reaction mixture was cooled to room temperature and concentrated using rotary evaporation. The residue was loaded onto silica gel and purified using column chromatography, eluting with hexanes $\left(R_{\mathrm{f}}=0.56\right)$ to afford $1.05 \mathrm{~g}$ of 2-(3,4'-dihexyl[2,2'-biselenophen]-5-yl)-3-hexylthiophene as a yellow oil (81\% yield). A small impurity was visible in the ${ }^{1} \mathrm{H}$ and ${ }^{13} \mathrm{C}$ that was removed in the subsequent bromination. ${ }^{1} \mathrm{H}$ NMR $\left(500 \mathrm{MHz}, \mathrm{CDCl}_{3}\right) \delta 7.52(\mathrm{~s}, 1 \mathrm{H}), 7.16-7.12(\mathrm{~m}, 2 \mathrm{H}), 7.11(\mathrm{~s}, 1 \mathrm{H}), 6.92(\mathrm{~d}, J=5.2 \mathrm{~Hz}$, 1H), 2.75 (t, $J=7.9 \mathrm{~Hz}, 2 \mathrm{H}), 2.70(\mathrm{t}, J=7.9 \mathrm{~Hz}, 2 \mathrm{H}), 2.57$ (t, $J=7.7 \mathrm{~Hz}, 2 \mathrm{H}), 1.70-$ $1.58(\mathrm{~m}, 6 \mathrm{H}), 1.45-1.22(\mathrm{~m}, 18 \mathrm{H}), 0.96-0.82(\mathrm{~m}, 9 \mathrm{H}) .{ }^{13} \mathrm{C} \mathrm{NMR}\left(126 \mathrm{MHz}, \mathrm{CDCl}_{3}\right) \delta$ $145.7,141.9,141.1,139.5,138.4,138.2,133.2,131.9,130.5,130.4,124.9,123.7,32.4$, 31.92 and 31.90 (2 overlapping signals), 30.92 and 30.89 (2 overlapping signals), 30.7, $30.5,29.6,29.5,29.2,22.9,14.3$. Note: only 12 of the 18 possible signals from the hexyl chains are visible due to similarities between chemical environments. HR-EIMS (m/z): $[\mathrm{M}]^{+}$calculated for $\mathrm{C}_{30} \mathrm{H}_{44} \mathrm{SSe}_{2}:$ 596.1494; found 596.1498. 
2-(5'-bromo-3,4'-dihexyl-[2,2'-biselenophen]-5-yl)-3-

hexylthiophene (4). A $100 \mathrm{~mL}$ round bottom flask equipped with a magnetic stir bar was charged with $\mathbf{C}(0.67 \mathrm{~g}, 1.13$

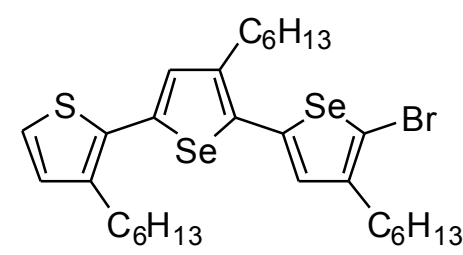
mmol), acetic acid $(12 \mathrm{~mL})$ and chloroform $(12 \mathrm{~mL})$. The flask was covered with aluminum foil and immersed in an ice bath and $\mathrm{N}$-bromosuccinimide $(0.20 \mathrm{~g}, 1.13 \mathrm{mmol})$, was added in small portions over a period of $5 \mathrm{~min}$. Upon complete addition of the NBS, the ice bath was removed and the reaction mixture was stirred overnight. The mixture was poured into water, and the organic phase was extracted and washed with saturated $\mathrm{NaHCO}_{3}$ solution and water $(3 \times 50 \mathrm{~mL})$. The organic extract was dried over $\mathrm{Na}_{2} \mathrm{SO}_{4}$ and filtered. Removal of the solvent by rotary evaporation furnished the crude product which was purified by chromatography on silica gel, eluting with hexanes $\left(R_{\mathrm{f}}=0.63\right)$ to afford $0.69 \mathrm{~g}$ of 2-(5'-bromo-3,4'-dihexyl-[2,2'-biselenophen]-5-yl)-3-hexylthiophene as a yellow oil (91\% yield). ${ }^{1} \mathrm{H}$ NMR (500 MHz, $\left.\mathrm{CDCl}_{3}\right) \delta 7.14(\mathrm{~d}, J=5.3 \mathrm{~Hz}, 1 \mathrm{H}), 7.12$ (s, 1H), $6.94-6.90(\mathrm{~m}, 2 \mathrm{H}), 2.78-2.70(\mathrm{~m}, 2 \mathrm{H}), 2.69-2.61(\mathrm{~m}, 2 \mathrm{H}), 2.57-2.50(\mathrm{~m}, 2 \mathrm{H})$, $1.69-1.55(\mathrm{~m}, 6 \mathrm{H}), 1.45-1.24(\mathrm{~m}, 18 \mathrm{H}), 0.95-0.82(\mathrm{~m}, 9 \mathrm{H}) .{ }^{13} \mathrm{C}$ NMR $(126 \mathrm{MHz}$, $\left.\mathrm{CDCl}_{3}\right) \delta 144.8,141.8,141.7,139.7,139.0,137.2,133.0,131.8,130.4,129.8,123.9$, $111.8,31.90$ and 31.88 and 31.86 ( 3 overlapping signals), 31.1, 30.93 and 30.90 (2 overlapping signals), 30.7, 29.8, 29.6, 29.48 and 29.47 (2 overlapping signals), 29.2, 22.9, $22.8,14.31$ and 14.30 ( 2 overlapping signals). Note: only 16 of the 18 possible signals from the hexyl chains are visible due to similarities between chemical environments. HREIMS (m/z): [M] $]^{+}$calculated for $\mathrm{C}_{30} \mathrm{H}_{43} \mathrm{SSe}_{2} \mathrm{Br}$ : 674.0599; found 674.0606. 


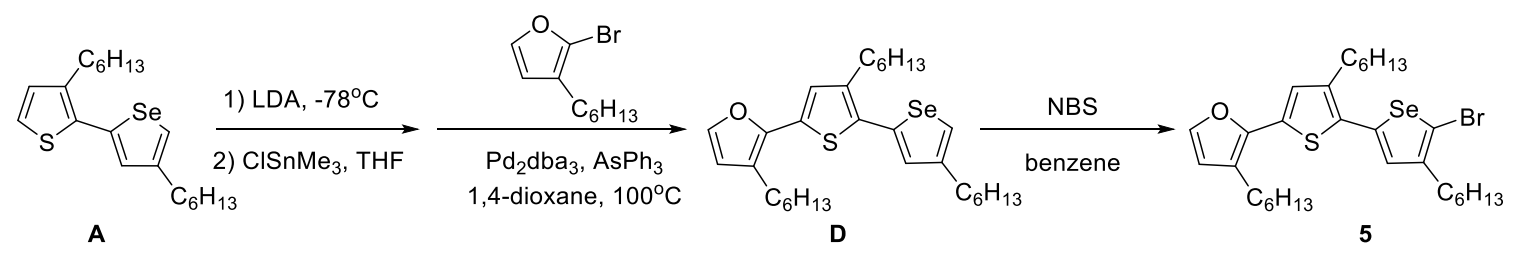

Scheme S5. Synthesis of monomer 5.

3-hexyl-2-(4-hexyl-5-(4-hexylselenophen-2-yl)thiophen-2-

yl)furan (D). An oven-dried $100 \mathrm{~mL}$ Schlenk flask equipped

with a magnetic stir bar was evacuated and backfilled with

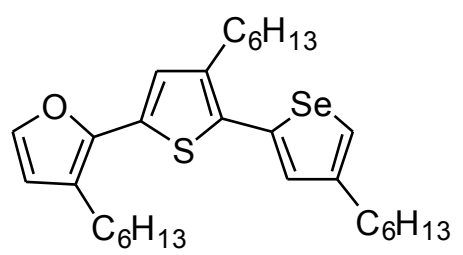

$\mathrm{N}_{2}$. The flask was charged with $35 \mathrm{~mL}$ of dry THF and $\mathbf{A}(1.69 \mathrm{~g}, 4.43 \mathrm{mmol})$. The reaction mixture was cooled to $-78^{\circ} \mathrm{C}$ using a dry-ice acetone bath. 1.2 equivalents of lithium diisopropylamide (1.0 M in THF/hexane, $5.32 \mathrm{~mL}, 5.32 \mathrm{mmol}$ ) was added to the cold solution dropwise, using a syringe. The reaction mixture was stirred at $-78{ }^{\circ} \mathrm{C}$ for 1 $\mathrm{h}$ and then warmed to room temperature and stirred for $1 \mathrm{~h}$. The reaction vessel was then placed in a $-78^{\circ} \mathrm{C}$ cold bath. Trimethyltin chloride $(1.06 \mathrm{~g}, 5.32 \mathrm{mmol})$ was added to the mixture by syringe, after which the cold bath was removed and the reaction mixture was warmed to room temperature and stirred overnight. The reaction mixture was poured into saturated aqueous $\mathrm{NH}_{4} \mathrm{Cl}(50 \mathrm{~mL})$. The organic phase was extracted and washed with water $(3 \times 50 \mathrm{~mL})$. The organic extract was dried over $\mathrm{Na}_{2} \mathrm{SO}_{4}$ and filtered. The solvent was removed by rotary evaporation and this crude material was used directly in the next step. An oven-dried $250 \mathrm{~mL}$ 3-necked flask equipped with a magnetic stir bar was charged with $\mathrm{Pd}_{2} \mathrm{dba}_{3}(0.20 \mathrm{~g}, 0.22 \mathrm{mmol})$ and $\mathrm{AsPh}_{3}(0.54 \mathrm{~g}, 1.76 \mathrm{mmol})$. 1,4-Dioxane $(75 \mathrm{~mL})$ was added to the flask by syringe and the mixture was stirred for $10 \mathrm{~min}$. 2bromo-3-hexylfuran was then added $(1.13 \mathrm{~g}, 4.89 \mathrm{mmol})$ and the mixture was stirred for $5 \mathrm{~min}$. Finally, the product from the first step $(2.41 \mathrm{~g}, 4.43 \mathrm{mmol})$ was added by syringe. 
The flask was subsequently immersed in an oil bath at $100{ }^{\circ} \mathrm{C}$ and stirred overnight. Upon completion, the reaction mixture was cooled to room temperature and concentrated using rotary evaporation. The residue was loaded onto silica gel and purified using column chromatography, eluting with hexanes $\left(R_{\mathrm{f}}=0.61\right)$ to afford $1.66 \mathrm{~g}$ of 3-hexyl-2(4-hexyl-5-(4-hexylselenophen-2-yl)thiophen-2-yl)furan as a yellow oil (70 \% yield). ${ }^{1} \mathrm{H}$ $\operatorname{NMR}\left(500 \mathrm{MHz}, \mathrm{CDCl}_{3}\right) \delta 7.51(\mathrm{~d}, J=1.3 \mathrm{~Hz}, 1 \mathrm{H}), 7.33(\mathrm{~d}, J=1.8 \mathrm{~Hz}, 1 \mathrm{H}), 7.17(\mathrm{~d}, J=$ $1.4 \mathrm{~Hz}, 1 \mathrm{H}), 7.05(\mathrm{~s}, 1 \mathrm{H}), 6.35(\mathrm{~d}, J=1.8 \mathrm{~Hz}, 1 \mathrm{H}), 2.78-2.71(\mathrm{~m}, 2 \mathrm{H}), 2.67-2.62(\mathrm{~m}$, 2H), $2.61-2.55(\mathrm{~m}, 2 \mathrm{H}), 1.72-1.59(\mathrm{~m}, 6 \mathrm{H}), 1.47-1.25(\mathrm{~m}, 18 \mathrm{H}), 0.96-0.84(\mathrm{~m}, 9 \mathrm{H})$. ${ }^{13} \mathrm{C}$ NMR $\left(126 \mathrm{MHz}, \mathrm{CDCl}_{3}\right) \delta 145.7,144.6,141.0,140.1,139.5,132.1,131.3,129.9$, 125.8, 124.5, 121.9, 113.7, 32.4, 31.93 and 31.91 ( 2 overlapping signals), 30.8, 30.5, 29.9, $29.6,29.5,29.4,29.2,25.9,22.9,14.32$ and 14.31 (2 overlapping signals). Note: only 14 of the 18 possible signals from the hexyl chains are visible due to similarities between chemical environments. HR-EIMS (m/z): $[\mathrm{M}]^{+}$calculated for $\mathrm{C}_{30} \mathrm{H}_{44} \mathrm{OSSe}$ : 532.2278; found 532.2273 .

2-(5-(5-bromo-4-hexylselenophen-2-yl)-4-hexylthiophen-2-

yl)-3-hexylfuran (5). A $100 \mathrm{~mL}$ round bottom flask equipped with a magnetic stir bar was charged with $\mathbf{D}(1.06 \mathrm{~g}, 1.99$

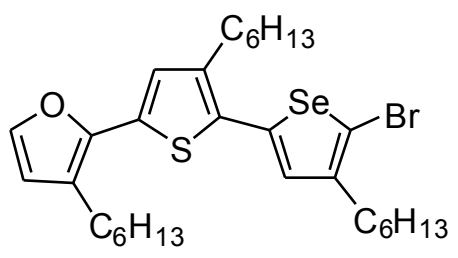
mmol) and benzene $(60 \mathrm{~mL})$. The flask was covered with aluminum foil and immersed in an ice bath and $\mathrm{N}$-bromosuccinimide $(0.35 \mathrm{~g}, 1.97 \mathrm{mmol})$, was added in small portions over a period of $5 \mathrm{~min}$. Upon complete addition of the NBS, the ice bath was removed and the reaction mixture was stirred for $2 \mathrm{~h}$. The mixture was poured into water, and the organic phase was extracted and washed with saturated $\mathrm{NaHCO}_{3}$ solution and water $(3 \times$ 
$50 \mathrm{~mL}$ ). The organic extract was dried over $\mathrm{Na}_{2} \mathrm{SO}_{4}$ and filtered. Removal of the solvent by rotary evaporation furnished the crude product which was purified by chromatography on silica gel, eluting with $0.5 \%$ triethylamine/hexanes $\left(R_{\mathrm{f}}=0.67\right)$ to afford $0.80 \mathrm{~g}$ of $2-(5-$ (5-bromo-4-hexylselenophen-2-yl)-4-hexylthiophen-2-yl)-3-hexylfuran as a yellow oil (66\% yield). A minor isomer was observed in the NMR spectra which corresponded to $\sim 10 \%$ of 5-bromo-3-hexyl-2-(4-hexyl-5-(4-hexylselenophen-2-yl)thiophen-2-yl)furan ( $\mathrm{Br}$

on furan, $\mathrm{H}$ on selenophene). ${ }^{1} \mathrm{H}$ NMR $\left(500 \mathrm{MHz}, \mathrm{CDCl}_{3}\right) \delta 7.32(\mathrm{~d}, J=1.8 \mathrm{~Hz}, 1 \mathrm{H})$, $7.02(\mathrm{~s}, 1 \mathrm{H}), 6.97(\mathrm{~s}, 1 \mathrm{H}), 6.35(\mathrm{~d}, J=1.9 \mathrm{~Hz}, 1 \mathrm{H}), 2.70-2.65(\mathrm{~m}, 2 \mathrm{H}), 2.65-2.60(\mathrm{~m}$, 2H), $2.57-2.51(\mathrm{~m}, 2 \mathrm{H}), 1.69-1.55(\mathrm{~m}, 6 \mathrm{H}), 1.45-1.24(\mathrm{~m}, 18 \mathrm{H}), 0.95-0.82(\mathrm{~m}, 9 \mathrm{H})$. ${ }^{13} \mathrm{C}$ NMR $\left(126 \mathrm{MHz}, \mathrm{CDCl}_{3}\right) \delta 144.9,144.4,141.2,140.1,140.0,131.9,131.2,129.2$, 125.7, 122.2, 113.7, 111.4, 31.92 and 31.89 and 31.87 (3 overlapping signals), 31.1, 30.8, $29.9,29.8,29.6,29.5,29.4,29.2,26.0,22.85$ and 22.84 ( 2 overlapping signals, 14.32 and 14.31 ( 2 overlapping signals). Note: only 16 of the 18 possible signals from the hexyl chains are visible due to similarities between chemical environments.

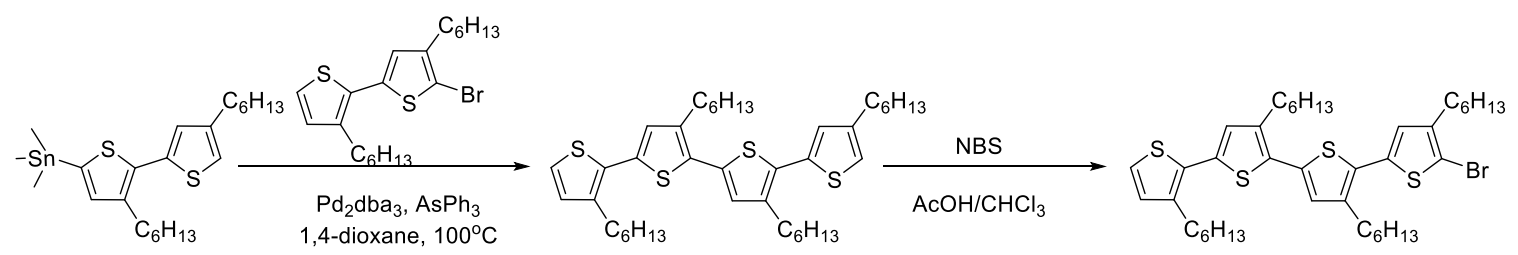

Scheme S6. Synthesis of quaterthiophene monomer.

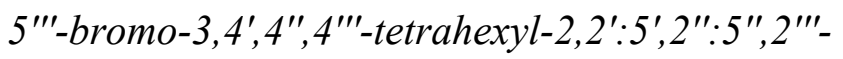
quaterthiophene

This compound was prepared according to a

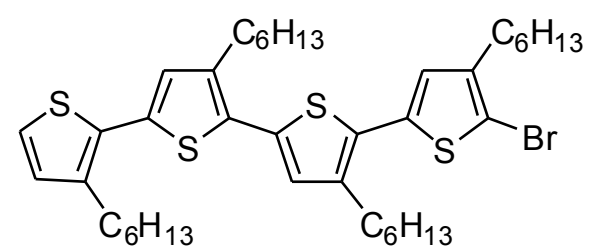


literature procedure. ${ }^{8}$ The ${ }^{1} \mathrm{H}$ NMR spectrum was compared to a previous report. ${ }^{7}$

Preparation of $\boldsymbol{T}-\boldsymbol{T}$. In a $\mathrm{N}_{2}$ filled glovebox, an oven-dried $50 \mathrm{~mL}$ Schlenk flask equipped with a magnetic stir bar was charged with compound $1(0.15 \mathrm{~g}, 0.36 \mathrm{mmol})$ and $9.1 \mathrm{~mL}$ of THF. Titrated

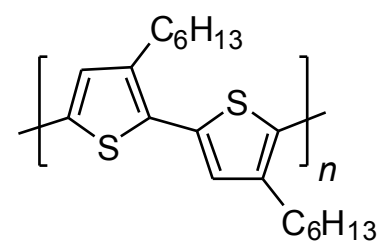
TMPMgCl$\cdot \mathrm{LiCl}$ solution $(0.79 \mathrm{M}, 0.55 \mathrm{~mL}, 0.43 \mathrm{mmol})$ was then added to the reaction solution, and the mixture was stirred at room temperature for $2 \mathrm{~h}$. The flask was sealed and removed from the glovebox. Under a $\mathrm{N}_{2}$ purge, a calculated amount of $\mathrm{Ni}(\mathrm{dppp}) \mathrm{Cl}_{2}(1,2$ and $4 \mathrm{~mol} \%)$ was then quickly added to the solution in one portion. The polymerization was stirred at room temperature for $15 \mathrm{~min}$, then quenched with $6 \mathrm{M}$ methanolic $\mathrm{HCl}$. The polymer was precipitated using methanol $(100 \mathrm{~mL})$, collected by vacuum filtration, washed with methanol and dried in vacuo. The final polymer was stored in a glovebox as a dark purple powder. Yield: M/Cat. = 25 (99 mg, 82\%), M/Cat. $=50(103 \mathrm{mg}, 85 \%)$ and $\mathrm{M} / \mathrm{Cat} .=100(90 \mathrm{mg}, 74 \%)$ from Table 1 in the paper. ${ }^{1} \mathrm{H}$ NMR data was compared to a previous report. ${ }^{9}$

Preparation of $\boldsymbol{T}$-Se. In a $\mathrm{N}_{2}$ filled glovebox, an oven-dried 50 mL Schlenk flask was charged with compound 2 (0.15 g, 0.33 $\mathrm{mmol}$ ) and $8.1 \mathrm{~mL}$ of $\mathrm{THF}$. Titrated $\mathrm{TMPMgCl} \cdot \mathrm{LiCl}$ solution

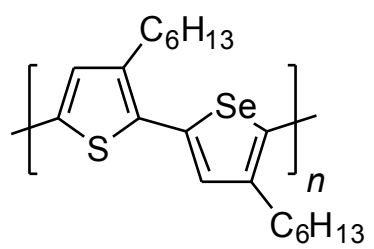
$(0.79 \mathrm{M}, 0.49 \mathrm{~mL}, 0.39 \mathrm{mmol})$ was then added to the reaction solution, and the mixture was stirred at room temperature for $2 \mathrm{~h}$. The flask was sealed and removed from the glovebox. Under a $\mathrm{N}_{2}$ purge, a calculated amount of $\mathrm{Ni}(\mathrm{dppp}) \mathrm{Cl}_{2}(1,2$ and $4 \mathrm{~mol} \%)$ was then quickly added to the solution in one portion. The polymerization was stirred at room 
temperature for $15 \mathrm{~min}$, and then quenched with $6 \mathrm{M}$ methanolic $\mathrm{HCl}$. The polymer was precipitated using methanol $(100 \mathrm{~mL})$, collected by vacuum filtration, washed with methanol and dried in vacuo. The final polymer was stored in the glovebox as a dark purple powder. Yield: M/Cat. $=25(107 \mathrm{mg}, 86 \%), \mathrm{M} /$ Cat. $=50(97 \mathrm{mg}, 78 \%)$ and $\mathrm{M} / \mathrm{Cat}$. $=100(75 \mathrm{mg}, 60 \%)$ from Table 1 in the paper. ${ }^{1} \mathrm{H}$ NMR $\left(500 \mathrm{MHz}, \mathrm{CDCl}_{3}\right) \delta 7.18(\mathrm{~s}$, 1H), $6.92(\mathrm{~s}, 1 \mathrm{H}), 2.84-2.68(\mathrm{~m}, 4 \mathrm{H}), 1.76-1.62(\mathrm{~m}, 4 \mathrm{H}), 1.48-1.39(\mathrm{~m}, 4 \mathrm{H}), 1.39-$ $1.22(\mathrm{~m}, 8 \mathrm{H}), 0.98-0.81(\mathrm{~m}, 6 \mathrm{H}) .{ }^{13} \mathrm{C} \mathrm{NMR}\left(126 \mathrm{MHz}, \mathrm{CDCl}_{3}\right) \delta 141.8,140.0,138.0$, $135.9,135.3,133.3,131.8,129.4,31.94$ and 31.93 (2 overlapping signals), 30.9, 30.83 and 30.77 ( 2 overlapping signals), $29.8,29.6,29.5,22.9,14.4,14.3$. Note: only 11 of the 12 possible signals from the hexyl chains are visible due to similarities between chemical environments. This polymer has been prepared previously using a different synthetic method. ${ }^{10}$

Preparation of T-T-Se. In a $\mathrm{N}_{2}$ filled glovebox, an ovendried $50 \mathrm{~mL}$ Schlenk flask was charged with compound $\mathbf{3}$ $(0.25 \mathrm{~g}, \quad 0.40 \mathrm{mmol})$ and $10 \mathrm{~mL}$ of THF. Titrated

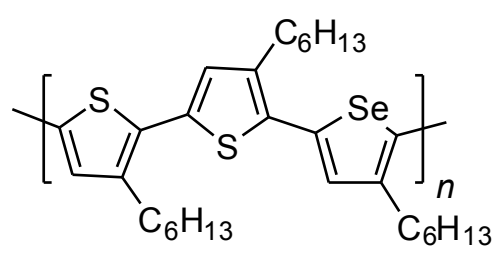
$\mathrm{TMPMgCl} \cdot \mathrm{LiCl}$ solution $(0.79 \mathrm{M}, 0.61 \mathrm{~mL}, 0.48 \mathrm{mmol})$ was added to the reaction solution, and the mixture was stirred at room temperature for $2 \mathrm{~h}$. The flask was sealed and removed from the glovebox. Under a $\mathrm{N}_{2}$ purge, a calculated amount of $\mathrm{Ni}(\mathrm{dppp}) \mathrm{Cl}_{2}(2 \mathrm{~mol} \%)$ was then quickly added to the solution in one portion. The polymerization was stirred at room temperature for $15 \mathrm{~min}$, then quenched with $6 \mathrm{M}$ methanolic $\mathrm{HCl}$. The polymer was precipitated using methanol $(100 \mathrm{~mL})$, collected by vacuum filtration, washed with methanol and dried in vacuo. The final polymer was 
stored in a glovebox as a dark purple powder. Yield: M/Cat. $=50(168 \mathrm{mg}, 77 \%)$ from Table 1 in the paper. ${ }^{1} \mathrm{H}$ NMR $\left(500 \mathrm{MHz}, \mathrm{CDCl}_{3}\right) \delta 7.19(\mathrm{~s}, 1 \mathrm{H}), 6.97(\mathrm{~s}, 1 \mathrm{H}), 6.92(\mathrm{~s}$, 1H), $2.85-2.70(\mathrm{~m}, 6 \mathrm{H}), 1.76-1.62(\mathrm{~m}, 6 \mathrm{H}), 1.49-1.40(\mathrm{~m}, 6 \mathrm{H}), 1.40-1.24(\mathrm{~m}, 12 \mathrm{H})$, $0.97-0.81(\mathrm{~m}, 9 \mathrm{H}) .{ }^{13} \mathrm{C} \mathrm{NMR}\left(126 \mathrm{MHz}, \mathrm{CDCl}_{3}\right) \delta 141.8,140.2,140.0,138.0,135.9$, $135.4,133.9,133.1,131.8,130.9,129.3,128.9,31.94$ and 31.93 (2 overlapping signals), 30.83 and 30.78 ( 2 overlapping signals), 30.7, 29.8, 29.7, 29.6, 29.5, 22.9, 14.4, 14.3. Note: only 12 of the 18 possible signals from the hexyl chains are visible due to similarities between chemical environments.

Preparation of T-Se-Se. In a $\mathrm{N}_{2}$ filled glovebox, an ovendried $50 \mathrm{~mL}$ Schlenk flask was charged with compound 4 $(0.2 \mathrm{~g}, \quad 0.30 \mathrm{mmol})$ and $7.5 \mathrm{~mL}$ of THF. Titrated

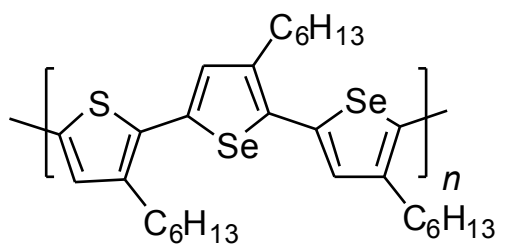
$\mathrm{TMPMgCl} \cdot \mathrm{LiCl}$ solution $(0.79 \mathrm{M}, 0.46 \mathrm{~mL}, 0.36 \mathrm{mmol})$ was added to the reaction solution, and the mixture was stirred at room temperature for $2 \mathrm{~h}$. The flask was sealed and removed from the glovebox. Under a $\mathrm{N}_{2}$ purge, a calculated amount of $\mathrm{Ni}(\mathrm{dppp}) \mathrm{Cl}_{2}(2 \mathrm{~mol} \%)$ was then quickly added to the solution in one portion. The polymerization was stirred at room temperature for $15 \mathrm{~min}$, and then quenched with $6 \mathrm{M}$ methanolic $\mathrm{HCl}$. The polymer was precipitated using methanol $(100 \mathrm{~mL})$, collected by vacuum filtration, washed with methanol and dried in vacuo. The final polymer was stored in a glovebox as a dark purple powder. Yield: M/Cat. $=50(147 \mathrm{mg}, 83 \%)$ from Table 1 in the paper. ${ }^{1} \mathrm{H}$ NMR $\left(500 \mathrm{MHz}, \mathrm{CDCl}_{3}\right) \delta 7.18(\mathrm{~s}, 1 \mathrm{H}), 7.12(\mathrm{~s}, 1 \mathrm{H}), 6.92(\mathrm{~s}$, 1H), $2.85-2.63(\mathrm{~m}, 6 \mathrm{H}), 1.77-1.61(\mathrm{~m}, 6 \mathrm{H}), 1.49-1.39(\mathrm{~m}, 6 \mathrm{H}), 1.39-1.22(\mathrm{~m}, 12 \mathrm{H})$, $0.98-0.81(\mathrm{~m}, 9 \mathrm{H}) .{ }^{13} \mathrm{C} \mathrm{NMR}\left(126 \mathrm{MHz}, \mathrm{CDCl}_{3}\right) \delta 141.8,141.6,140.02$ and $139.95(2$ 
overlapping signals), 137.90 and 137.86 (2 overlapping signals), 135.9, 135.6, 133.3, $132.5,131.8,129.4,31.93$ and 31.92 (2 overlapping signals), 30.90 and 30.85 (2 overlapping signals), 30.82 and 30.76 (2 overlapping signals), 29.8, 29.6, 29.5, 22.89 and 22.88 ( 2 overlapping signals), 14.35 and 14.34 (2 overlapping signals). Note: only 13 of the 18 possible signals from the hexyl chains are visible due to similarities between chemical environments.

Preparation of $\boldsymbol{F}-\boldsymbol{T}-\mathrm{Se}$. In a $\mathrm{N}_{2}$ filled glovebox, an ovendried $50 \mathrm{~mL}$ Schlenk flask was charged with compound $\mathbf{5}$ $(0.2 \mathrm{~g}, \quad 0.33 \mathrm{mmol})$ and $8.2 \mathrm{~mL}$ of THF. Titrated

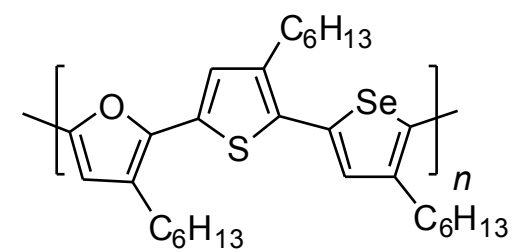
TMPMgCl$\cdot \mathrm{LiCl}$ solution $(0.82 \mathrm{M}, 0.49 \mathrm{~mL}, 0.40 \mathrm{mmol})$ was added to the reaction solution, and the mixture was stirred at room temperature for $2 \mathrm{~h}$. The flask was sealed and removed from the glovebox. Under a $\mathrm{N}_{2}$ purge, a calculated amount of $\mathrm{Ni}(\mathrm{dppp}) \mathrm{Cl}_{2}(1$ and $2 \mathrm{~mol} \%)$ was then quickly added to the solution in one portion. The polymerization was stirred at room temperature for $15 \mathrm{~min}$, and then quenched with $6 \mathrm{M}$ methanolic $\mathrm{HCl}$. The polymer was precipitated using methanol $(100 \mathrm{~mL})$, collected by vacuum filtration, washed with methanol and dried in vacuo. The final polymer was stored in a glovebox as a dark purple powder. Yield: M/Cat. $=50(73 \mathrm{mg}, 42 \%)$ and $\mathrm{M} /$ Cat. $=100(52 \mathrm{mg}, 30 \%)$ from Table 1 in the paper. ${ }^{1} \mathrm{H}$ NMR $\left(500 \mathrm{MHz}, \mathrm{CDCl}_{3}\right) \delta$ $7.18(\mathrm{~s}, 1 \mathrm{H}), 7.08(\mathrm{~s}, 1 \mathrm{H}), 6.39(\mathrm{~s}, 1 \mathrm{H}), 2.80(\mathrm{t}, J=7.9 \mathrm{~Hz}, 4 \mathrm{H}), 2.67(\mathrm{t}, J=7.7 \mathrm{~Hz}, 2 \mathrm{H})$, $1.78-1.64(\mathrm{~m}, 6 \mathrm{H}), 1.51-1.42(\mathrm{~m}, 6 \mathrm{H}), 1.41-1.25(\mathrm{~m}, 12 \mathrm{H}), 0.98-0.83(\mathrm{~m}, 9 \mathrm{H}) .{ }^{13} \mathrm{C}$ NMR (126 MHz, $\left.\mathrm{CDCl}_{3}\right) \delta 149.1,143.7,141.1,139.9,137.7,132.0,131.8,131.1,131.0$, $126.0,124.7,110.9,32.1,32.0,31.9,31.4,30.8,30.3,29.9,29.8,29.6,29.4,26.2,23.0$, 
22.90 and 22.88 ( 2 overlapping signals), 14.4 . Note: only 15 of the 18 possible signals from the hexyl chains are visible due to similarities between chemical environments.

Preparation of $\boldsymbol{P 3 H T}$ using quaterthiophene monomer. In a $\mathrm{N}_{2}$ filled glovebox, an ovendried $50 \mathrm{~mL}$ Schlenk flask was charged with the quaterthiophene monomer $(0.2 \mathrm{~g}, 0.27$ mmol) and $6.7 \mathrm{~mL}$ of THF. Titrated TMPMgCl$\cdot \mathrm{LiCl}$ solution $(0.79 \mathrm{M}, 0.41 \mathrm{~mL}, 0.32$ mmol) was added to the reaction solution, and the mixture was stirred at room temperature for $2 \mathrm{~h}$. The flask was sealed and removed from the glovebox. Under a $\mathrm{N}_{2}$ purge, a calculated amount of $\mathrm{Ni}(\mathrm{dppp}) \mathrm{Cl}_{2}(4 \mathrm{~mol} \%)$ was then quickly added to the solution in one portion. The polymerization was stirred at room temperature for $15 \mathrm{~min}$, and then quenched with $6 \mathrm{M}$ methanolic $\mathrm{HCl}$. The polymer was precipitated using methanol $(100 \mathrm{~mL})$, collected by vacuum filtration, washed with methanol and dried in vacuo. The final polymer was stored in a glovebox as a dark purple powder. Yield: $149 \mathrm{mg}, 83 \%$. ${ }^{1} \mathrm{H}$ NMR data was compared to a previous report. ${ }^{9}$

\section{Procedure for obtaining $M_{\mathrm{n}}$ versus conversion plot of T-T}

In a $\mathrm{N}_{2}$ filled glovebox, an oven-dried $50 \mathrm{~mL}$ was charged with compound $1(0.075 \mathrm{~g}$, $0.18 \mathrm{mmol})$, nonadecane $(0.049 \mathrm{~g}, 0.18 \mathrm{mmol})$ as the internal standard and $18.2 \mathrm{~mL}$ of THF. TMPMgCl$\cdot \mathrm{LiCl}$ solution $(0.82 \mathrm{M}, 0.27 \mathrm{~mL}, 0.22 \mathrm{mmol})$ was then added to the reaction solution at room temperature and the mixture was stirred for $2 \mathrm{~h}$ at room temperature. An aliquot was withdrawn and subjected to GC-MS analysis to determine the initial ratio of monomer to the internal standard. The flask was sealed and removed from the glovebox. Under a $\mathrm{N}_{2}$ purge, $\mathrm{Ni}(\mathrm{dppp}) \mathrm{Cl}_{2}(2.0 \mathrm{mg}, 0.0036 \mathrm{mmol})$ was then 
quickly added to the solution in one portion. Aliquots $(\sim 0.6 \mathrm{~mL})$ were withdrawn periodically over a period of 15 min to determine the monomer conversion (GC-MS) and polymer molecular weight (GPC).

Table S1. Data used to construct $M_{\mathrm{n}}$ versus monomer conversion plot of T-T.

\begin{tabular}{lll}
\hline Monomer Conversion (\%) & $M_{\mathrm{n}}$ & $D$ \\
\hline 12 & 5700 & 1.14 \\
23 & 6100 & 1.14 \\
37 & 10000 & 1.13 \\
48 & 11800 & 1.13 \\
58 & 14800 & 1.11 \\
72 & 18300 & 1.13 \\
89 & 21600 & 1.14 \\
95 & 20600 & 1.13 \\
\hline
\end{tabular}

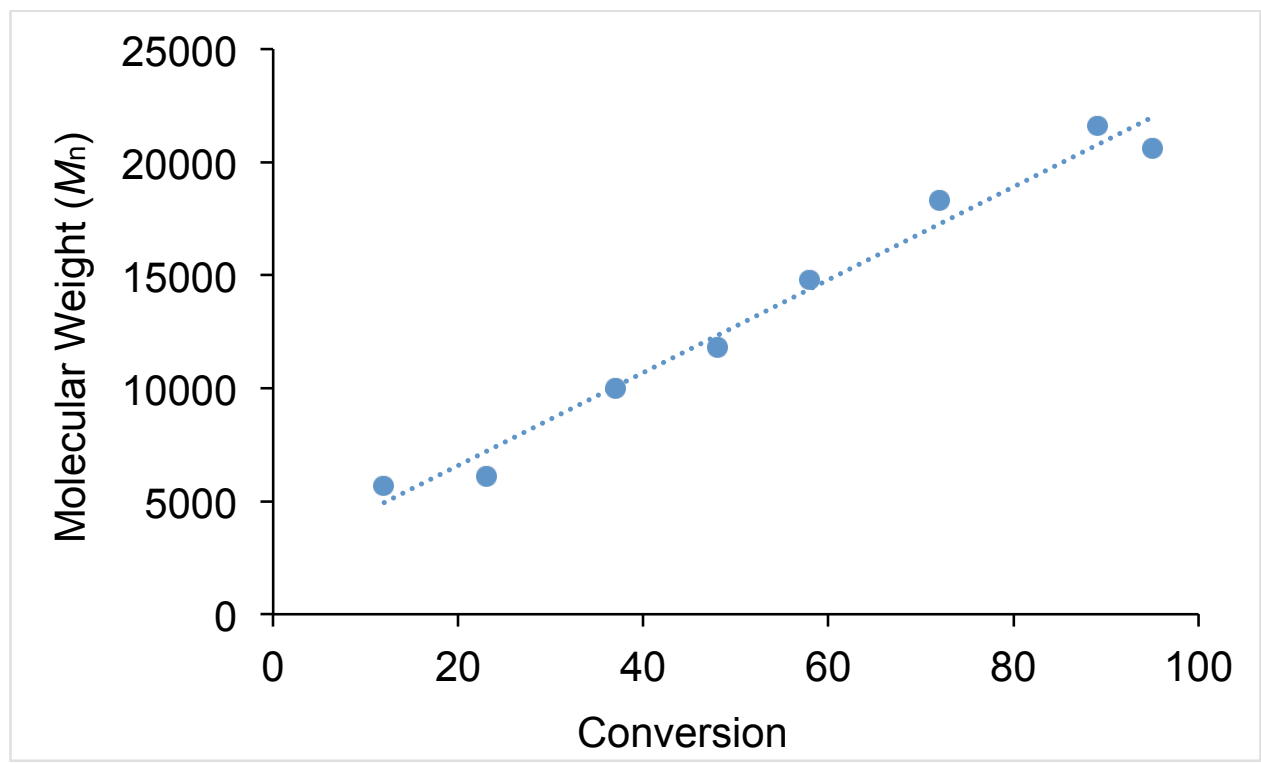

Figure S1. $M_{\mathrm{n}}$ versus conversion plot of polymerization of T-T.

\section{Procedure for obtaining $M_{\mathrm{n}}$ versus conversion plot of T-Se}

In a $\mathrm{N}_{2}$ filled glovebox, an oven-dried $50 \mathrm{~mL}$ Schlenk flask was charged with compound $2(0.15 \mathrm{~g}, 0.33 \mathrm{mmol})$, nonadecane $(0.087 \mathrm{~g}, 0.33 \mathrm{mmol})$ as the internal standard and 8.1 
$\mathrm{mL}$ of THF. TMPMgCl$\cdot \mathrm{LiCl}$ solution $(0.82 \mathrm{M}, 0.48 \mathrm{~mL}, 0.39 \mathrm{mmol})$ was then added to the reaction solution at room temperature and the mixture was stirred for $2 \mathrm{~h}$ at room temperature. An aliquot was withdrawn and subjected to GC-MS analysis to determine the initial ratio of monomer to the internal standard. The flask was sealed and removed from the glovebox. Under a $\mathrm{N}_{2}$ purge, $\mathrm{Ni}(\mathrm{dppp}) \mathrm{Cl}_{2}(1.8 \mathrm{mg}, 0.0033 \mathrm{mmol})$ was then quickly added to the solution in one portion. Aliquots $(\sim 0.4 \mathrm{~mL})$ were withdrawn periodically over a period of 15 min to determine the monomer conversion (GC-MS) and polymer molecular weight (GPC).

Table S2. Data used to construct $M_{\mathrm{n}}$ versus monomer conversion plot of T-Se.

\begin{tabular}{lll}
\hline Monomer Conversion $(\%)$ & $M_{\mathrm{n}}$ & $\oplus$ \\
\hline 25 & 7600 & 1.14 \\
28 & 11700 & 1.11 \\
41 & 18100 & 1.11 \\
69 & 28100 & 1.13 \\
83 & 34200 & 1.20 \\
85 & 36800 & 1.23 \\
\hline
\end{tabular}

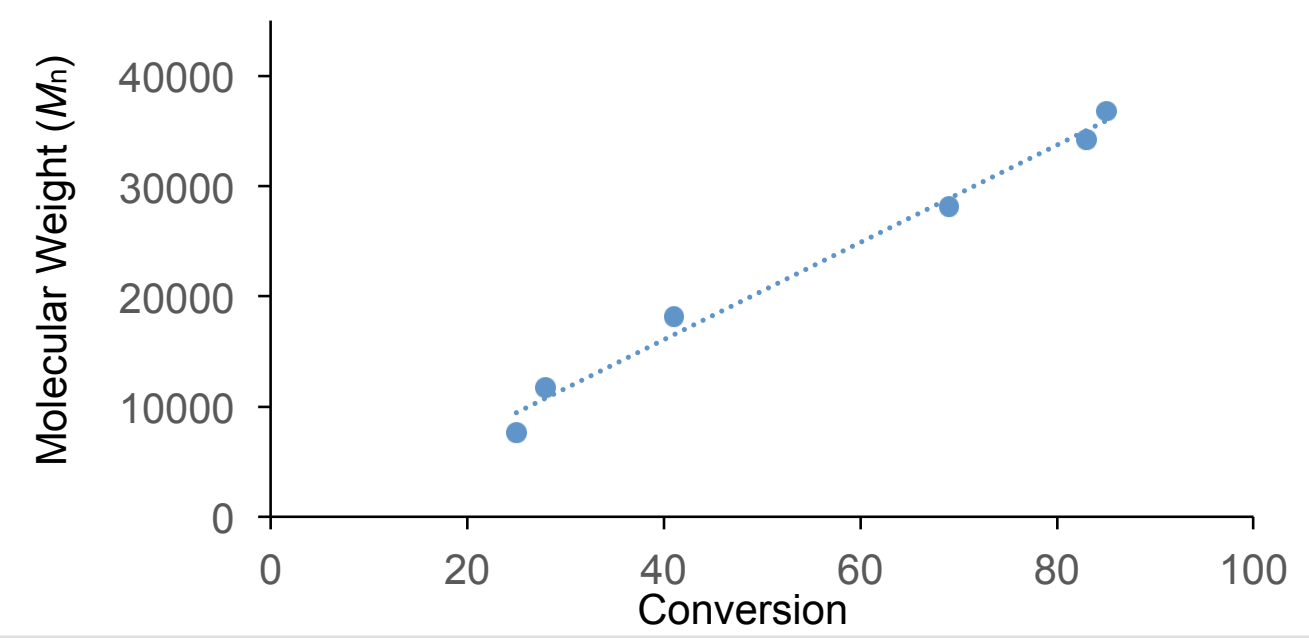

Figure S2. $M_{\mathrm{n}}$ versus conversion Plot of polymerization of T-Se. 


\section{Quenching study for Monomer 2}
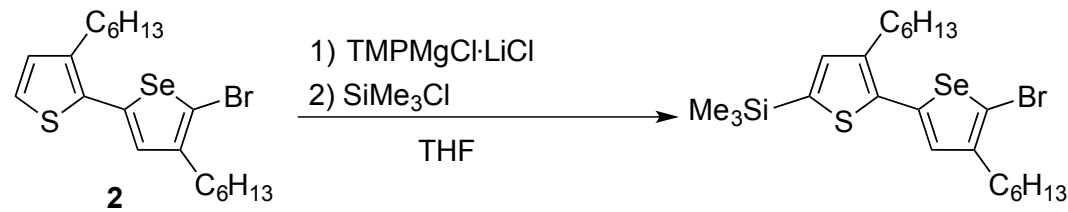

An oven-dried $20 \mathrm{~mL}$ scintillation vial equipped with a magnetic stir bar was brought into a $\mathrm{N}_{2}$ filled glove box. The vial was charged with compound 2 (75 $\left.\mathrm{mg}, 0.16 \mathrm{mmol}\right)$ and $4.0 \mathrm{~mL}$ of THF. Titrated TMPMgCl$\cdot \mathrm{LiCl}$ solution $(0.82 \mathrm{M}, 0.24 \mathrm{~mL}, 0.20 \mathrm{mmol})$ was added to the reaction solution and the vial was closed with a septum-sealed cap. The vial was removed from the glove box and the mixture was stirred at room temperature for 2 h. The reaction mixture was then quenched with $\mathrm{SiMe}_{3} \mathrm{Cl}$ in $\mathrm{THF}$ and stirred for $1 \mathrm{~h}$. Analysis using GC-MS and ${ }^{1} \mathrm{H}$ NMR spectroscopy is shown below (Figures S3 and S4).

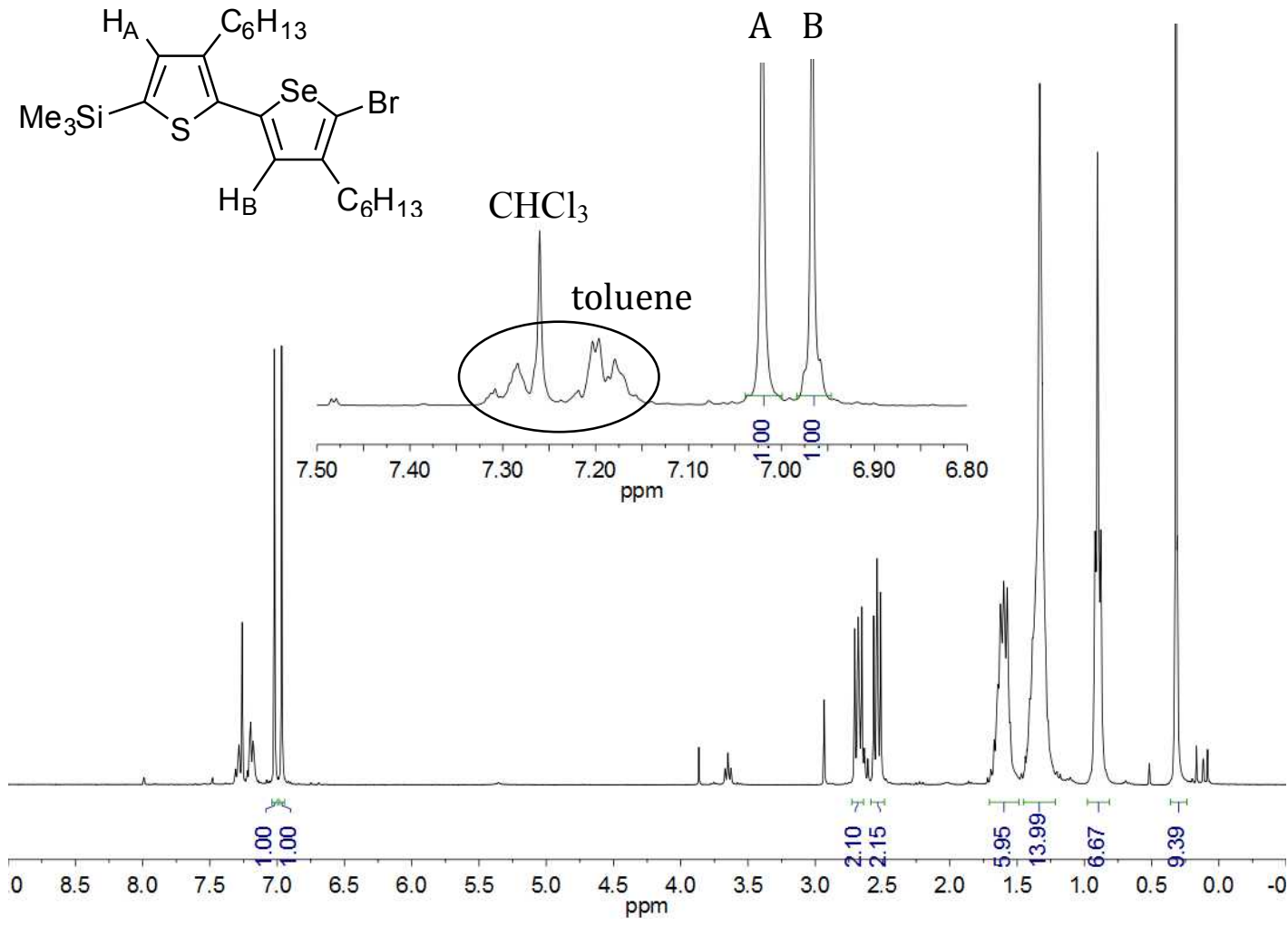

Figure S3. ${ }^{1} \mathrm{H}$ NMR spectrum of the crude reaction mixture. Insert is an expansion of the aromatic region (between 7.5 and $6.8 \mathrm{ppm}$ ). Signals of the product are labeled. 


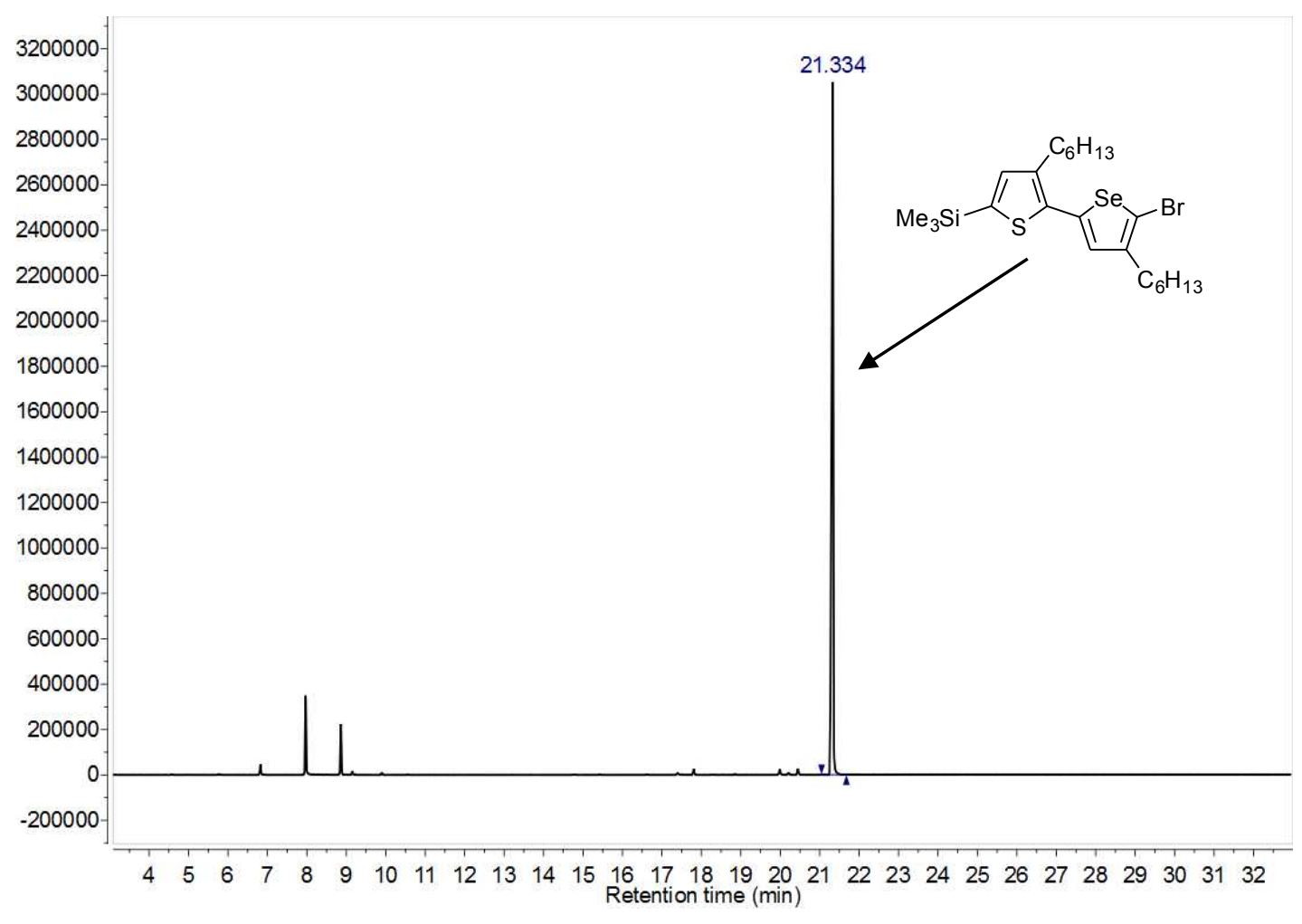

Figure S4. GC-MS chromatogram of the crude reaction mixture. Signal of the product is labeled. 

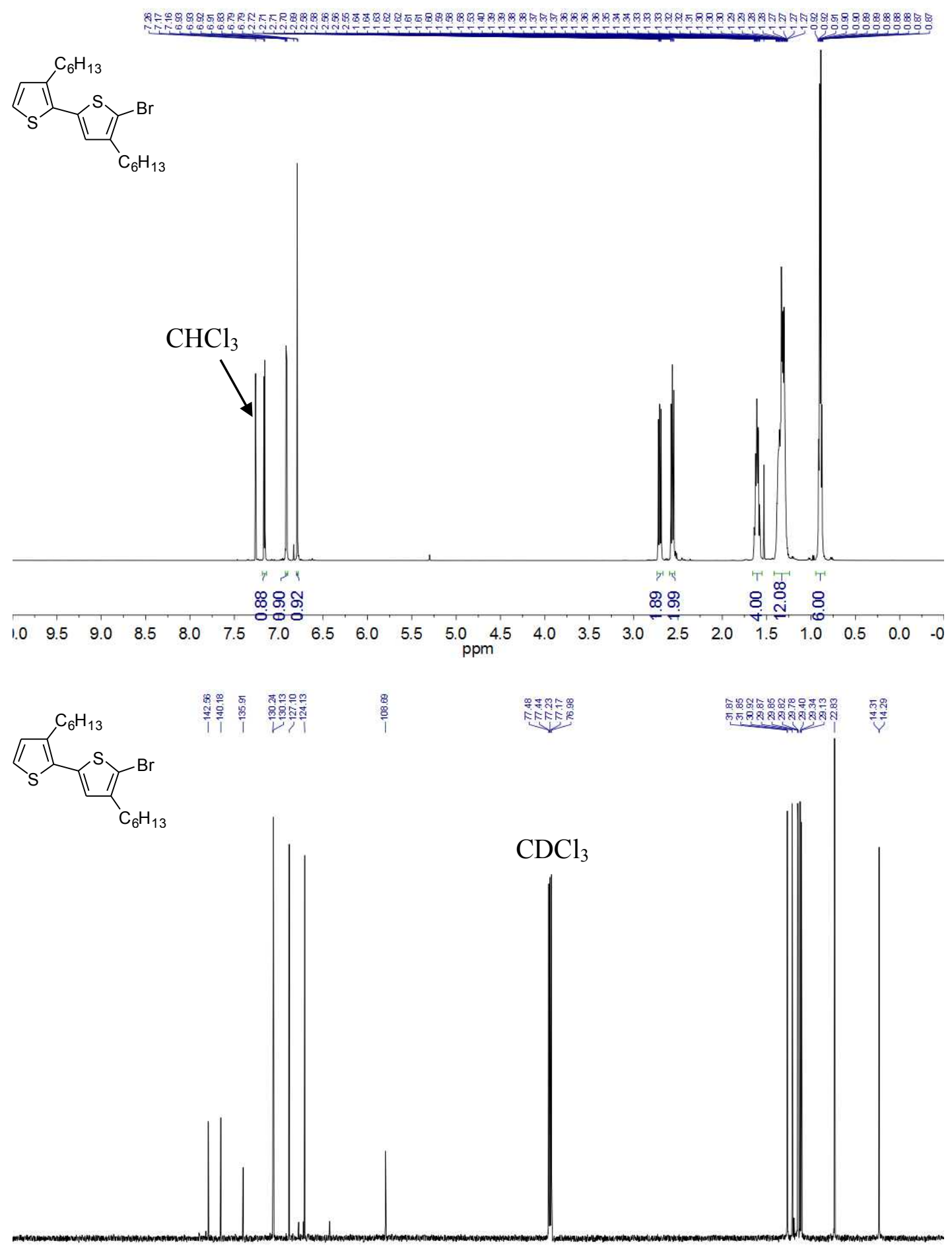

$\begin{array}{llllllllllllllllll}30 & 170 & 160 & 150 & 140 & 130 & 120 & 110 & 100 & \begin{array}{r}90 \\ \mathrm{ppm}\end{array} & 80 & 70 & 60 & 50 & 40 & 30 & 20 & 10\end{array}$

Figure S5. Compound $1{ }^{1} \mathrm{H}$ NMR Spectrum - $500 \mathrm{MHz}, \mathrm{CDCl}_{3}$ (top), ${ }^{13} \mathrm{C} \mathrm{NMR}$ Spectrum $-126 \mathrm{MHz}, \mathrm{CDCl}_{3}$ (bottom). 

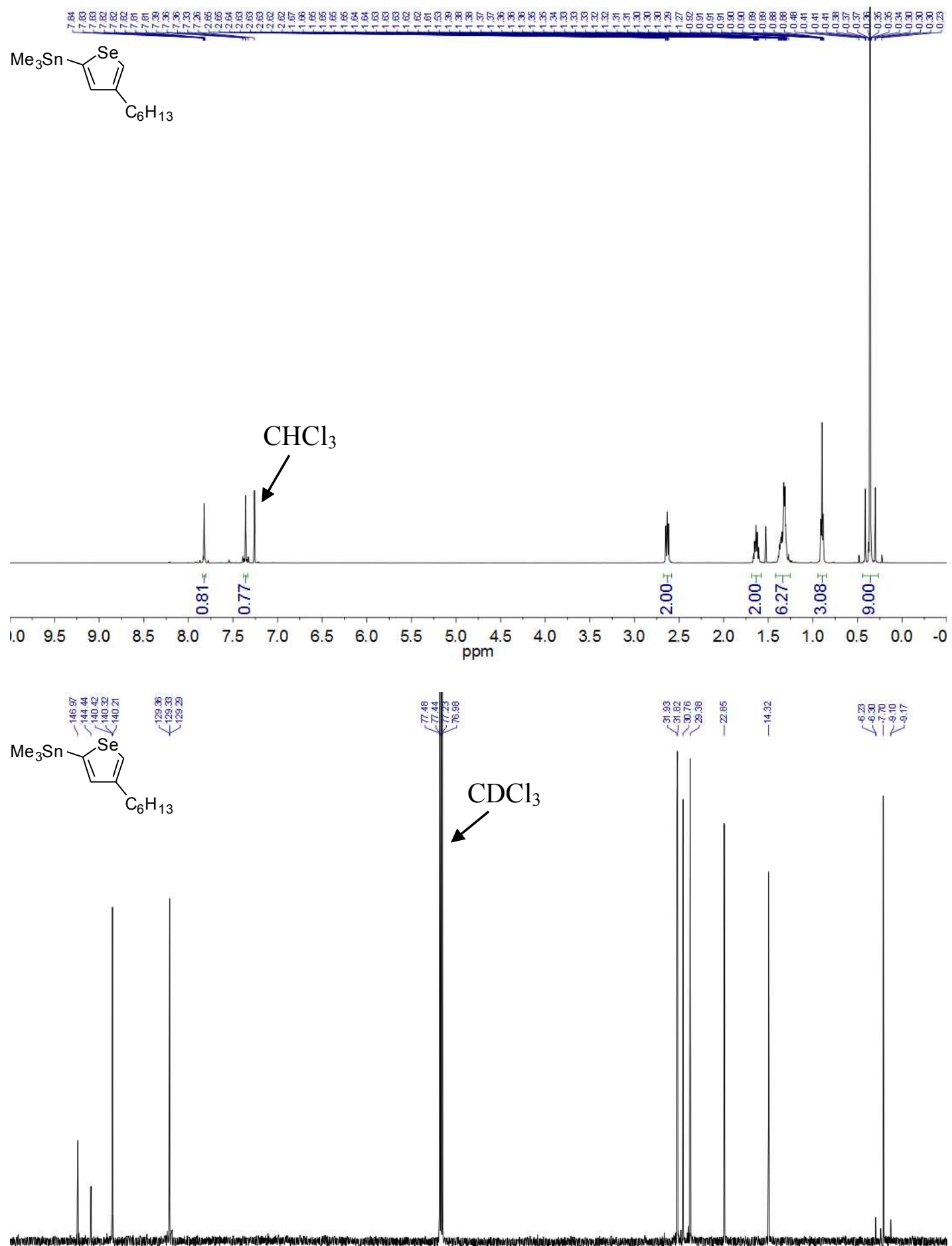

30 $\quad \begin{array}{llllllllllllllllll}150 & 140 & 130 & 120 & 110 & 100 & 90 & 80 & \begin{array}{c}70 \\ \mathrm{ppm}\end{array} & 60 & 50 & 40 & 30 & 20 & 10 & 0 & -10 & -2\end{array}$

Figure S6. (4-hexylselenophen-2-yl)trimethylstannane ${ }^{1} \mathrm{H}$ NMR Spectrum - $500 \mathrm{MHz}$, $\mathrm{CDCl}_{3}$ (top), ${ }^{13} \mathrm{C} \mathrm{NMR}$ Spectrum $-126 \mathrm{MHz}, \mathrm{CDCl}_{3}$ (bottom). 
198889888967 (C)
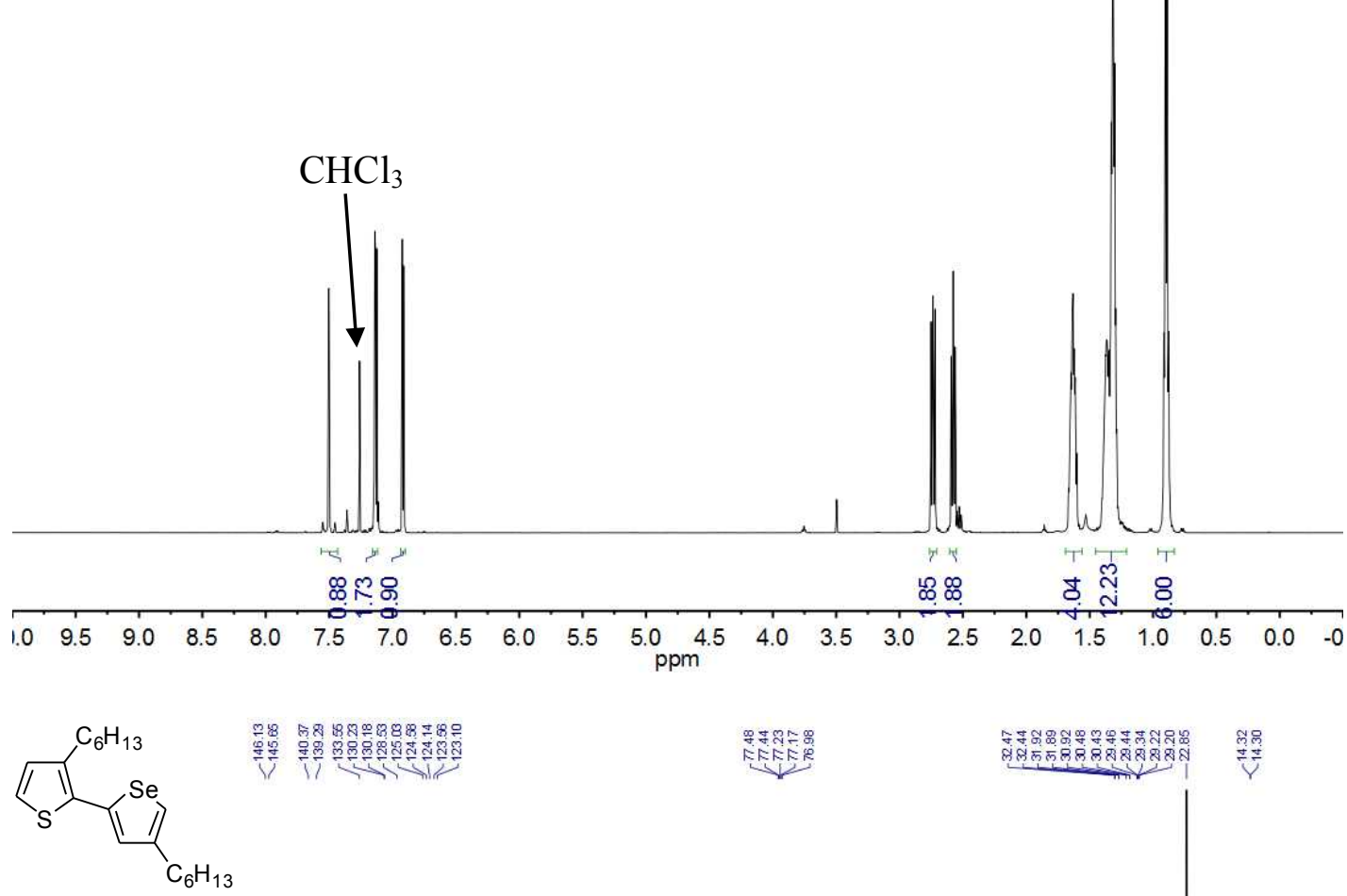

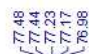
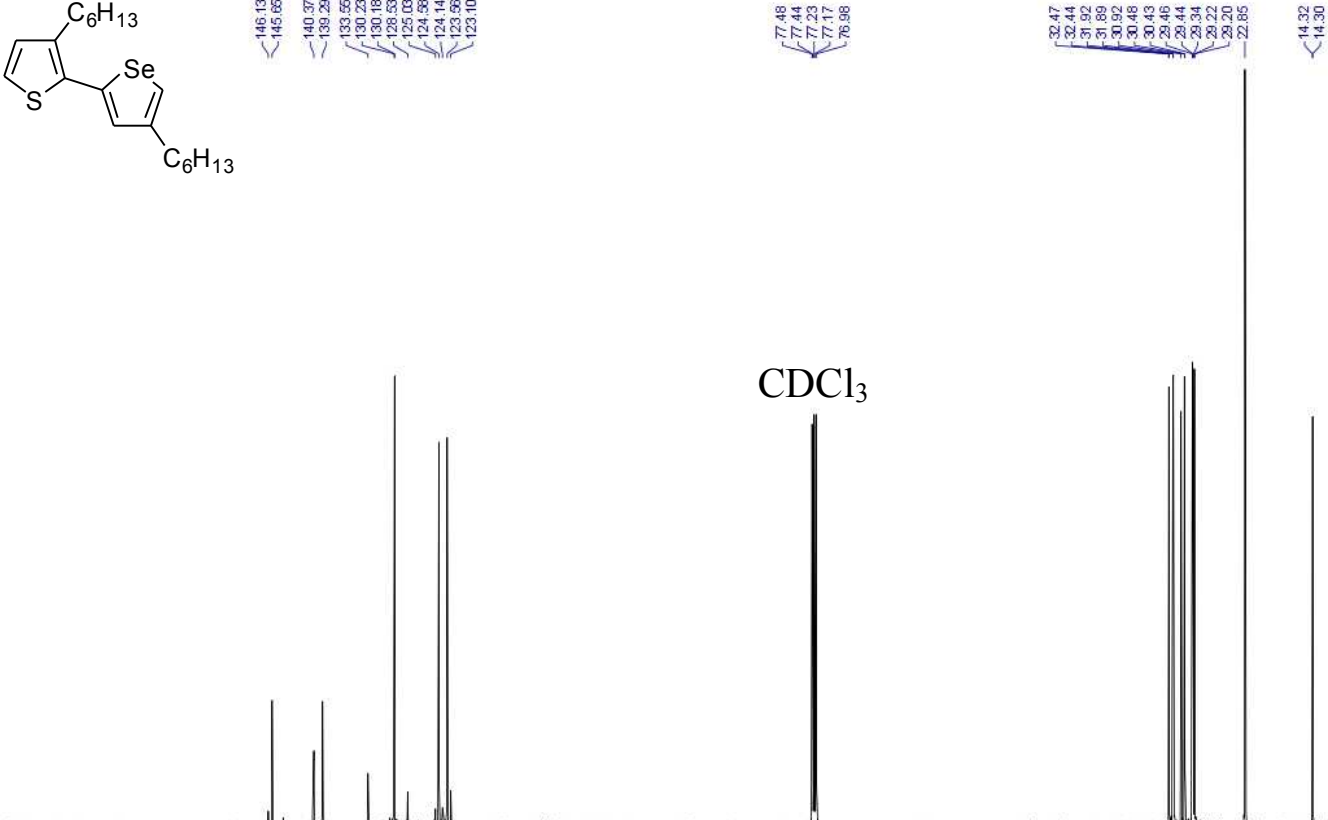

$\mathrm{CDCl}_{3}$
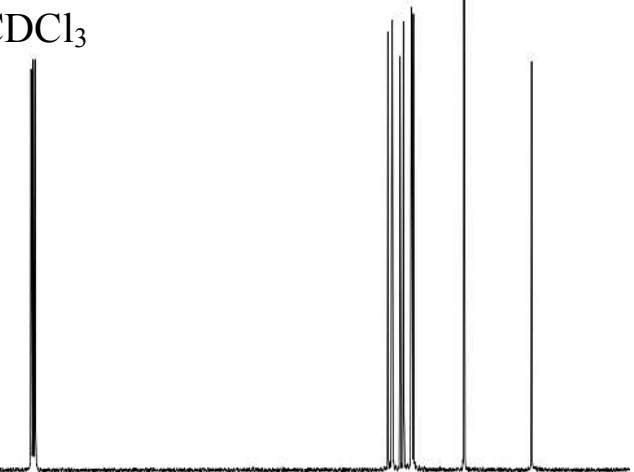

$\begin{array}{llllllllllllllllll}30 & 170 & 160 & 150 & 140 & 130 & 120 & 110 & 100 & \begin{array}{r}90 \\ \mathrm{ppm}\end{array} & 80 & 70 & 60 & 50 & 40 & 30 & 20 & 10\end{array}$

Figure S7. Compound $\mathbf{A}^{1} \mathrm{H}$ NMR Spectrum $-500 \mathrm{MHz}, \mathrm{CDCl}_{3}$ (top), ${ }^{13} \mathrm{C} \mathrm{NMR}$ Spectrum $-126 \mathrm{MHz}, \mathrm{CDCl}_{3}$ (bottom). 


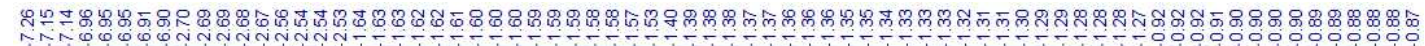<smiles>Cc1cc(-c2sccc2C)sc1Br</smiles>

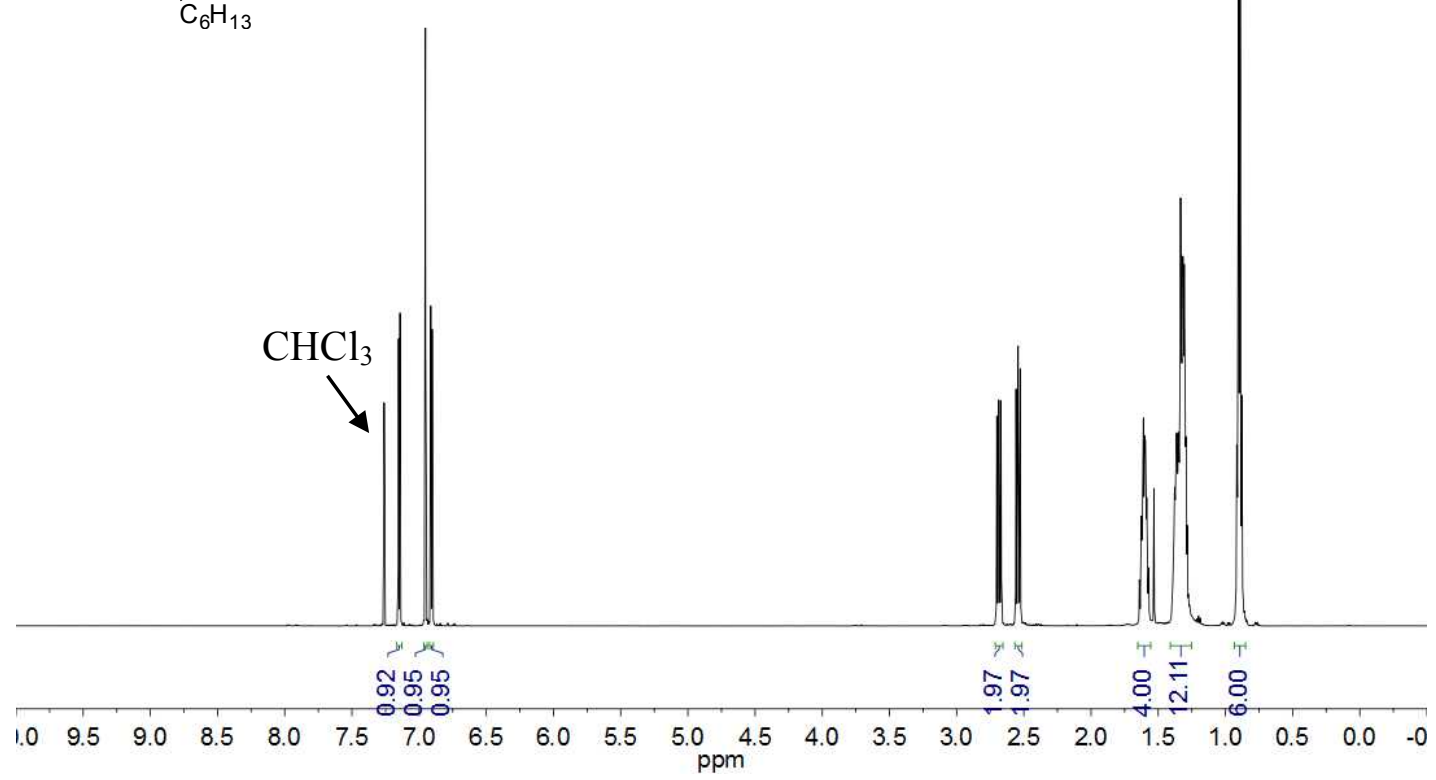<smiles></smiles>
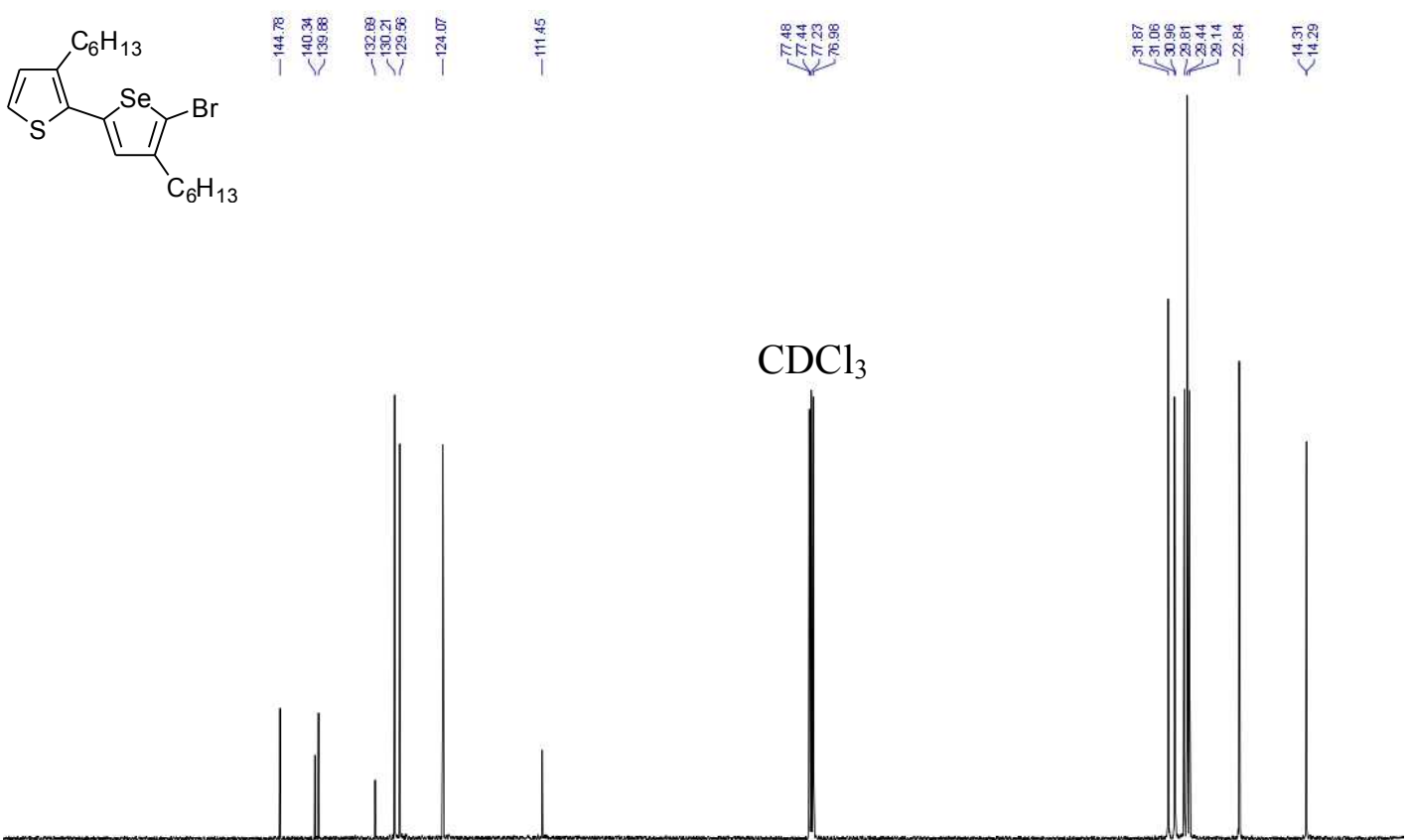

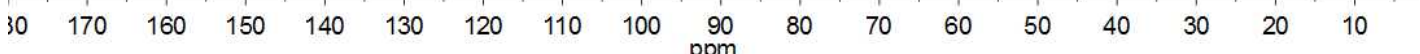

Figure S8. Compound $2{ }^{1} \mathrm{H}$ NMR Spectrum $-500 \mathrm{MHz}, \mathrm{CDCl}_{3}$ (top), ${ }^{13} \mathrm{C} \mathrm{NMR}$ Spectrum $-126 \mathrm{MHz}, \mathrm{CDCl}_{3}$ (bottom). 
B818.5 (c)
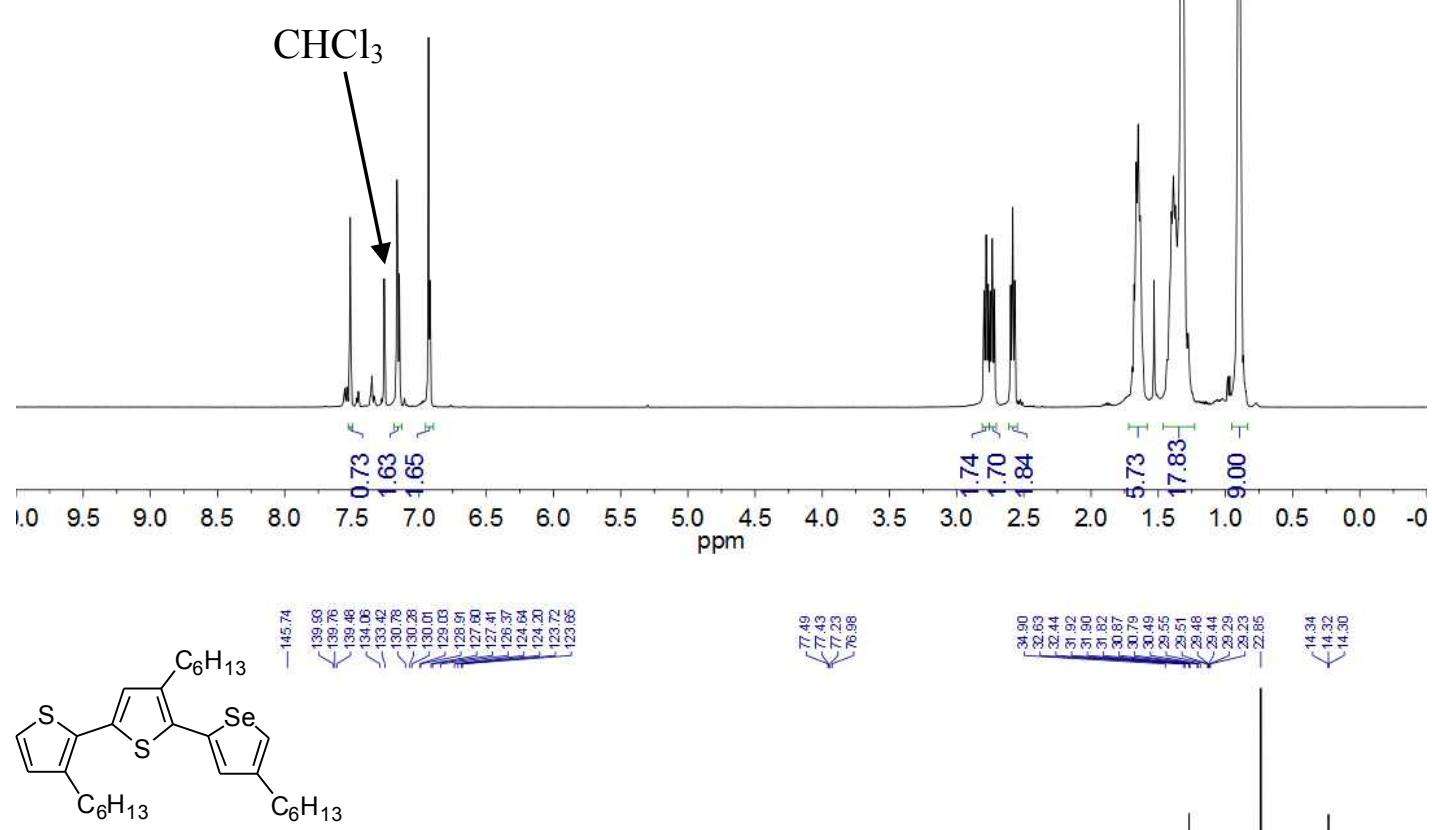

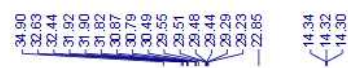

证
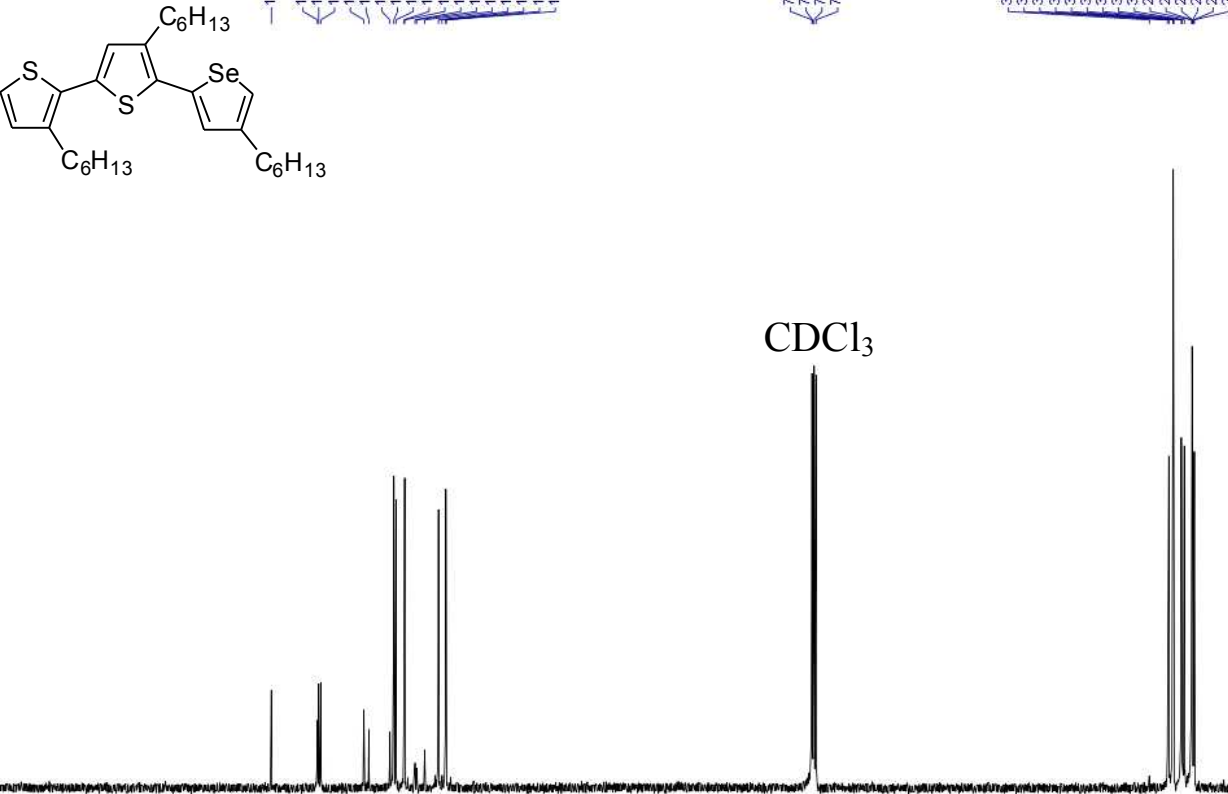

$\mathrm{CDCl}_{3}$

$\begin{array}{llllllllllllllllll}30 & 170 & 160 & 150 & 140 & 130 & 120 & 110 & 100 & \begin{array}{c}90 \\ \mathrm{ppm}\end{array} & 80 & 70 & 60 & 50 & 40 & 30 & 20 & 10\end{array}$

Figure S9. Compound $\mathbf{B}{ }^{1} \mathrm{H}$ NMR Spectrum $-500 \mathrm{MHz}, \mathrm{CDCl}_{3}$ (top), ${ }^{13} \mathrm{C} \mathrm{NMR}$ Spectrum $-126 \mathrm{MHz}, \mathrm{CDCl}_{3}$ (bottom). 

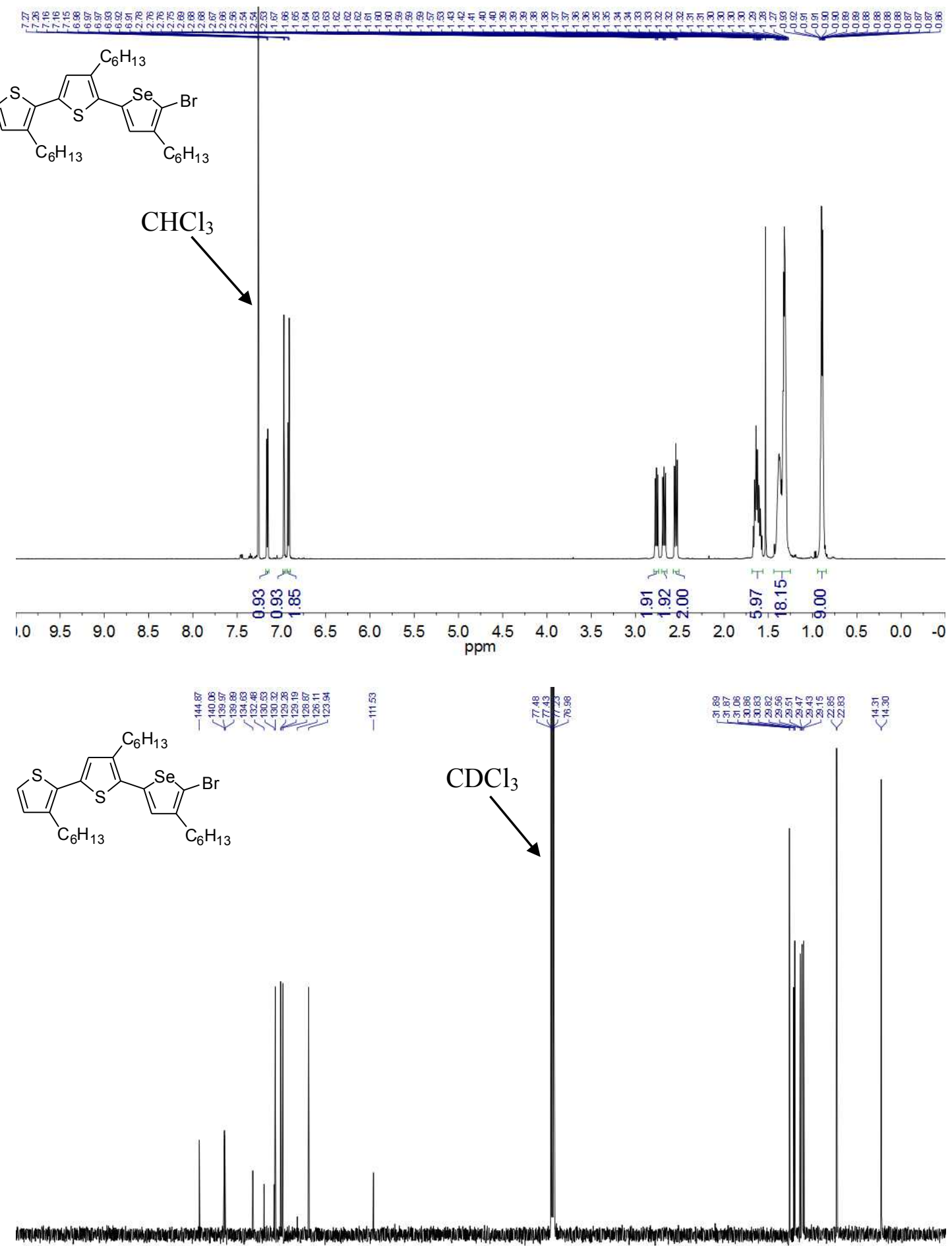

$\begin{array}{llllllllllllllllll}30 & 170 & 160 & 150 & 140 & 130 & 120 & 110 & 100 & \begin{array}{r}90 \\ \mathrm{ppm}\end{array} & 80 & 70 & 60 & 50 & 40 & 30 & 20 & 10\end{array}$

Figure S10. Compound $3{ }^{1} \mathrm{H}$ NMR Spectrum - $500 \mathrm{MHz}, \mathrm{CDCl}_{3}$ (top), ${ }^{13} \mathrm{C}$ NMR Spectrum $-126 \mathrm{MHz}, \mathrm{CDCl}_{3}$ (bottom). 

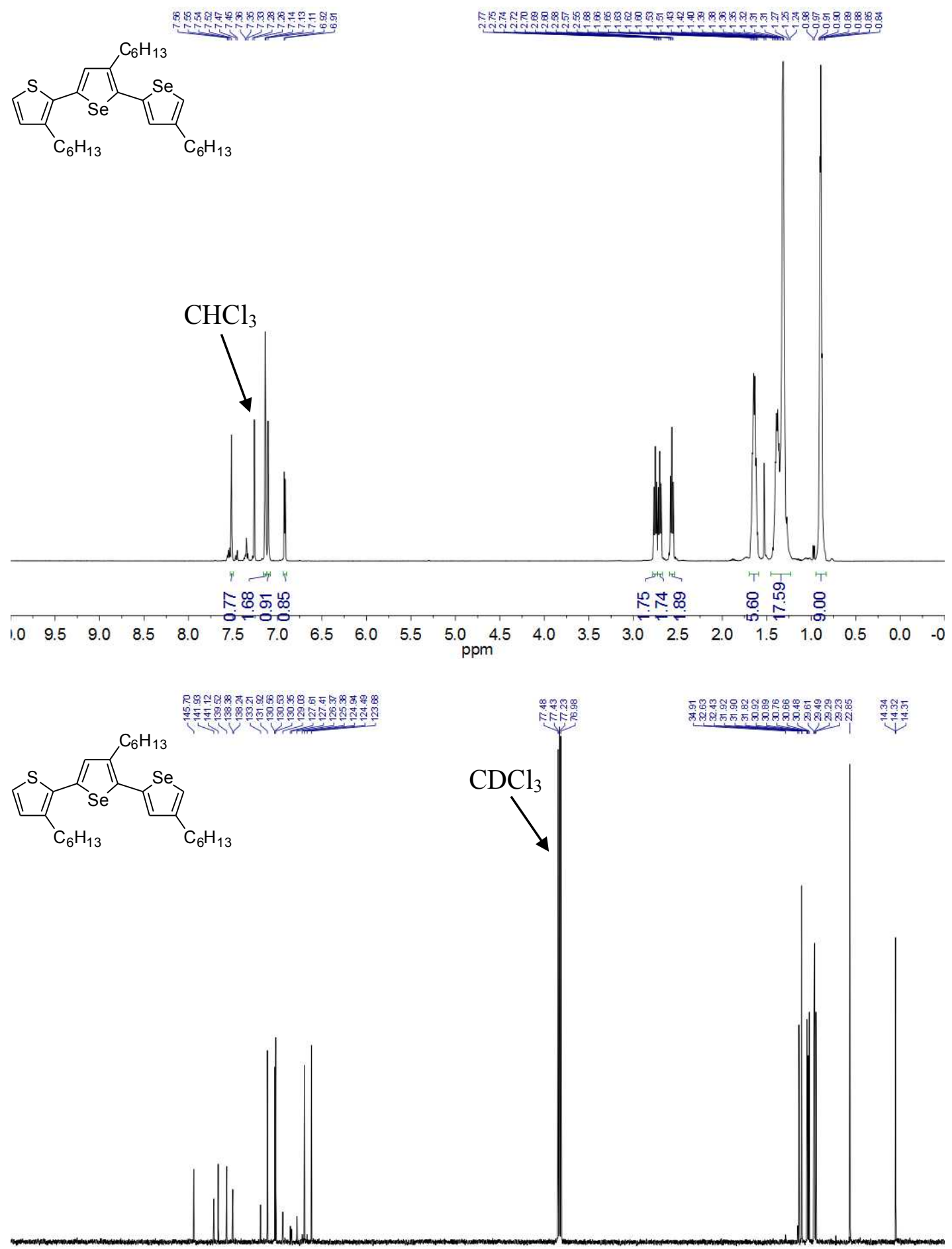

$\begin{array}{llllllllllllllllll}30 & 170 & 160 & 150 & 140 & 130 & 120 & 110 & 100 & \begin{array}{c}90 \\ \mathrm{ppm}\end{array} & 80 & 70 & 60 & 50 & 40 & 30 & 20 & 10\end{array}$

Figure S11. Compound $\mathbf{C}^{1} \mathrm{H}$ NMR Spectrum - $500 \mathrm{MHz}, \mathrm{CDCl}_{3}$ (top), ${ }^{13} \mathrm{C}$ NMR Spectrum $-126 \mathrm{MHz}, \mathrm{CDCl}_{3}$ (bottom). 

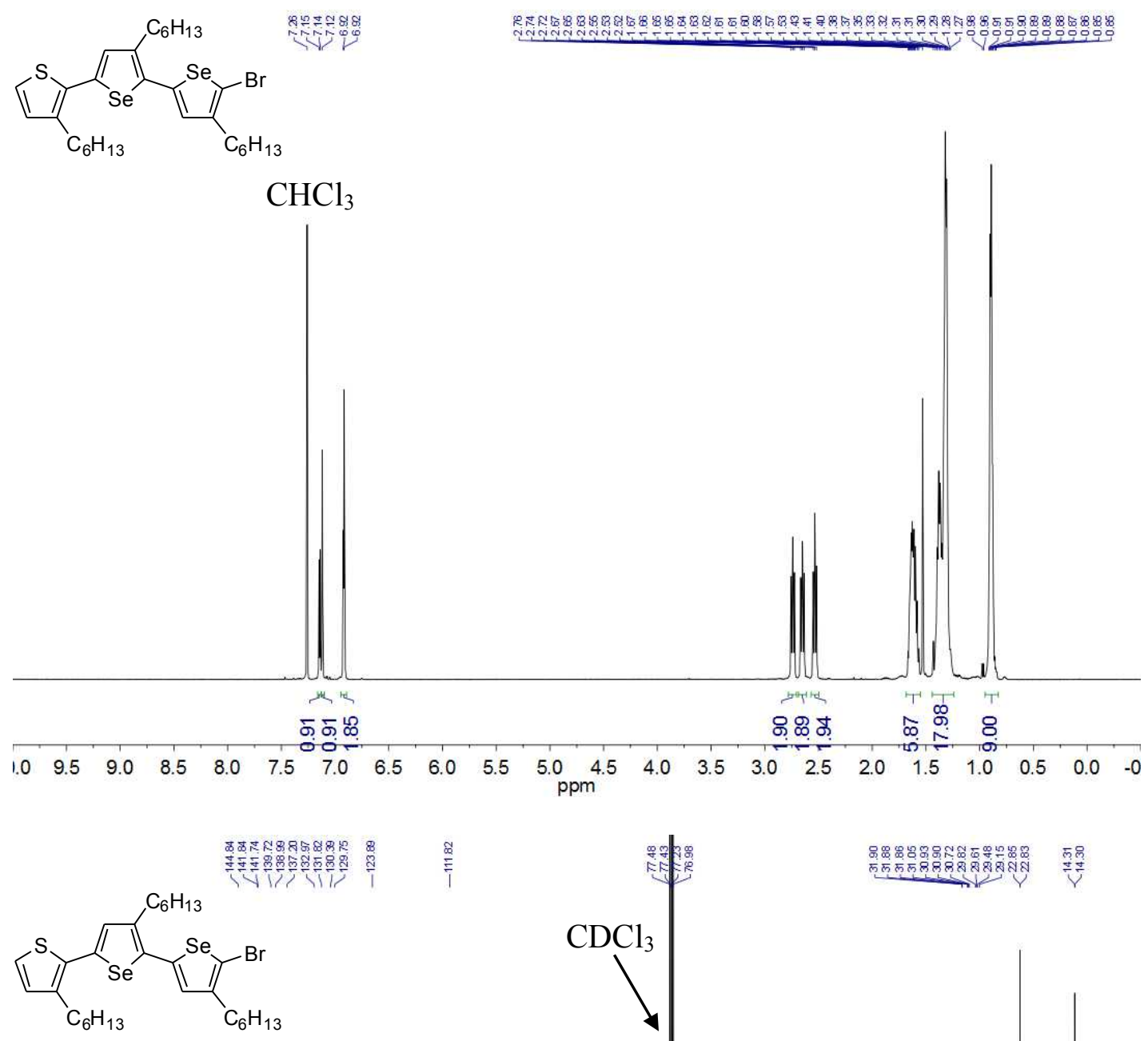

焉产

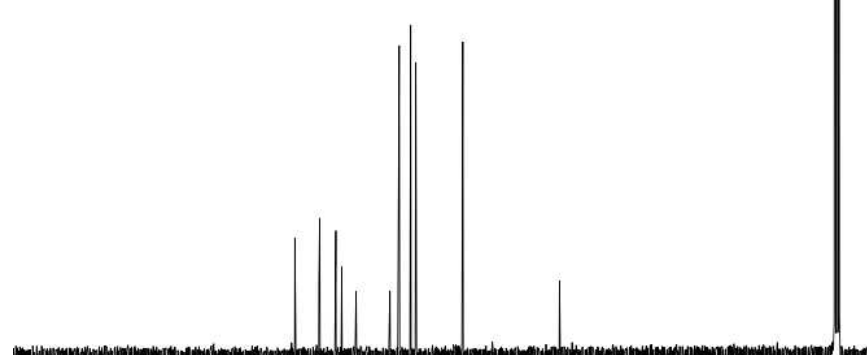

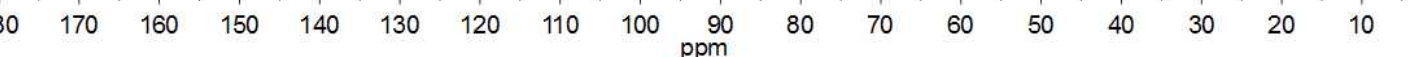

Figure S12. Compound $4{ }^{1} \mathrm{H}$ NMR Spectrum - $500 \mathrm{MHz}, \mathrm{CDCl}_{3}$ (top), ${ }^{13} \mathrm{C}$ NMR Spectrum $-126 \mathrm{MHz}, \mathrm{CDCl}_{3}$ (bottom). 

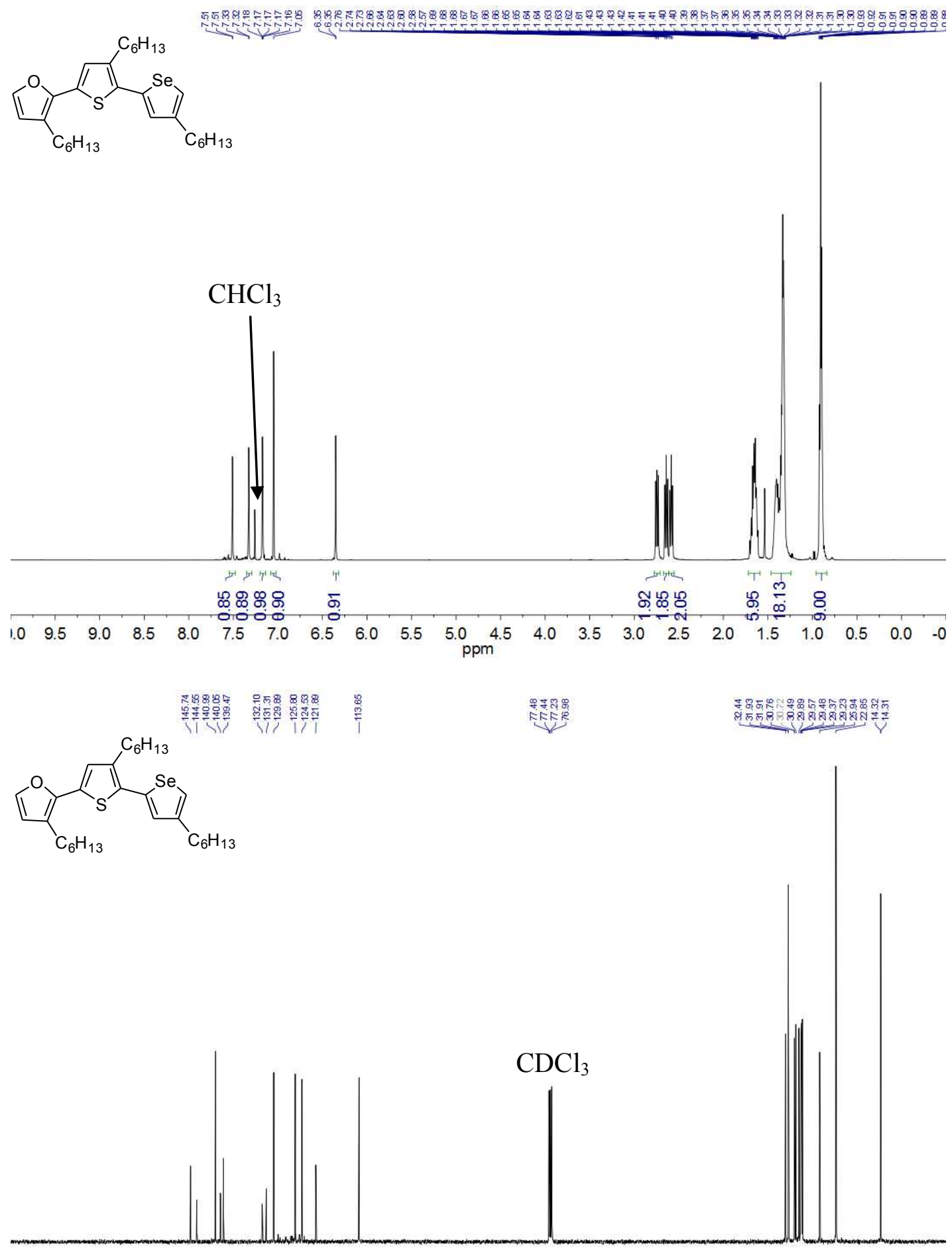

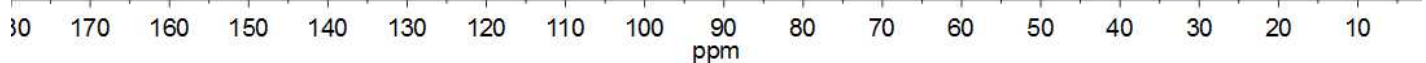

Figure S13. Compound $\mathbf{D}^{1} \mathrm{H}$ NMR Spectrum - $500 \mathrm{MHz}, \mathrm{CDCl}_{3}$ (top), ${ }^{13} \mathrm{C}$ NMR Spectrum - $126 \mathrm{MHz}, \mathrm{CDCl}_{3}$ (bottom). 

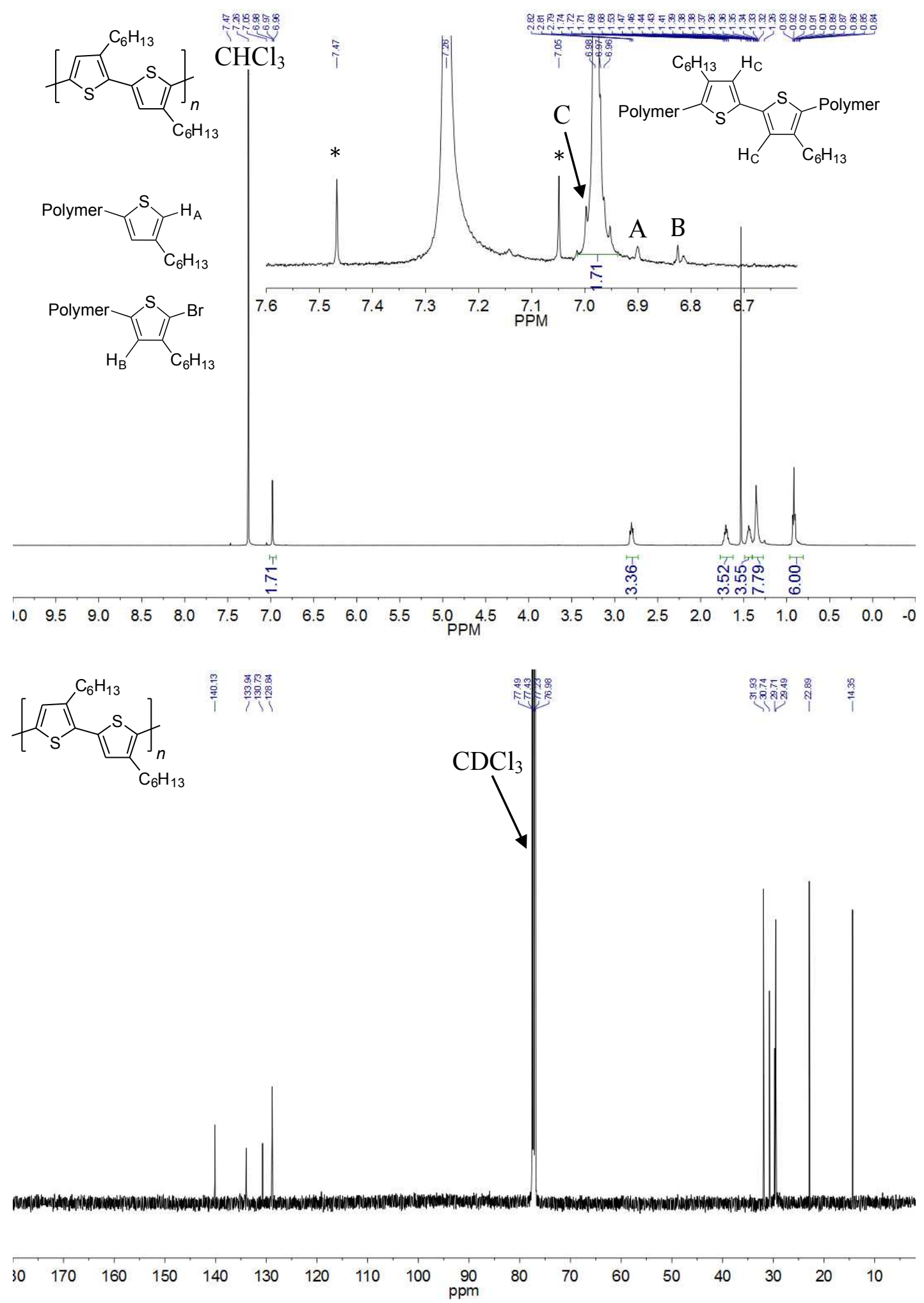

Figure S15. Polymer T-T with $M_{\mathrm{n}}=36,100, D=1.16 .{ }^{1} \mathrm{H}$ NMR Spectrum $-500 \mathrm{MHz}$, $\mathrm{CDCl}_{3}$ (top), ${ }^{13} \mathrm{C}$ NMR Spectrum $-126 \mathrm{MHz}, \mathrm{CDCl}_{3}$ (bottom). The star $(*)$ indicates $\mathrm{CHCl}_{3}$ satellites. 

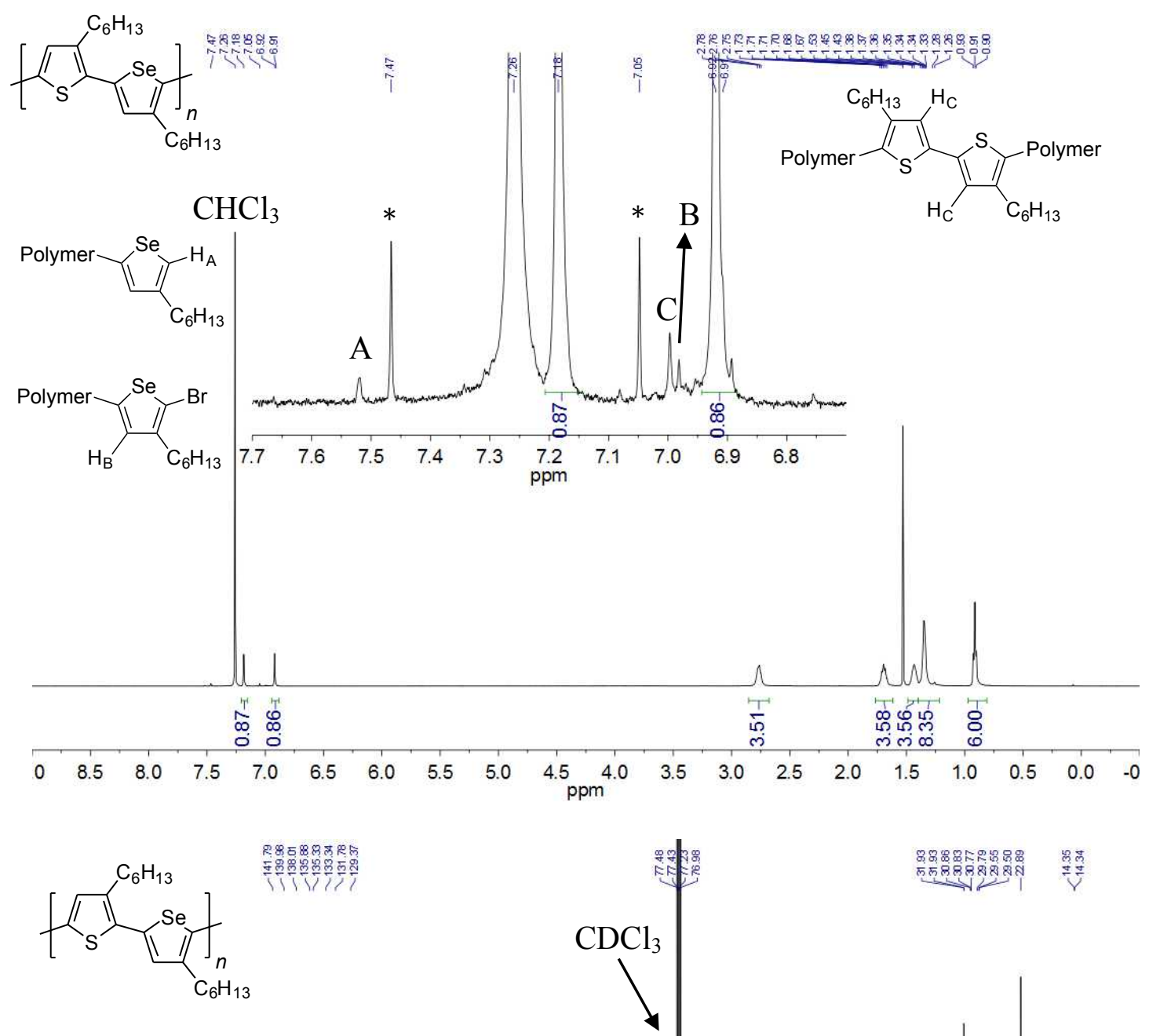

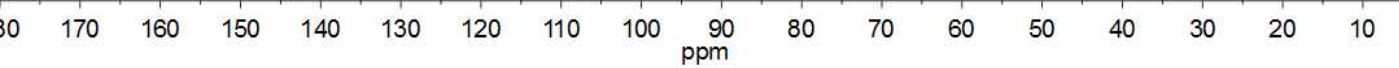

Figure S16. Polymer T-Se with $M_{\mathrm{n}}=39,800, \emptyset=1.18 .{ }^{1} \mathrm{H}$ NMR Spectrum $-500 \mathrm{MHz}$, $\mathrm{CDCl}_{3}$ (top), ${ }^{13} \mathrm{C} \mathrm{NMR}$ Spectrum $-126 \mathrm{MHz}, \mathrm{CDCl}_{3}$ (bottom). The star (*) indicates $\mathrm{CHCl}_{3}$ satellites. 


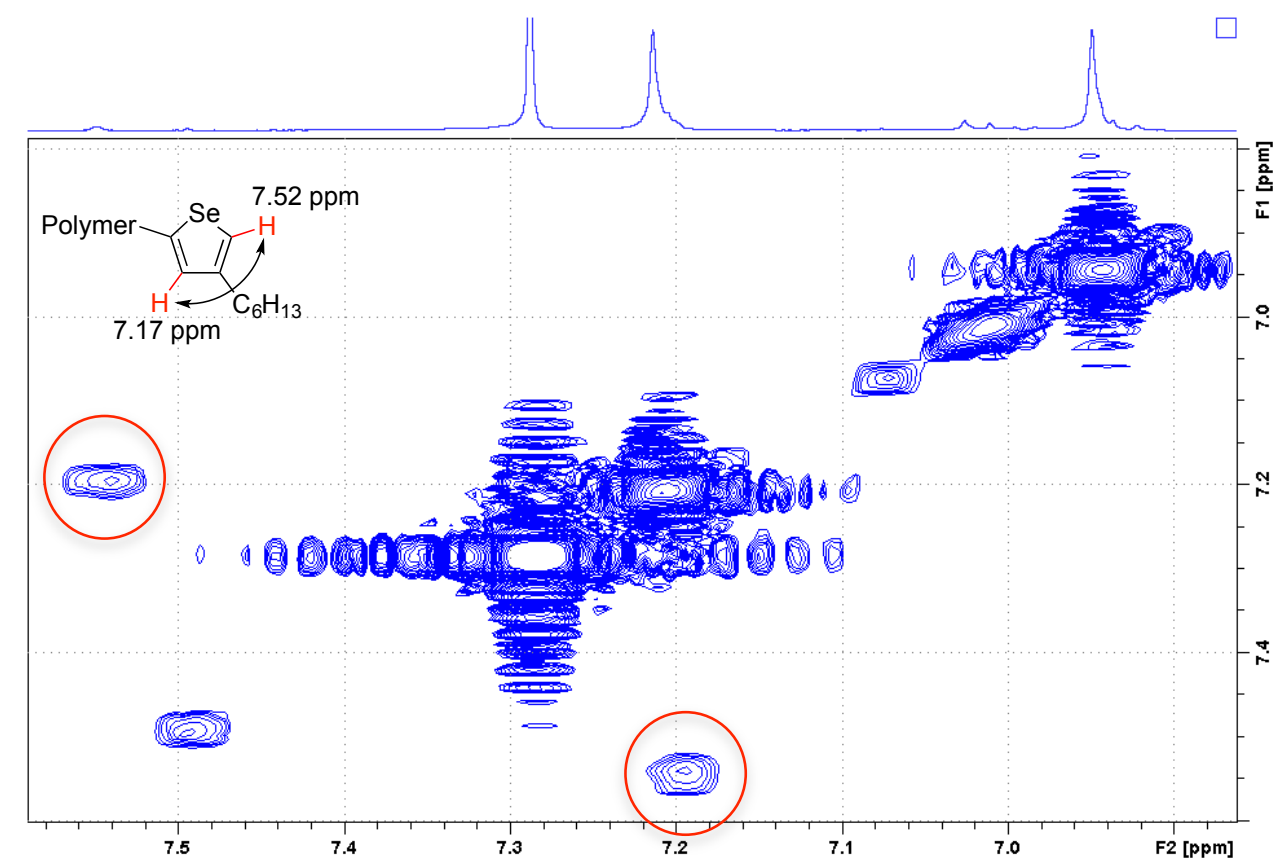

Figure S17. Long Range COSY Spectrum of T-Se $\left(M_{\mathrm{n}}=15,000, D=1.16\right)$ polymer illustrating the coupling of the $\mathrm{H}$ terminated end group.

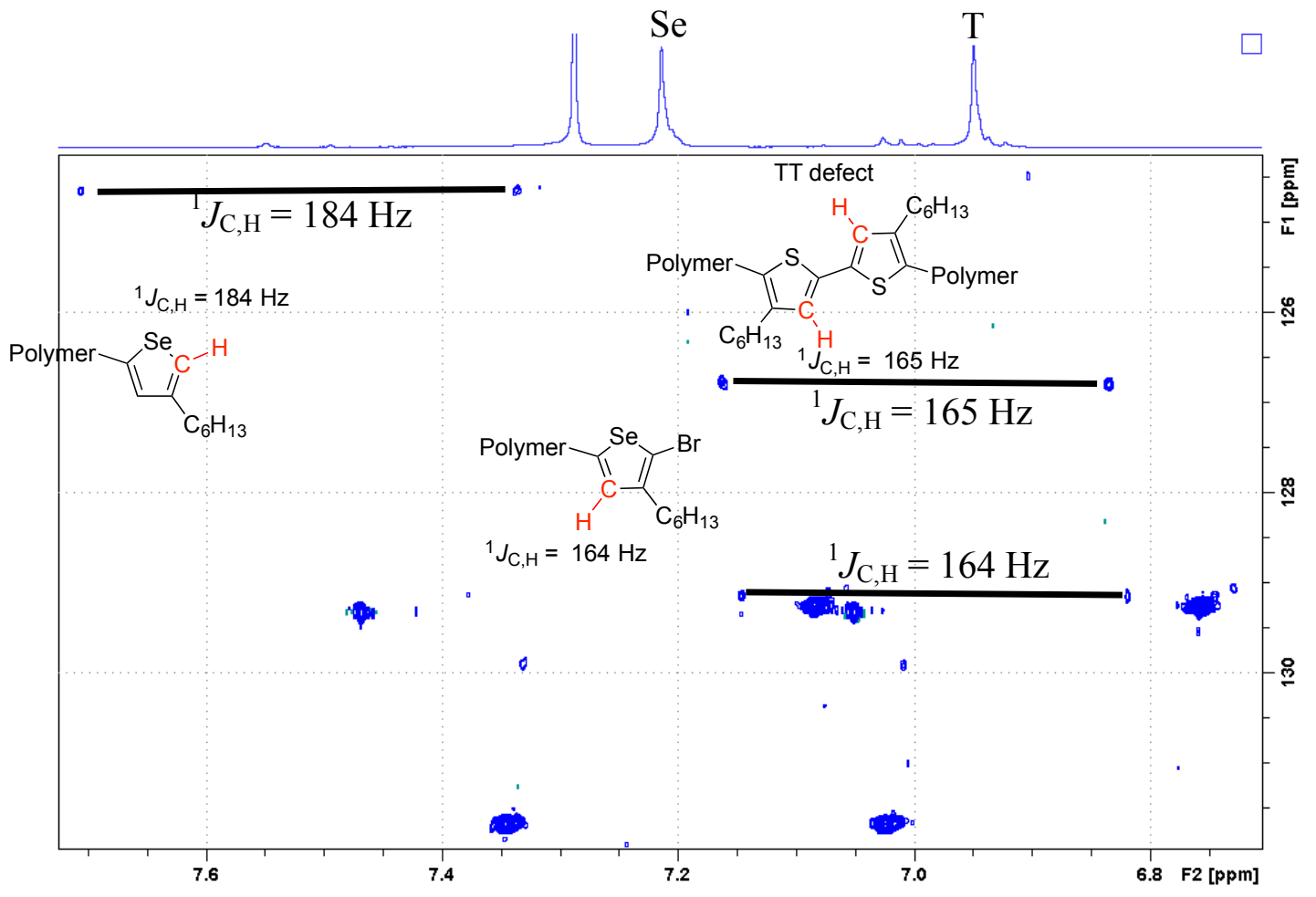

Figure S18. High resolution coupled HSQC of T-Se $\left(M_{\mathrm{n}}=15,000, Ð=1.16\right)$ illustrating ${ }^{1} J_{\mathrm{C}, \mathrm{H}}$ coupling constant between the aromatic protons and attached carbon atoms. Signals of TT defect and end groups are labeled; the main chain protons are labeled on the top of the 1D spectrum with simple T, Se designations. 

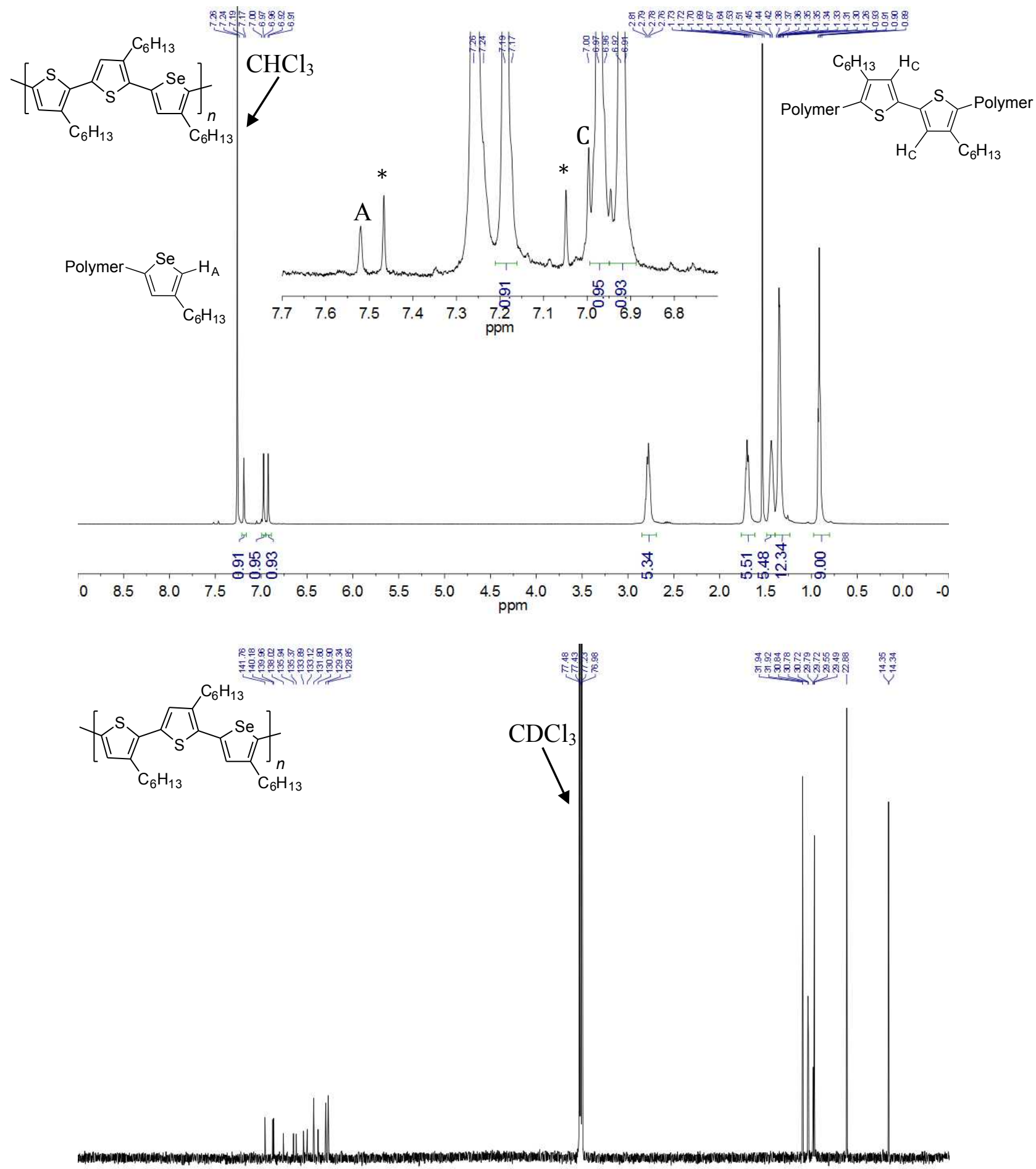

$\begin{array}{llllllllllllllllll}30 & 170 & 160 & 150 & 140 & 130 & 120 & 110 & 100 & \begin{array}{r}90 \\ \mathrm{ppm}\end{array} & 80 & 70 & 60 & 50 & 40 & 30 & 20 & 10\end{array}$

Figure S19. Polymer T-T-Se with $M_{\mathrm{n}}=32,100, D=1.23 .{ }^{1} \mathrm{H}$ NMR Spectrum -500 $\mathrm{MHz}, \mathrm{CDCl}_{3}$ (top), ${ }^{13} \mathrm{C}$ NMR Spectrum $-126 \mathrm{MHz}, \mathrm{CDCl}_{3}$ (bottom). The star $\left({ }^{*}\right)$ indicates $\mathrm{CHCl}_{3}$ satellites. 

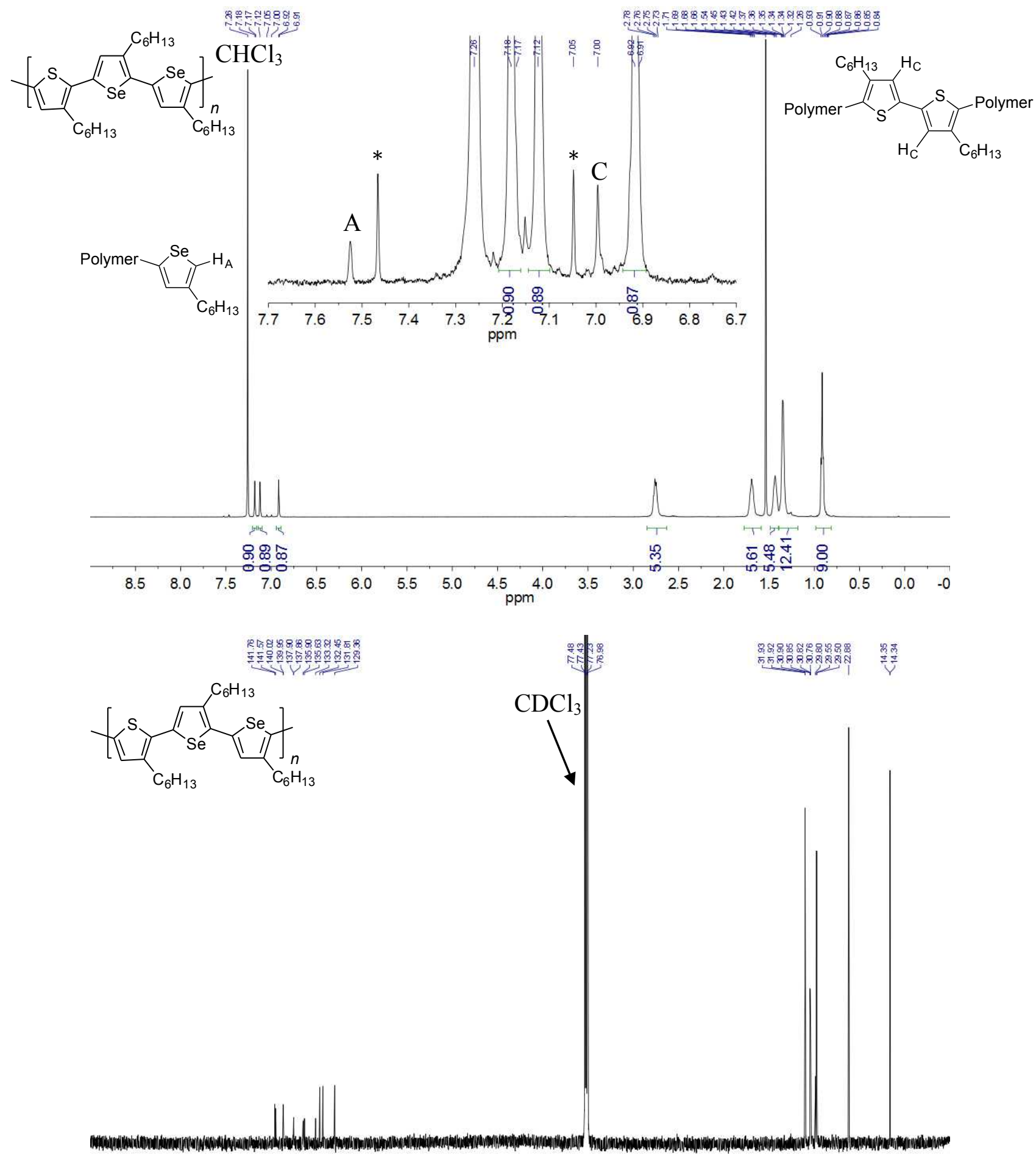

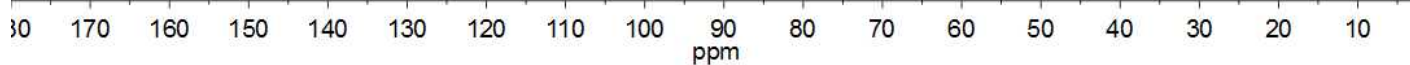

Figure S20. Polymer T-Se-Se with $M_{\mathrm{n}}=39,000, D=1.16 .{ }^{1} \mathrm{H}$ NMR Spectrum -500 $\mathrm{MHz}, \mathrm{CDCl}_{3}$ (top), ${ }^{13} \mathrm{C}$ NMR Spectrum - $126 \mathrm{MHz}, \mathrm{CDCl}_{3}$ (bottom). The star $\left({ }^{*}\right.$ ) indicates $\mathrm{CHCl}_{3}$ satellites. 

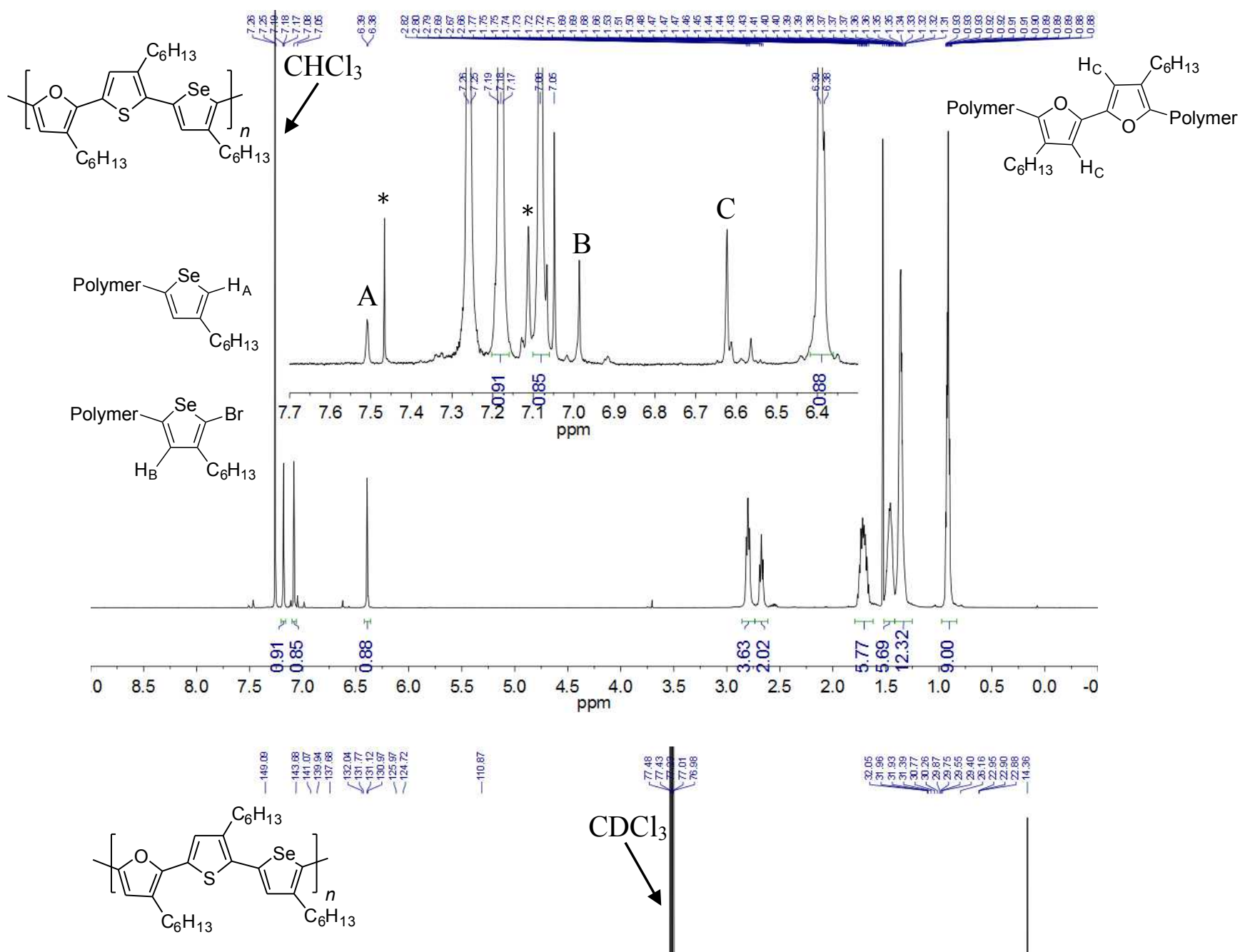

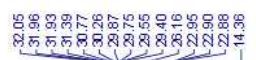

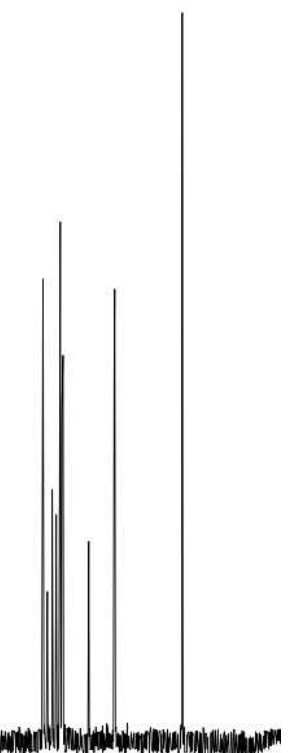

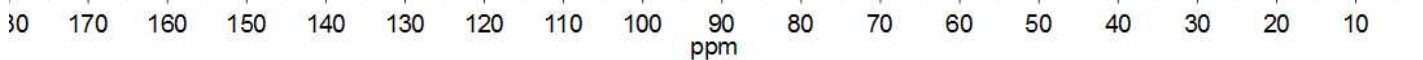

Figure S21. Polymer F-T-Se with $M_{\mathrm{n}}=23,100, \nexists=1.22 .{ }^{1} \mathrm{H}$ NMR Spectrum $-500 \mathrm{MHz}$, $\mathrm{CDCl}_{3}$ (top), ${ }^{13} \mathrm{C}$ NMR Spectrum $-126 \mathrm{MHz}, \mathrm{CDCl}_{3}$ (bottom). The star $(*)$ indicates $\mathrm{CHCl}_{3}$ satellites. 


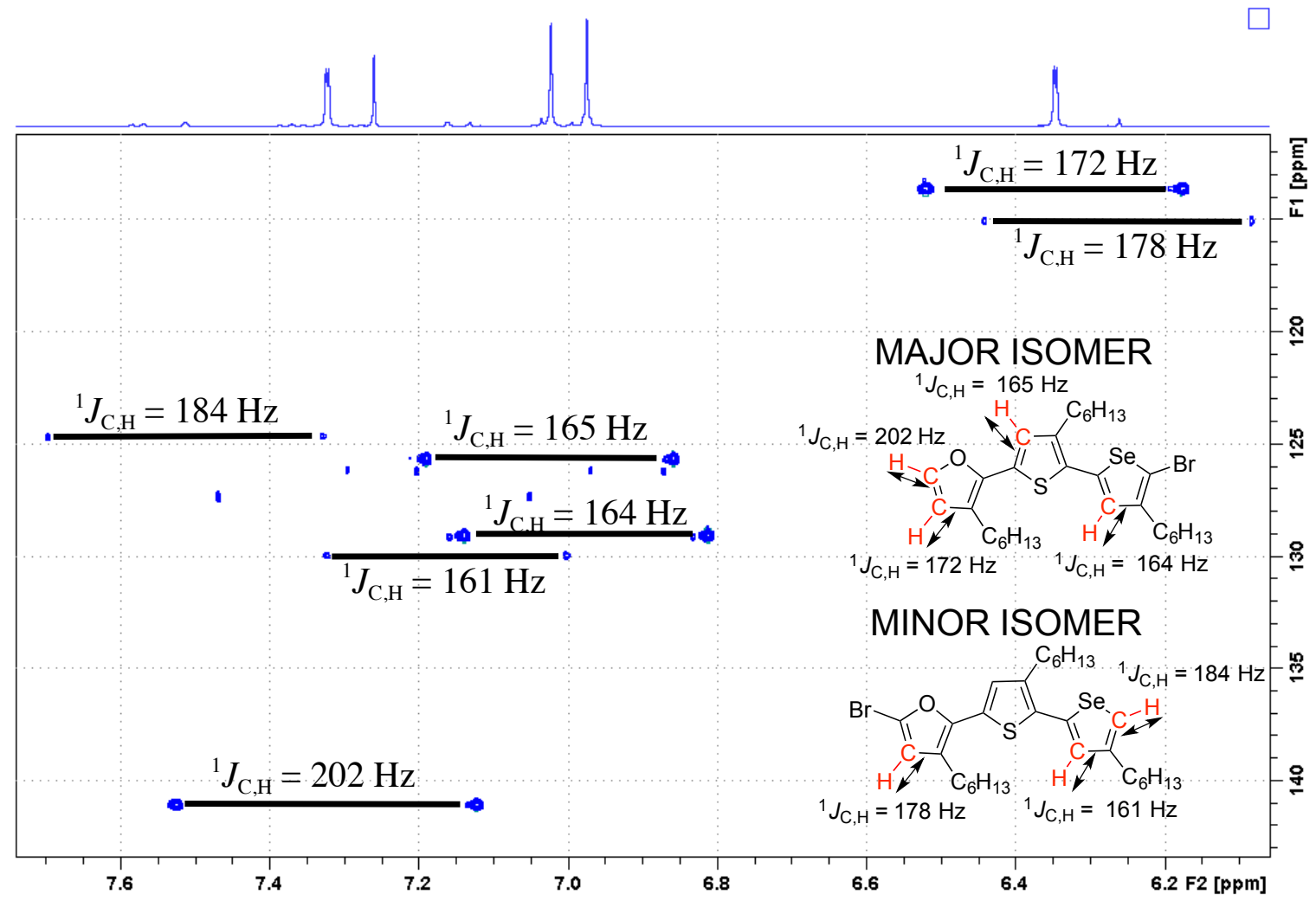

Figure S22. High resolution coupled HSQC of Compound 5 illustrating ${ }^{1} J_{\mathrm{C}, \mathrm{H}}$ coupling constant between the aromatic protons and attached carbon atoms. Signals are labeled and were used to help with the assignment of the F-T-Se polymer. 


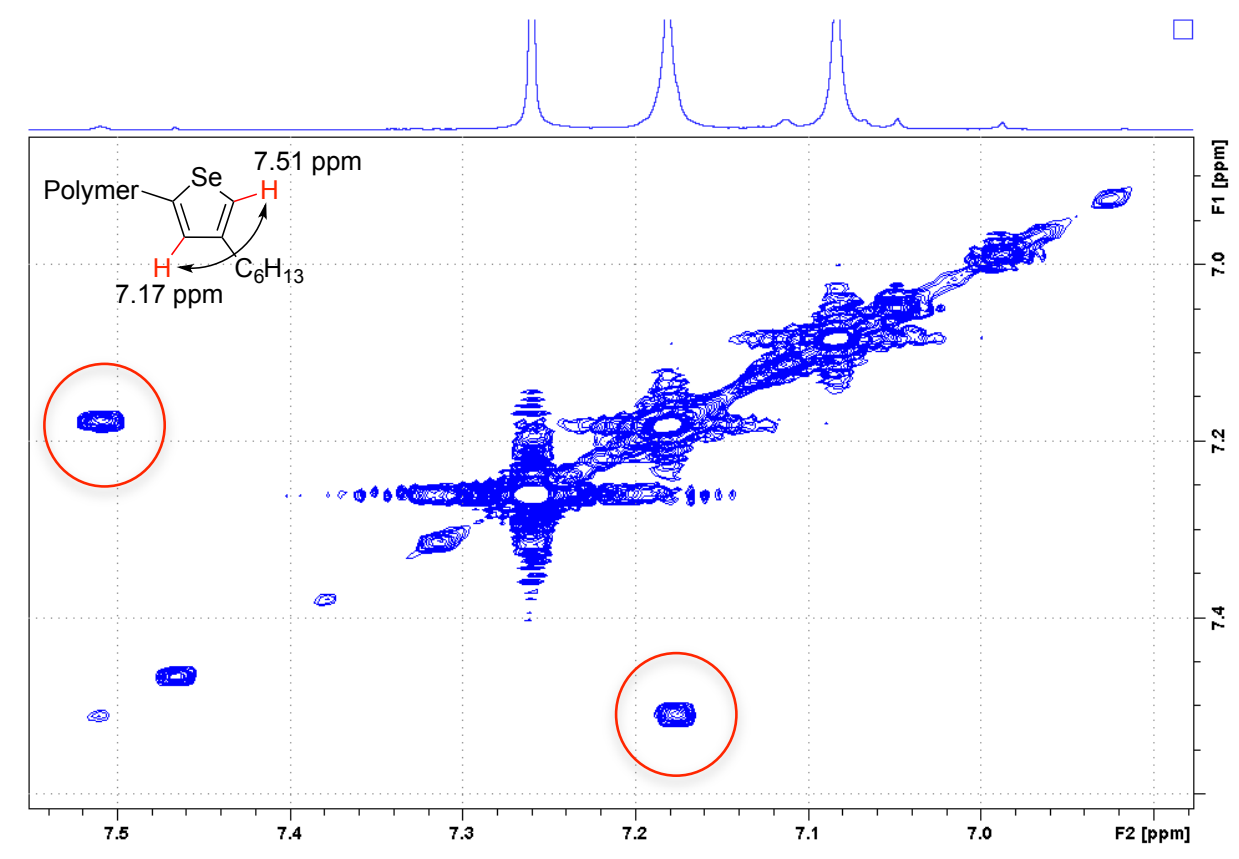

Figure S23. Long Range COSY Spectrum of the F-T-Se polymer $\left(M_{\mathrm{n}}=23,100, \emptyset=1.22\right)$ illustrating the coupling of the $\mathrm{H}$ terminated end group.

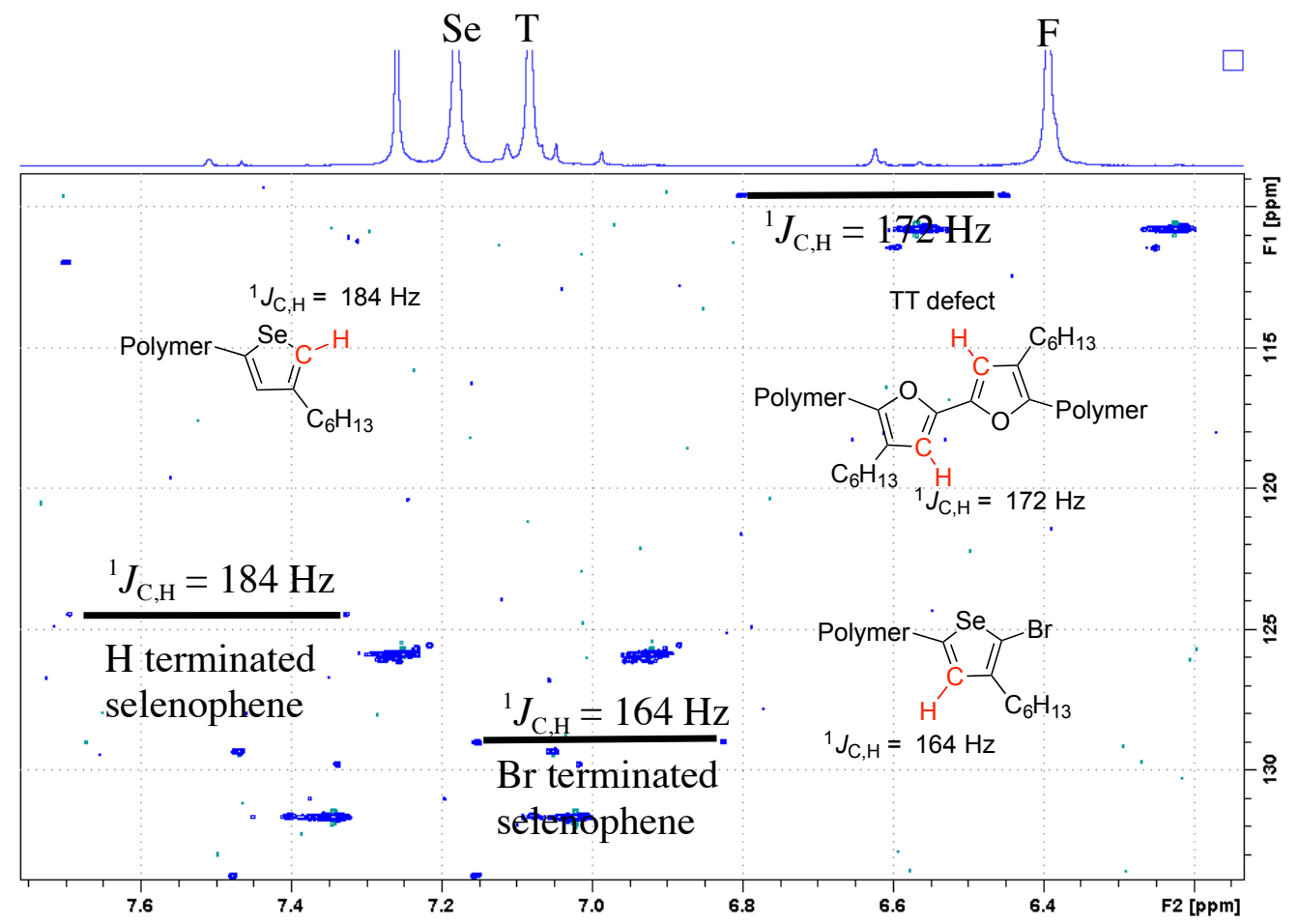

Figure S24. High resolution coupled HSQC of F-T-Se $\left(M_{\mathrm{n}}=23,100, Ð=1.22\right)$

illustrating ${ }^{1} J_{\mathrm{C}, \mathrm{H}}$ coupling constant between the aromatic protons and attached carbon atoms. Signals of TT defect and end groups are labeled, the main chain protons are labeled on the top of the 1D spectrum with simple F, T, Se designations. 

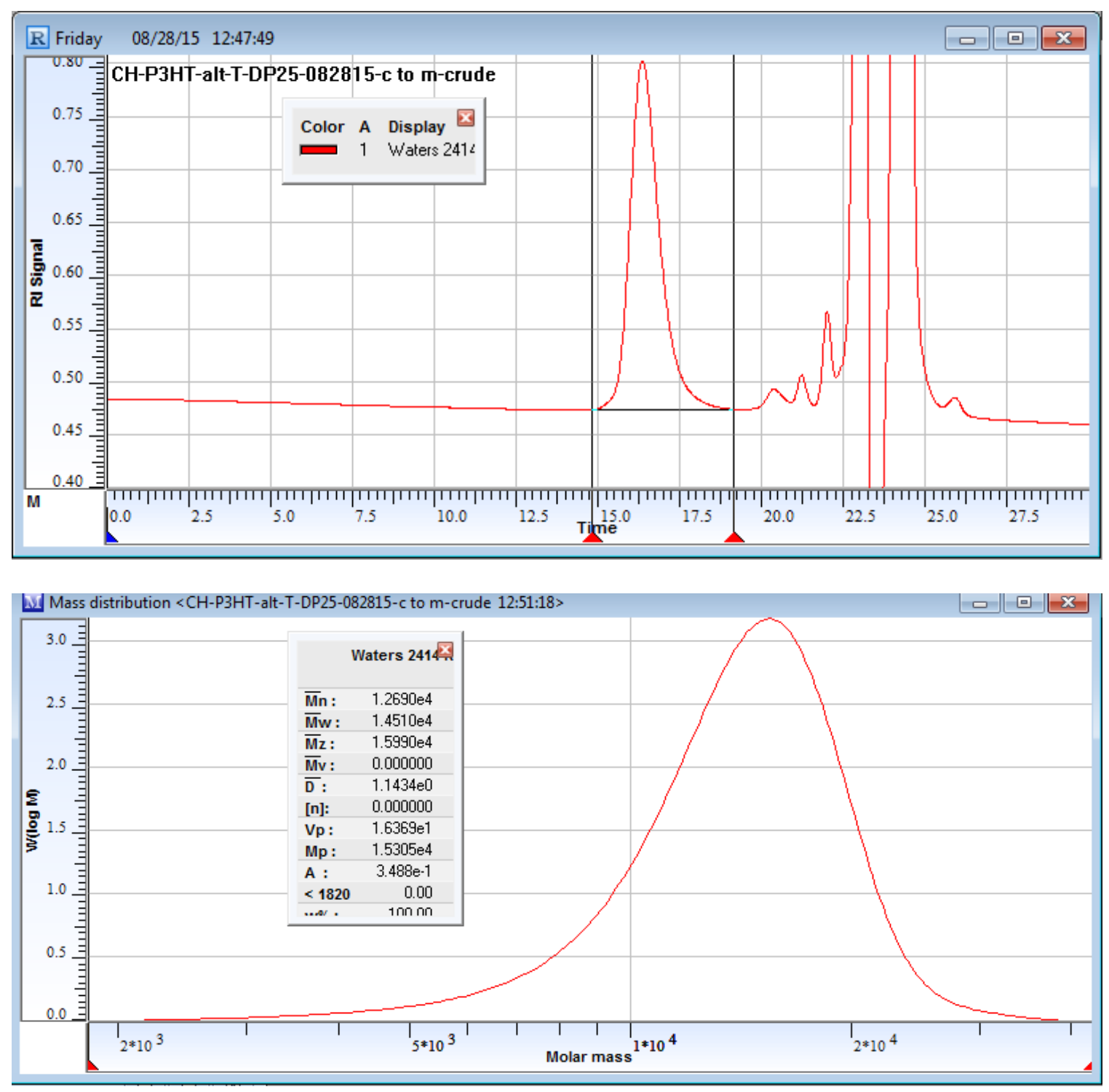

Figure S25. GPC Chromatogram and analysis of T-T (M/Cat. = 25) in Table 1. 

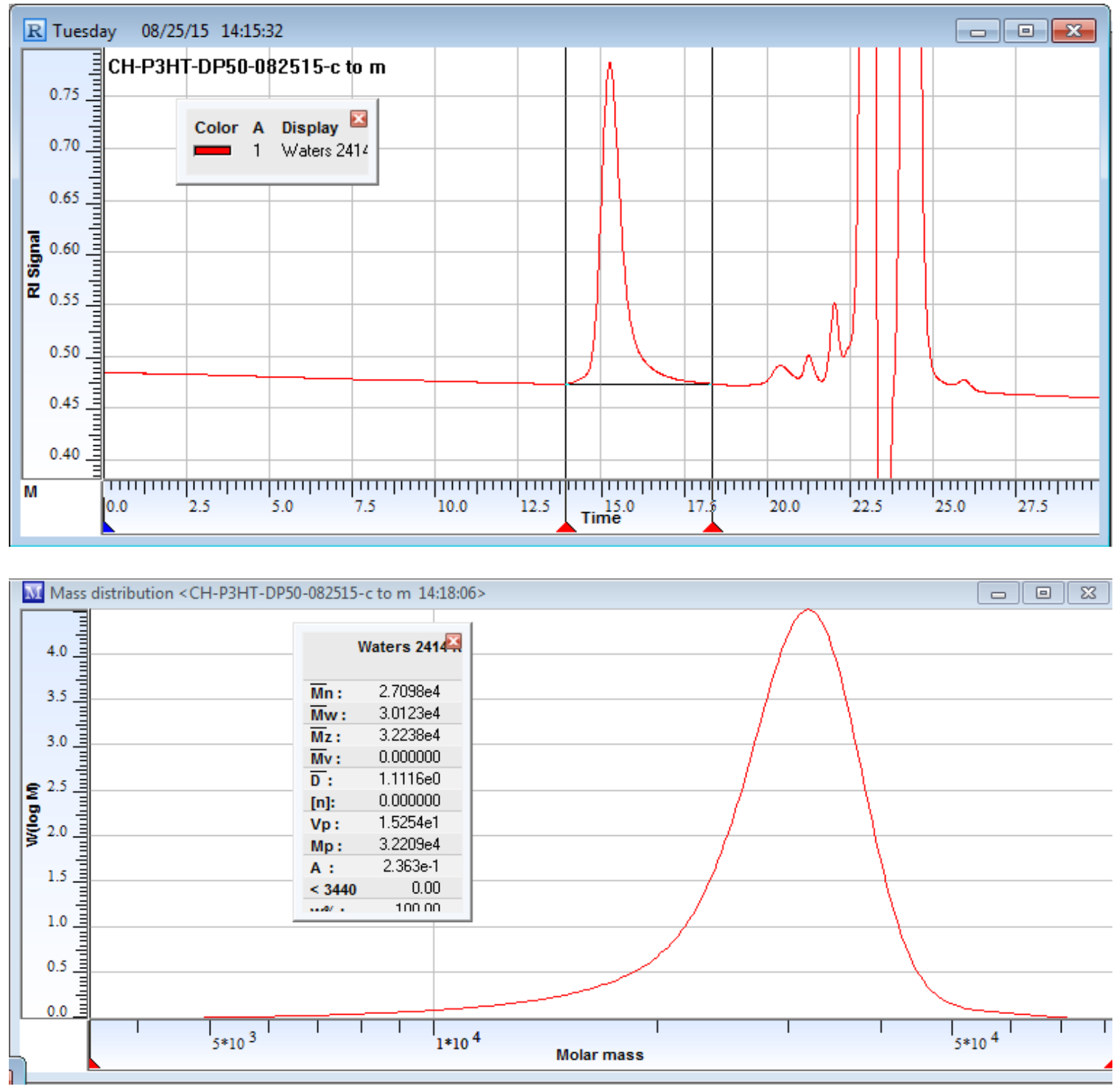

Figure S26. GPC Chromatogram and analysis of T-T $(\mathrm{M} /$ Cat. $=50)$ in Table 1. 

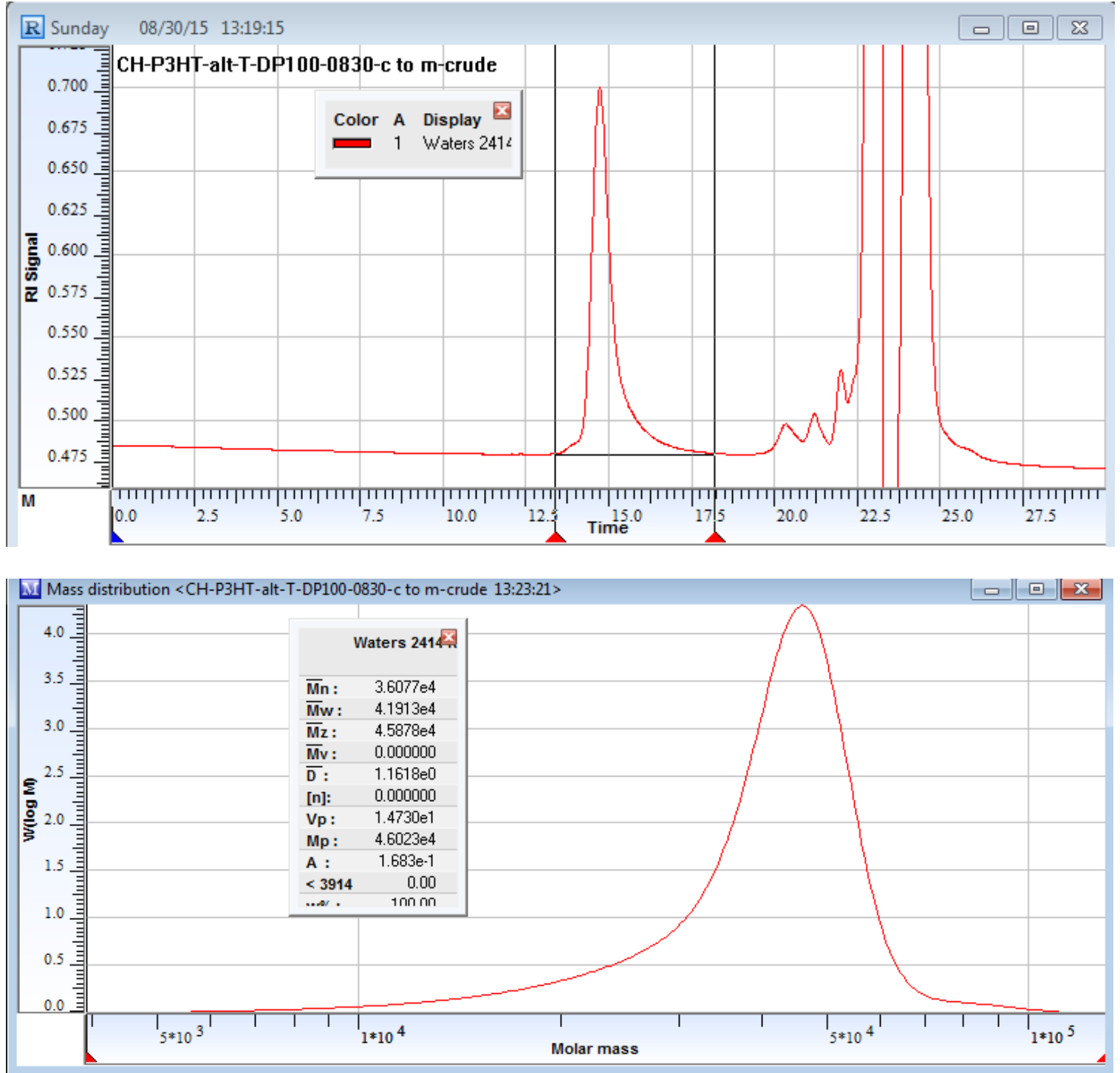

Figure S27. GPC Chromatogram and analysis of T-T $(\mathrm{M} / \mathrm{Cat} .=100)$ in Table 1. 

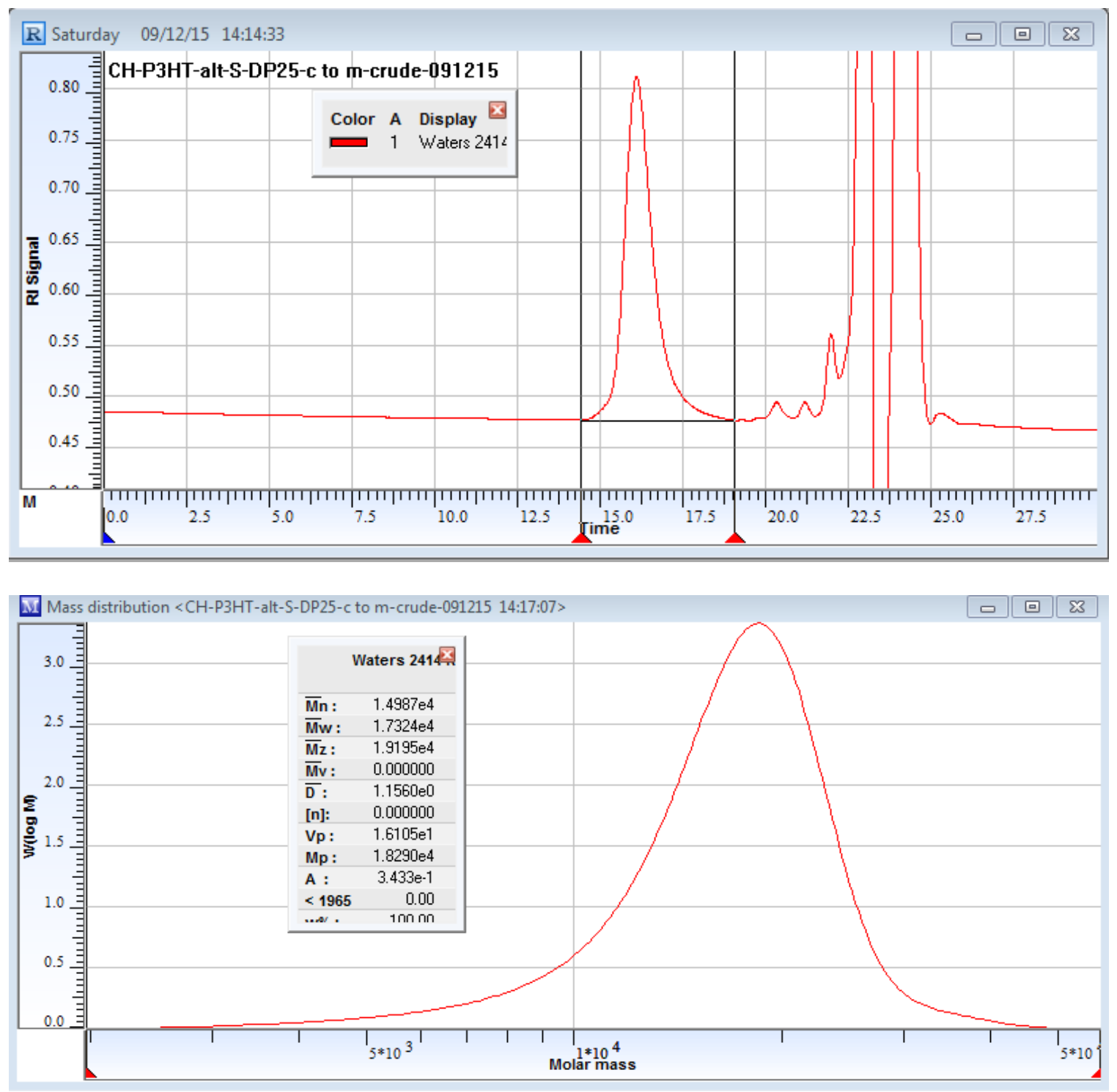

Figure S28. GPC Chromatogram and analysis of T-Se $(\mathrm{M} / \mathrm{Cat}=25)$ in Table 1. 

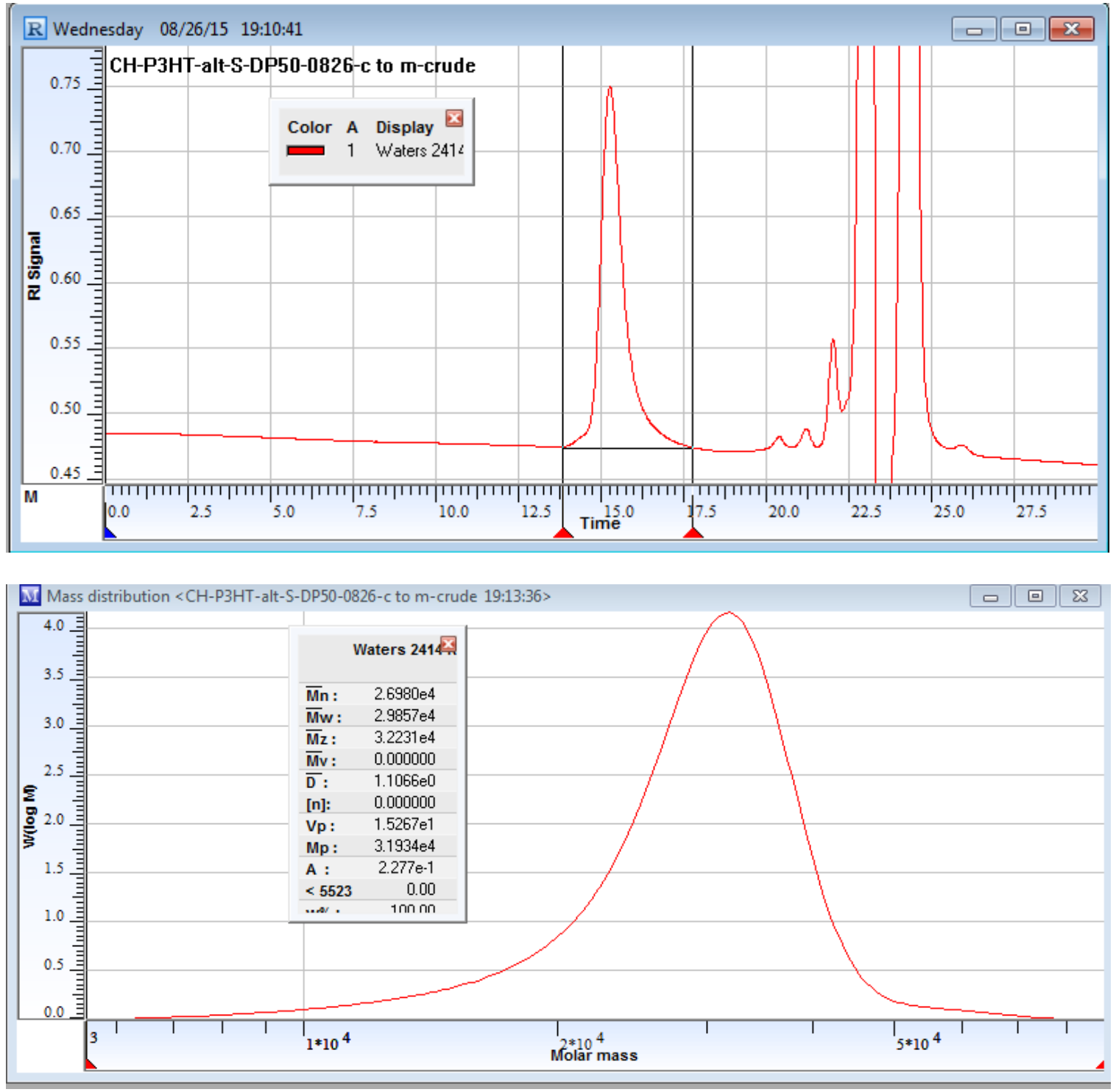

Figure S29. GPC Chromatogram and analysis of T-Se $(\mathrm{M} / \mathrm{Cat} .=50)$ in Table 1. 

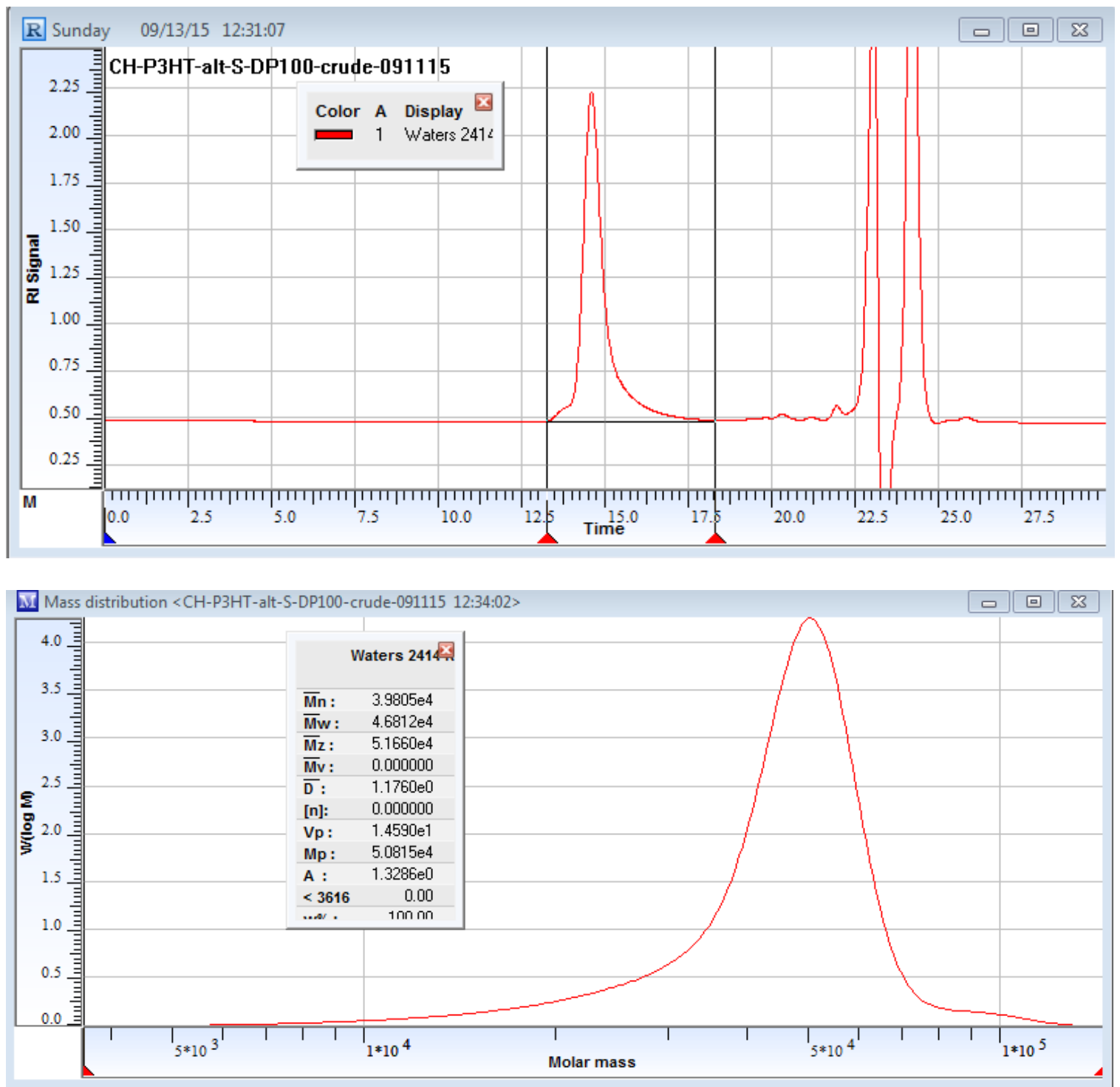

Figure S30. GPC Chromatogram and analysis of T-Se $(\mathrm{M} /$ Cat. $=100)$ in Table 1. 

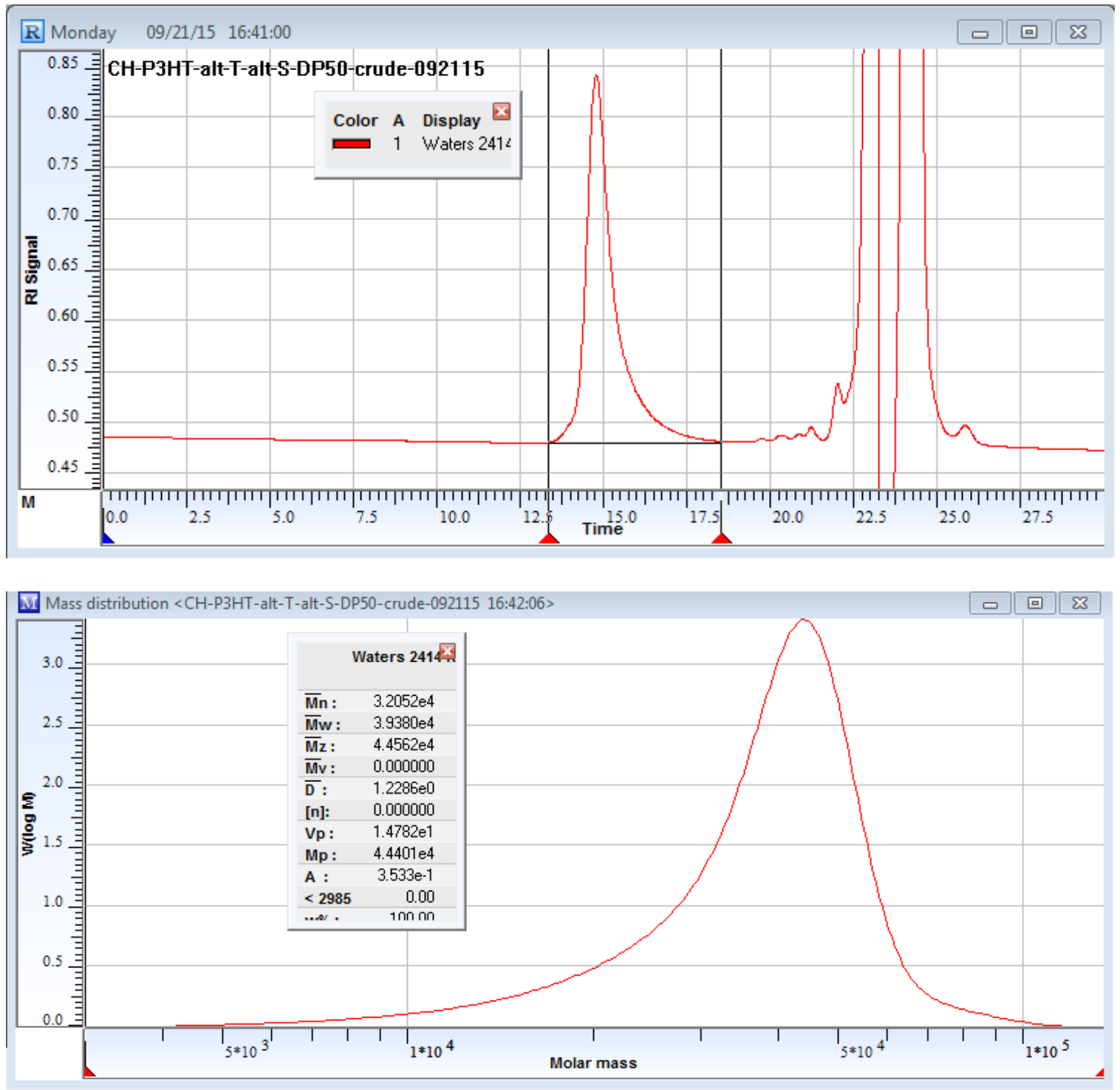

Figure S31. GPC Chromatogram and analysis of T-T-Se $(\mathrm{M} / \mathrm{Cat} .=50)$ in Table 1. 

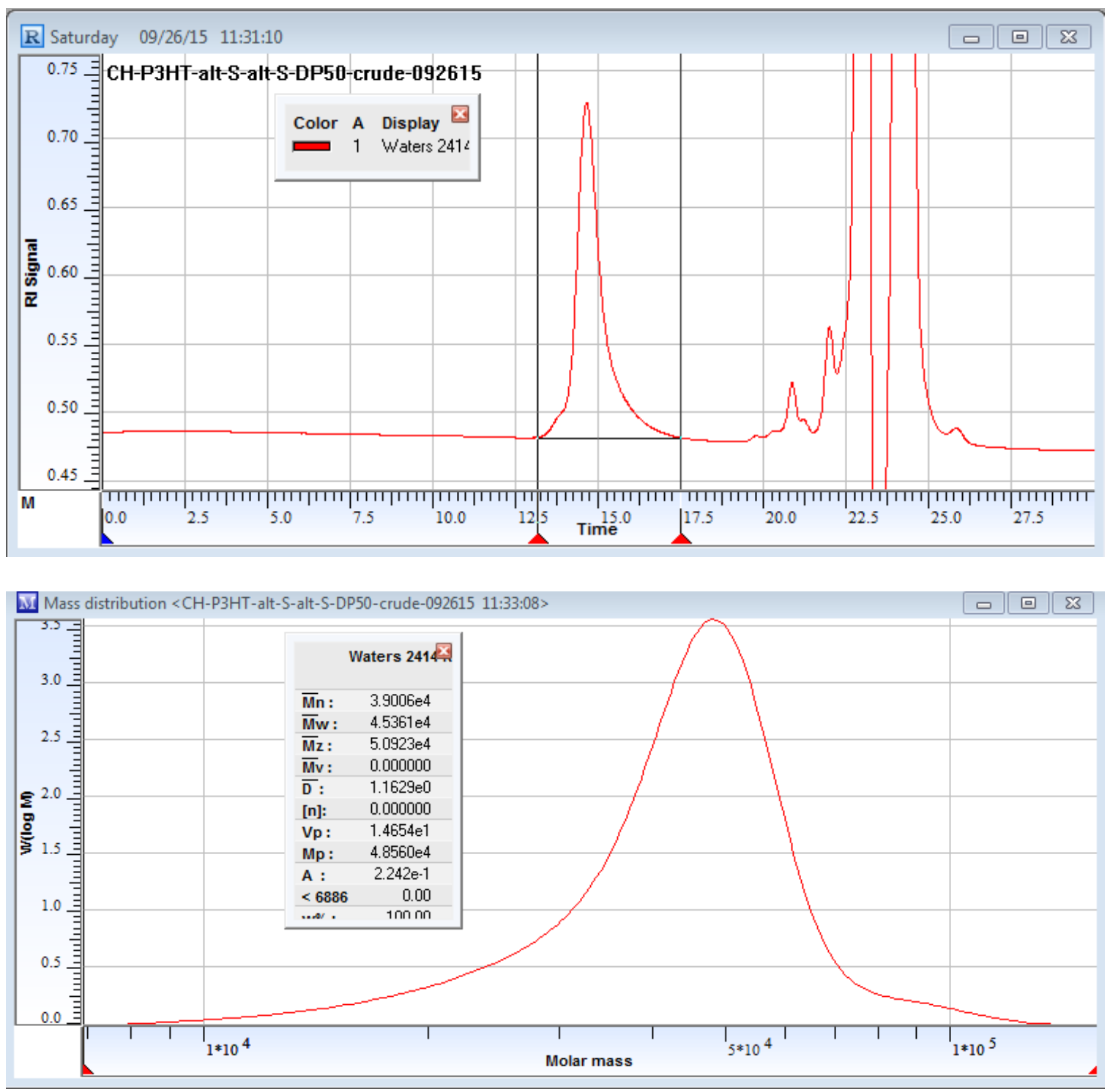

Figure S32. GPC Chromatogram and analysis of T-Se-Se $(\mathrm{M} / \mathrm{Cat} .=50)$ in Table 1. 

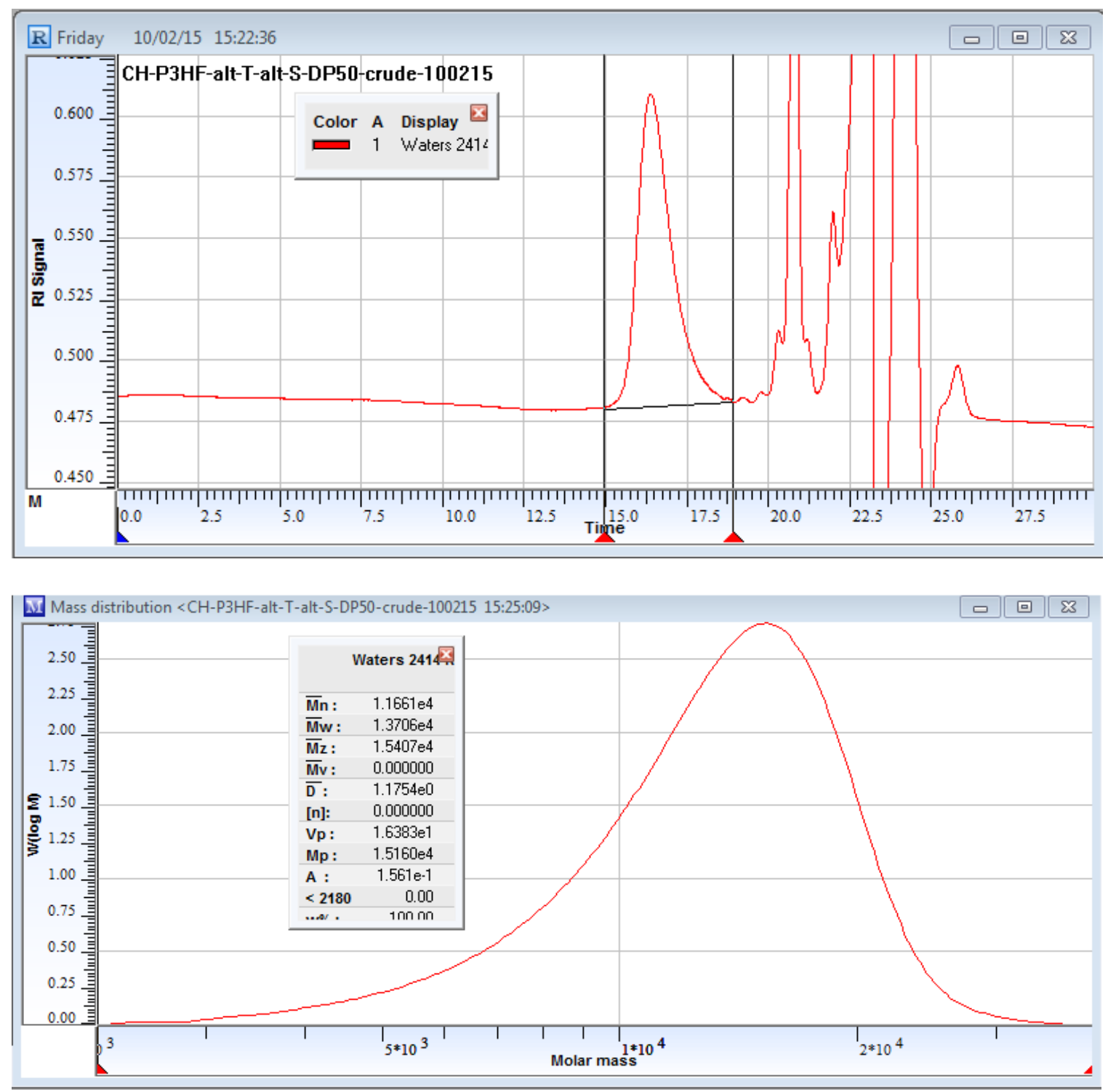

Figure S33. GPC Chromatogram and analysis of F-T-Se $(\mathrm{M} /$ Cat. $=50)$ in Table 1. 

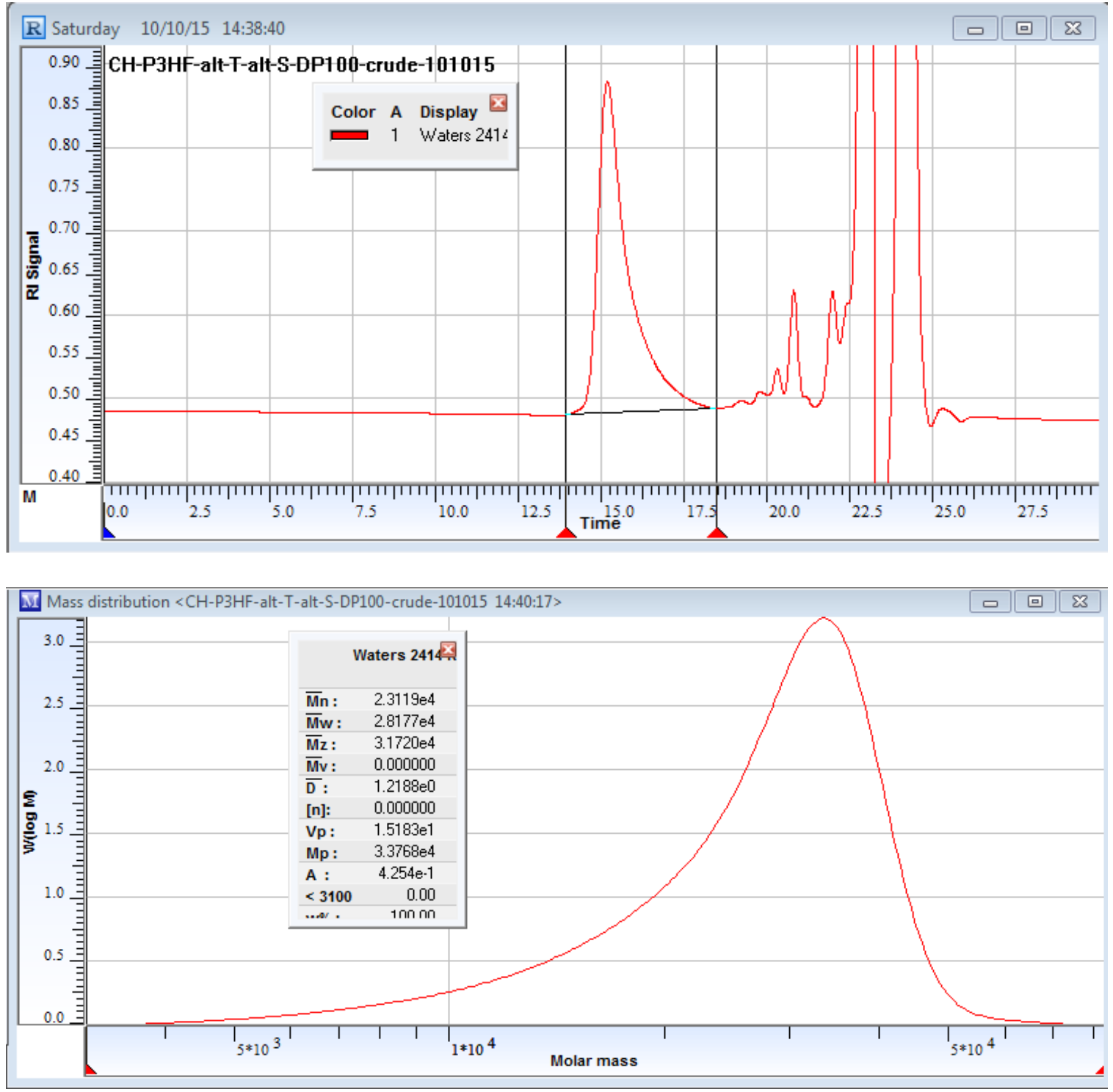

Figure S34. GPC Chromatogram and analysis of F-T-Se $(\mathrm{M} /$ Cat. $=100)$ in Table 1. 

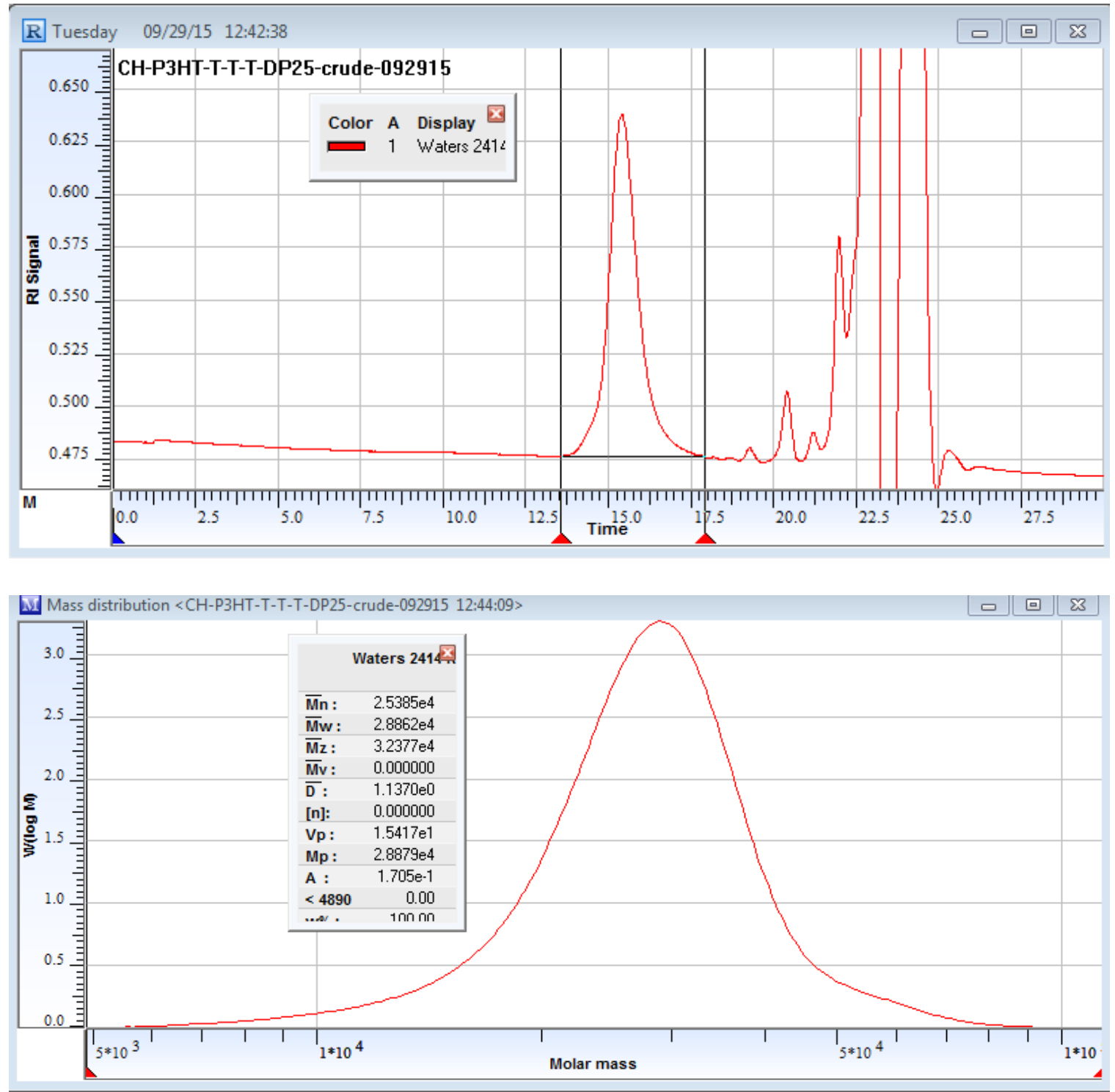

Figure S35. GPC Chromatogram and analysis of P3HT using quaterthiophene $(\mathrm{M} / \mathrm{Cat}$. $=$ 25). 

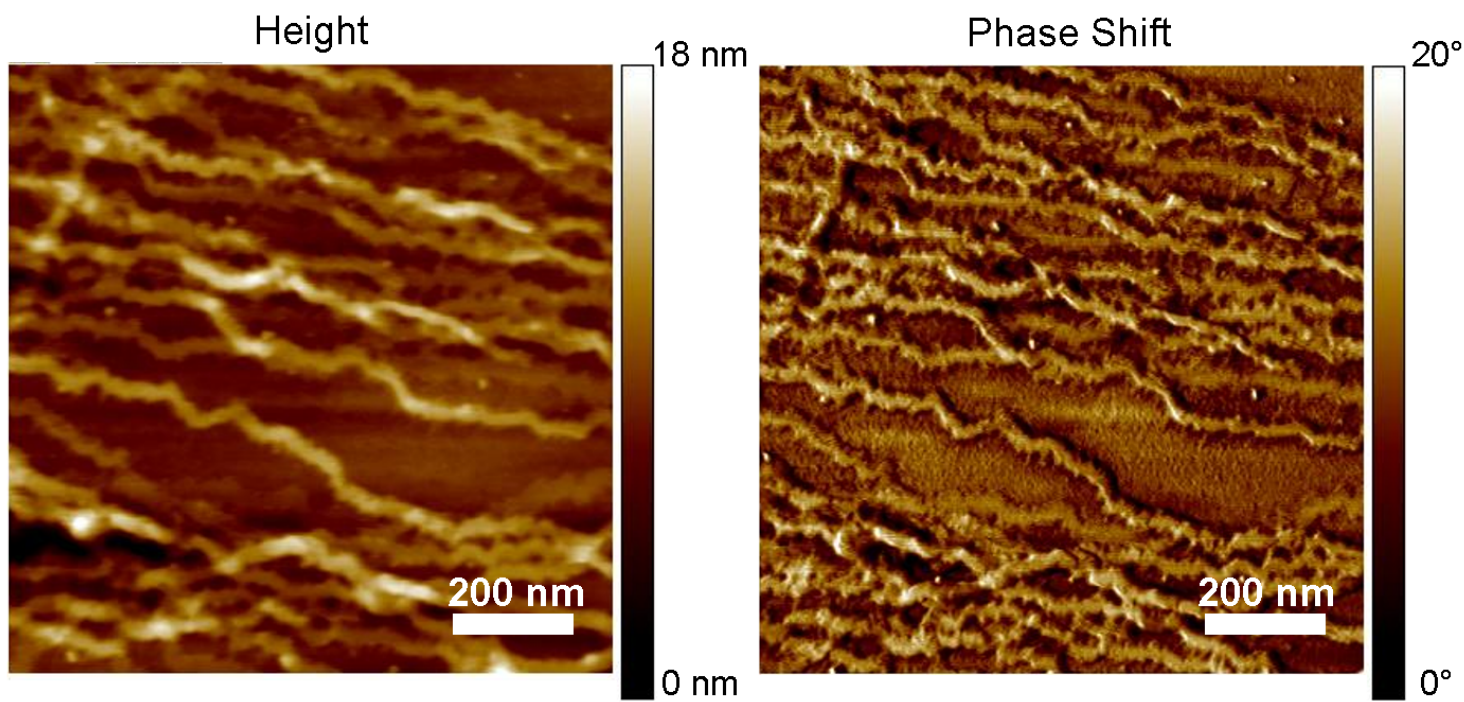

Figure S36. $1 \mu \mathrm{m} * 1 \mu \mathrm{m}$ AFM height and phase images of compound T-T $\left(M_{\mathrm{n}}=36,100\right.$, $Ð=1.16)$.
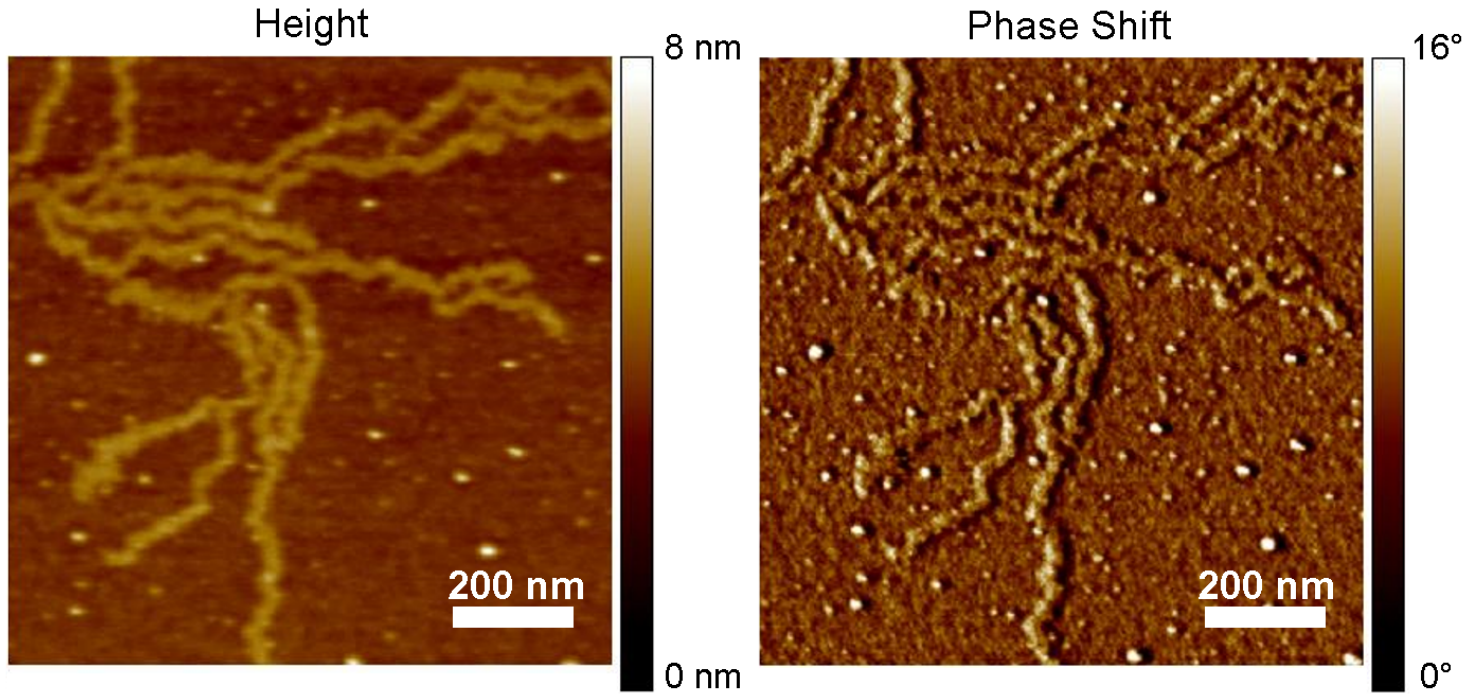

Figure S37. $1 \mu \mathrm{m} * 1 \mu \mathrm{m}$ AFM height and phase images of compound T-T-Se $\left(M_{\mathrm{n}}=\right.$ $32,100, Ð=1.23)$. 


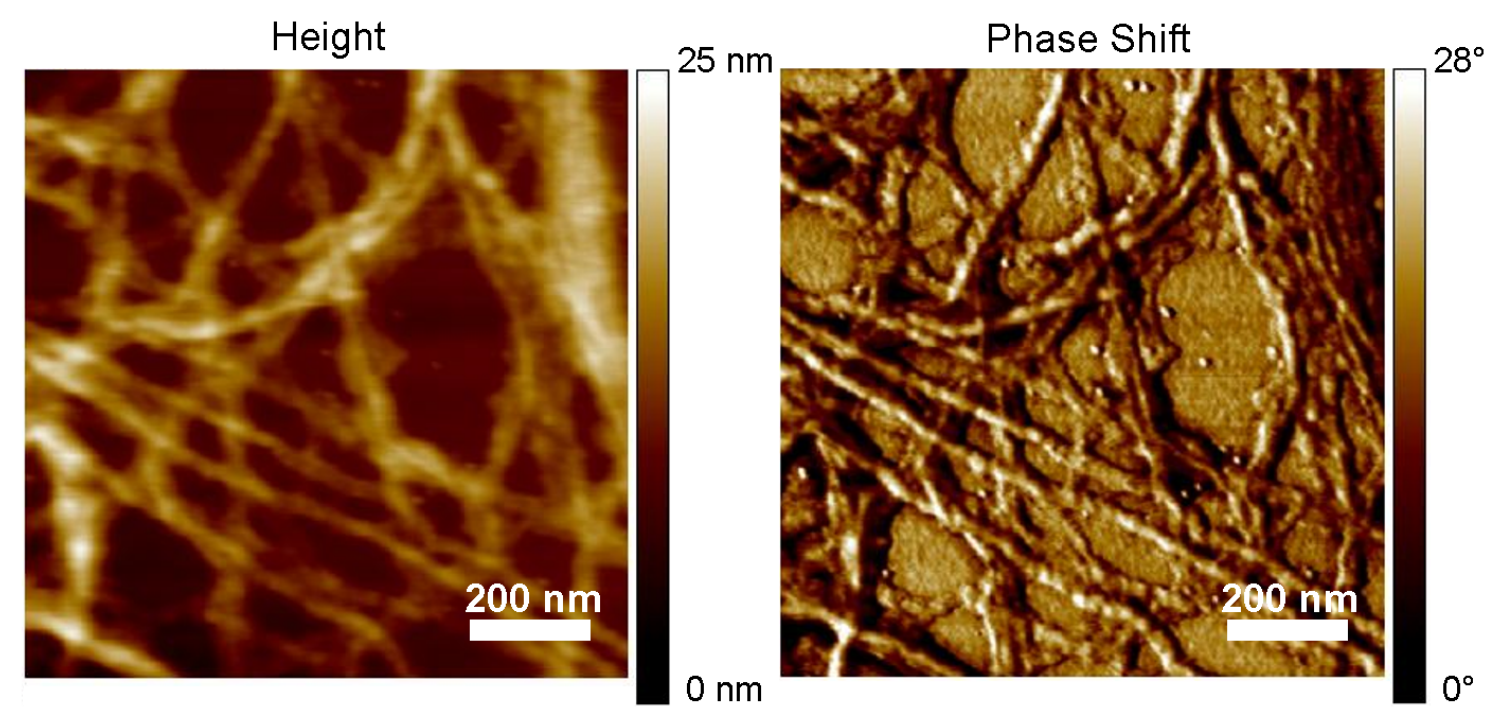

Figure S38. $1 \mu \mathrm{m}^{*} 1 \mu \mathrm{m}$ AFM height and phase images of compound T-Se $\left(M_{\mathrm{n}}=39,800\right.$, $Ð=1.18)$.

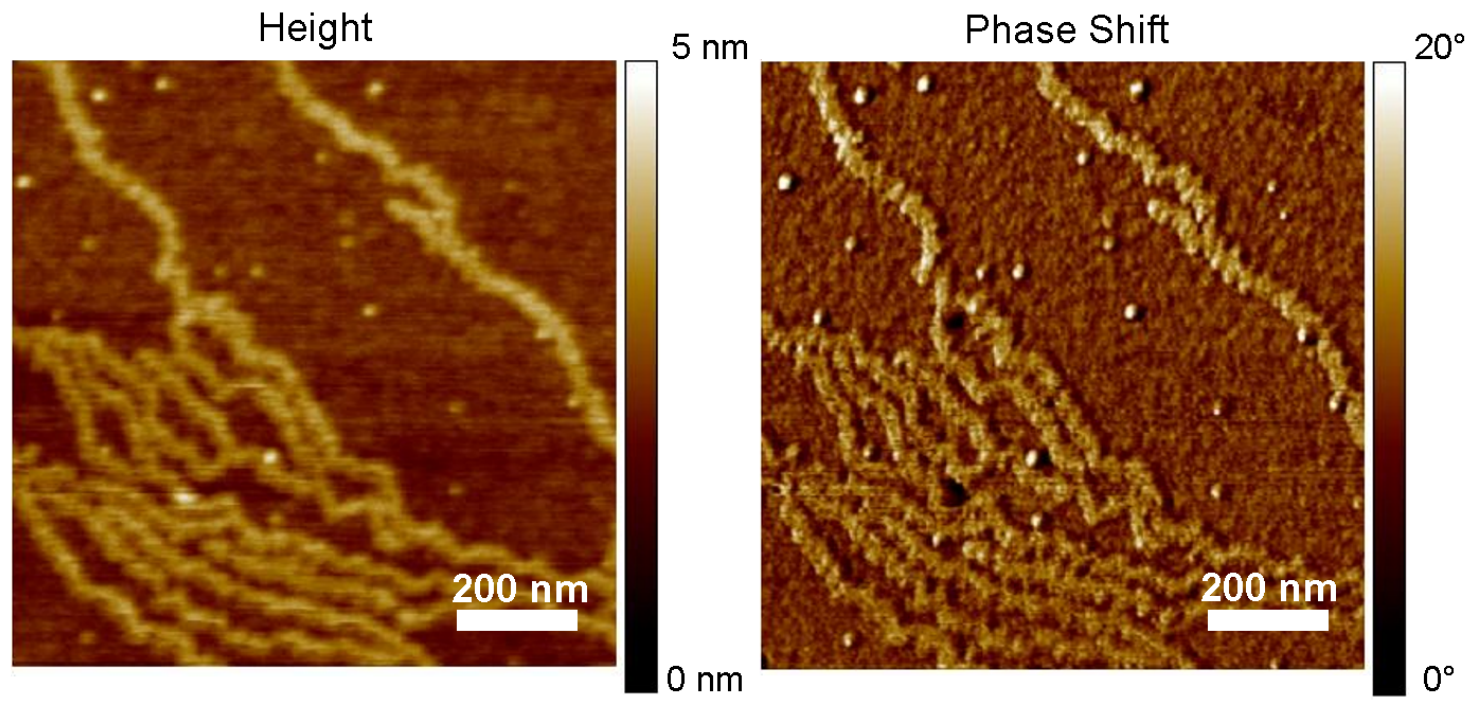

Figure S39. $1 \mu \mathrm{m} * 1 \mu \mathrm{m}$ AFM height and phase images of compound T-Se-Se $\left(M_{\mathrm{n}}=\right.$ $39,000, Ð=1.16)$. 


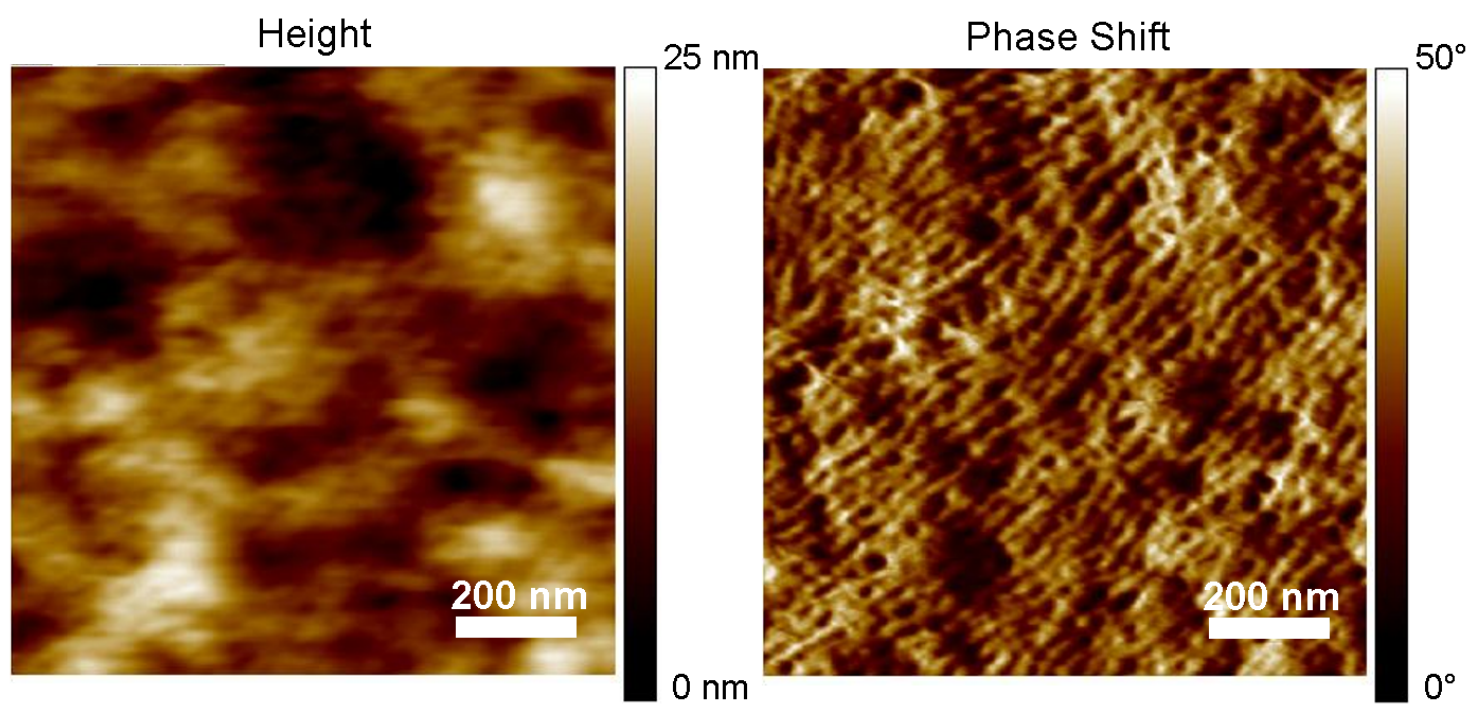

Figure S40. $1 \mu \mathrm{m} * 1 \mu \mathrm{m}$ AFM height and phase images of compound F-T-Se $\left(M_{\mathrm{n}}=\right.$ $23,100, Ð=1.22)$.

Table S3. Physical characterization data for all polymer samples.

\begin{tabular}{|c|c|c|c|c|c|c|c|}
\hline Sample & $\begin{array}{c}\lambda_{\operatorname{max~sol}} \\
\mathrm{nm}\end{array}$ & $\underset{\mathrm{nm}}{\lambda_{\max \text { film }}}$ & $\begin{array}{c}E_{\mathrm{g}} \text { edge } \\
\mathrm{eV}\end{array}$ & $\begin{array}{l}T_{\mathrm{c}} \\
{ }^{\circ} \mathrm{C}\end{array}$ & $\begin{array}{l}T_{\mathrm{m}} \\
{ }^{\circ} \mathrm{C}\end{array}$ & $\begin{array}{l}\Delta H_{\mathrm{m}} \\
(\mathrm{J} / \mathrm{g})\end{array}$ & $\begin{array}{l}T_{\mathrm{d}}{ }^{\circ} \mathrm{C} \\
\text { initial }\end{array}$ \\
\hline T-T & 455 & 561 & 1.89 & 210 & 242 & 20.45 & 380 \\
\hline T-T-Se & 466 & 583 & 1.81 & 201 & 233 & 20.44 & 367 \\
\hline T-Se & 473 & 593 & 1.77 & 188 & 227 & 12.24 & 357 \\
\hline T-Se-Se & 480 & 607 & 1.72 & 207 & 240 & 13.98 & 350 \\
\hline F-T-Se & 494 & 564 & 1.88 & 179 & 214 & 15.66 & 339 \\
\hline P3HSe $^{a}$ & 499 & 630 & 1.60 & 225 & 255 & 16 & 350 \\
\hline
\end{tabular}




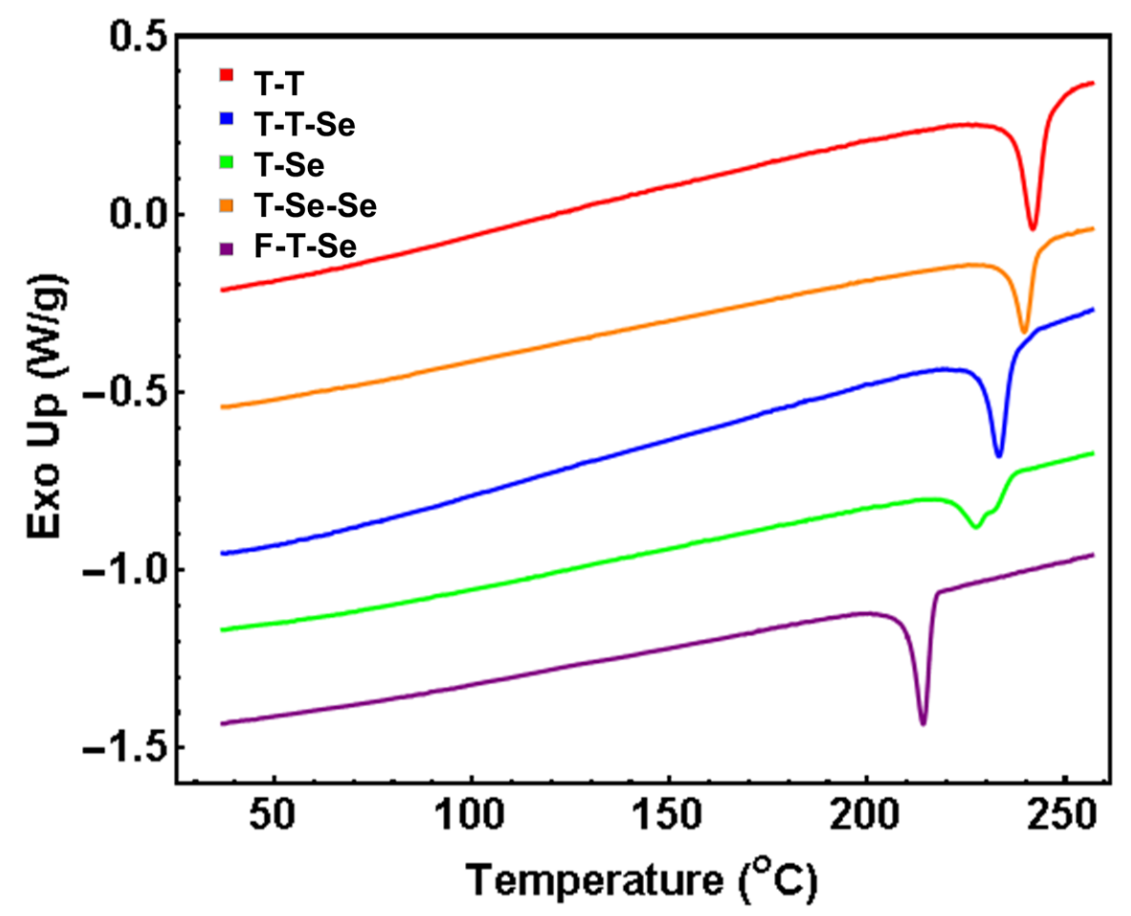

Figure S41. DSC $2^{\text {nd }}$ heating cycles for all polymers.

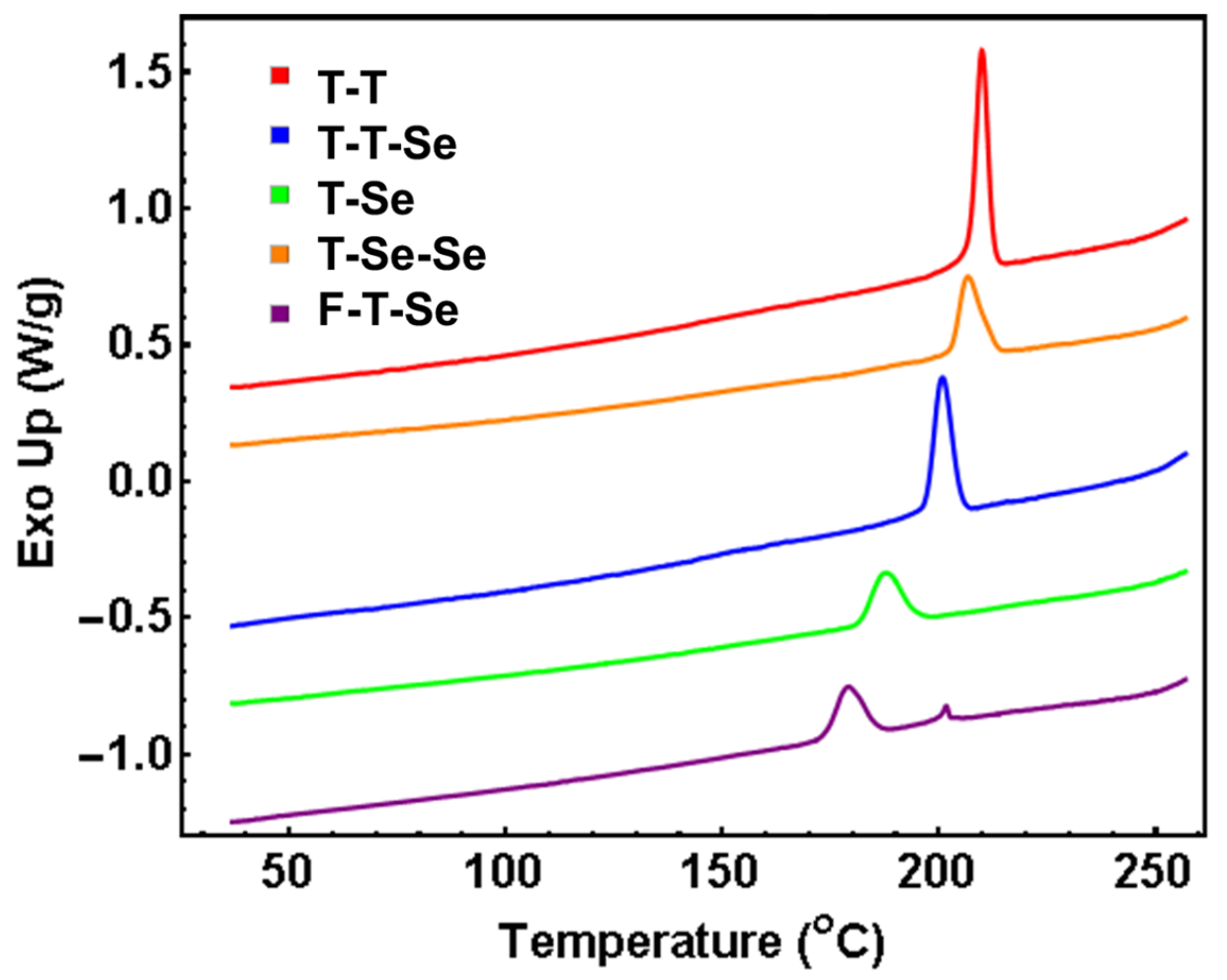

Figure S42. DSC $2^{\text {nd }}$ cooling cycles for all polymers. 


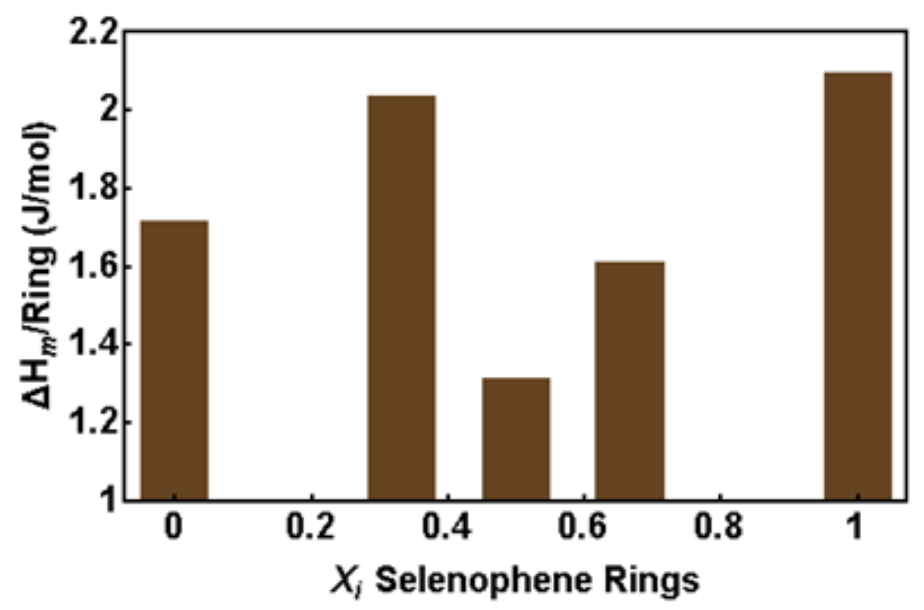

Figure S43. Heat of Fusion/Ring ( $/ \mathrm{mol})$ vs. Se Content $\left(X_{\mathrm{i}}=\right.$ Selenophene Rings). Data point for $X_{\mathrm{i}}=1$ obtained from report by Heeney and co-workers. ${ }^{11}$

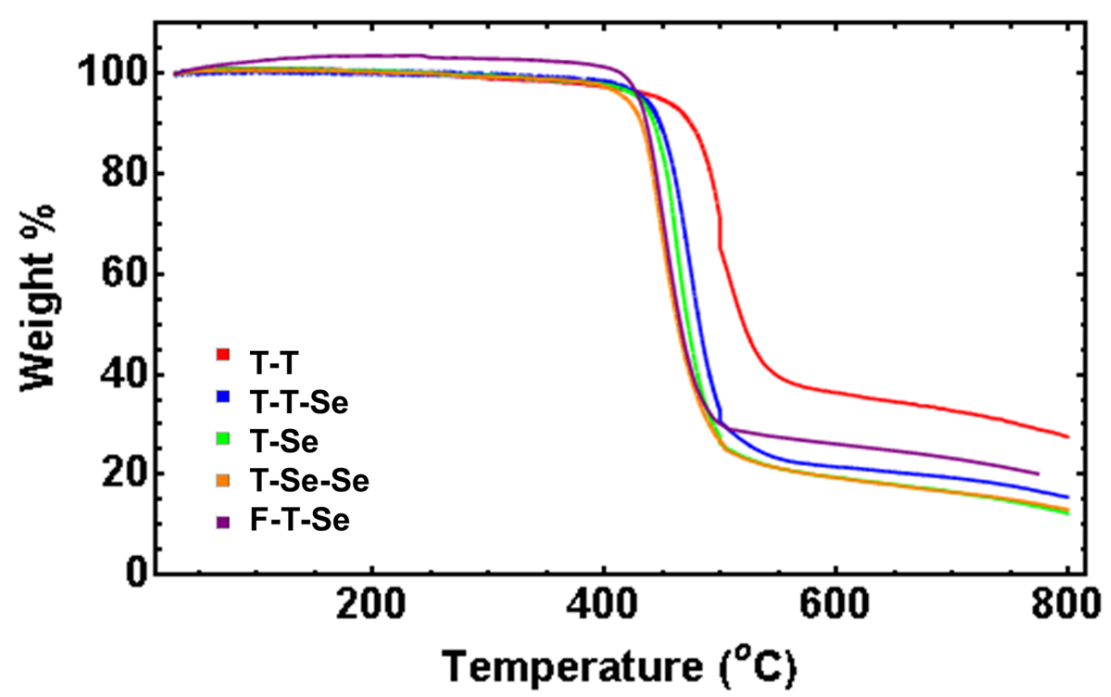

Figure S44. Thermal degradation analysis of all polymers.

Table S4. Average oxidation and reduction values calculated from CV onset and $1^{\text {st }}$ derivative plots.

\begin{tabular}{r|lll} 
Sample & Eox Avg. (V) & Ered Avg. (V) & Eg Avg. (V) \\
$T-T$ & $0.0960 \pm 0.121$ & $-2.297 \pm 0.198$ & $2.364 \pm 0.0661$ \\
$T-T-S e$ & $0.0267 \pm 0.124$ & $-2.190 \pm 0.0958$ & $2.201 \pm 0.0865$ \\
$T$-Se & $0.0376 \pm 0.0916$ & $-2.199 \pm 0.0897$ & $2.195 \pm 0.104$ \\
T-Se-Se & $0.00423 \pm 0.0967$ & $-2.151 \pm 0.133$ & $2.131 \pm 0.113$ \\
F-T-Se & $-0.169 \pm 0.232$ & $-1.997 \pm 0.139$ & $1.898 \pm 0.195$
\end{tabular}




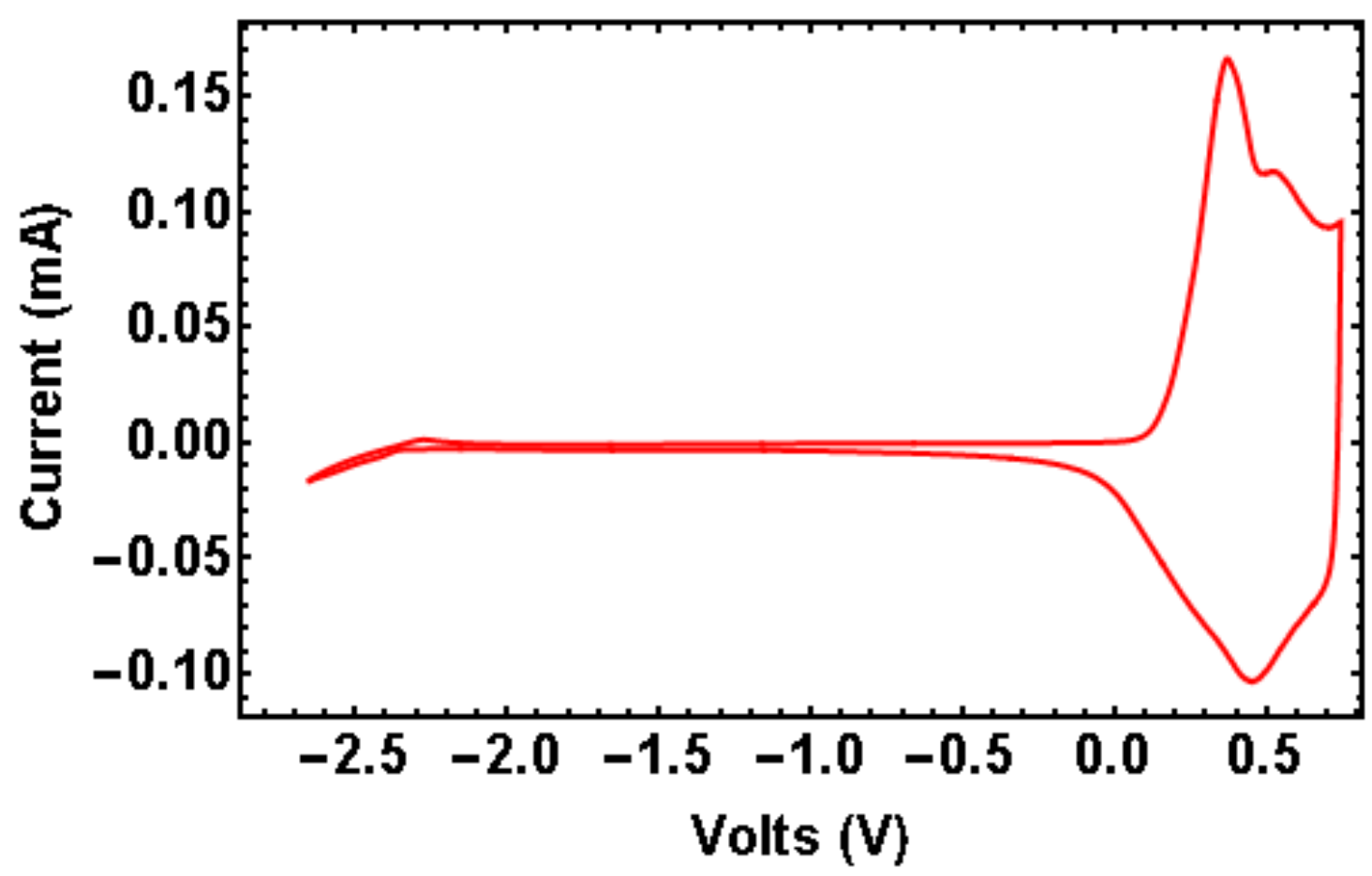

Figure S45. Cyclic Voltammogram for T-T.

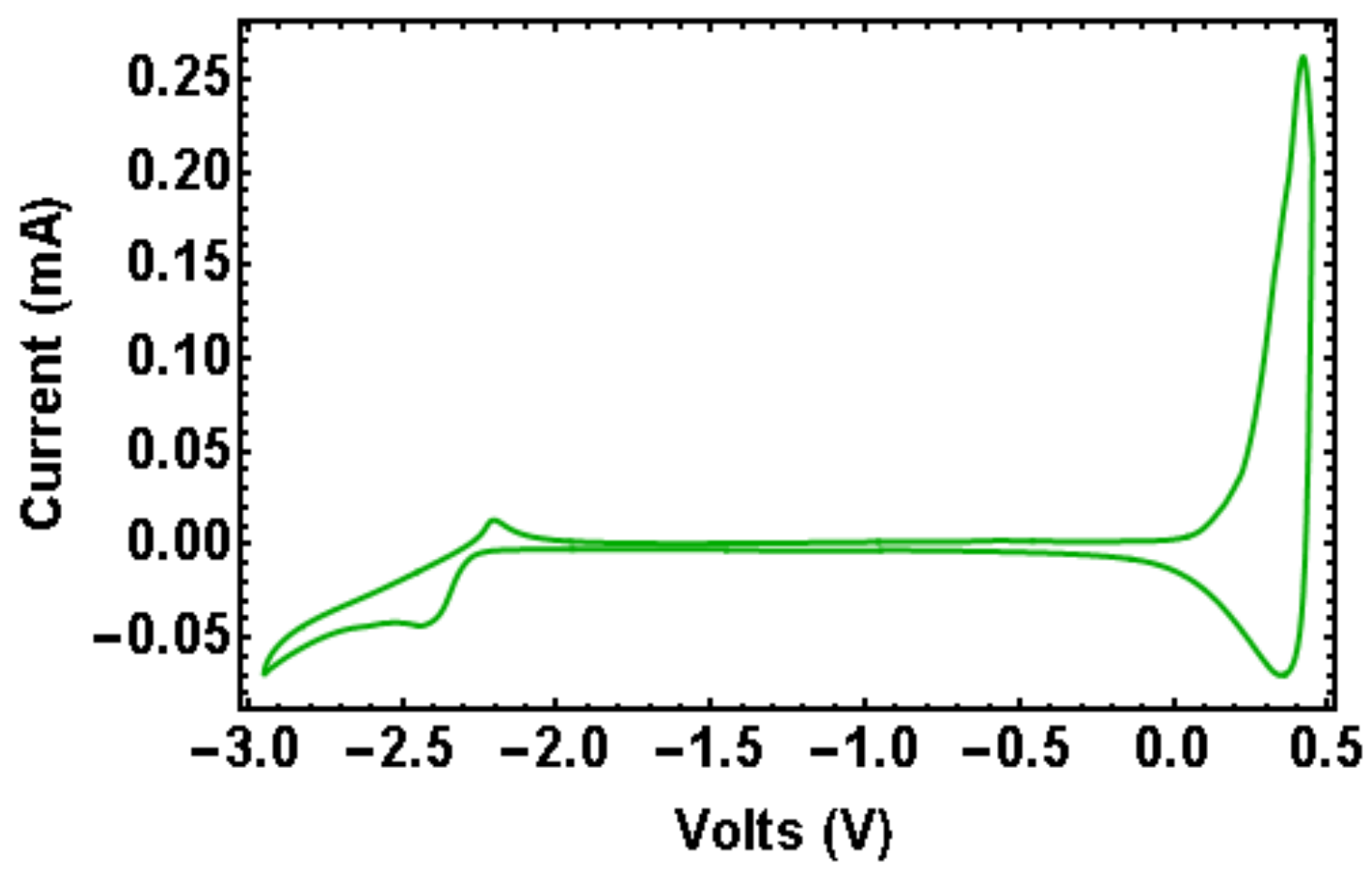

Figure S46. Cyclic Voltammogram for T-Se. 


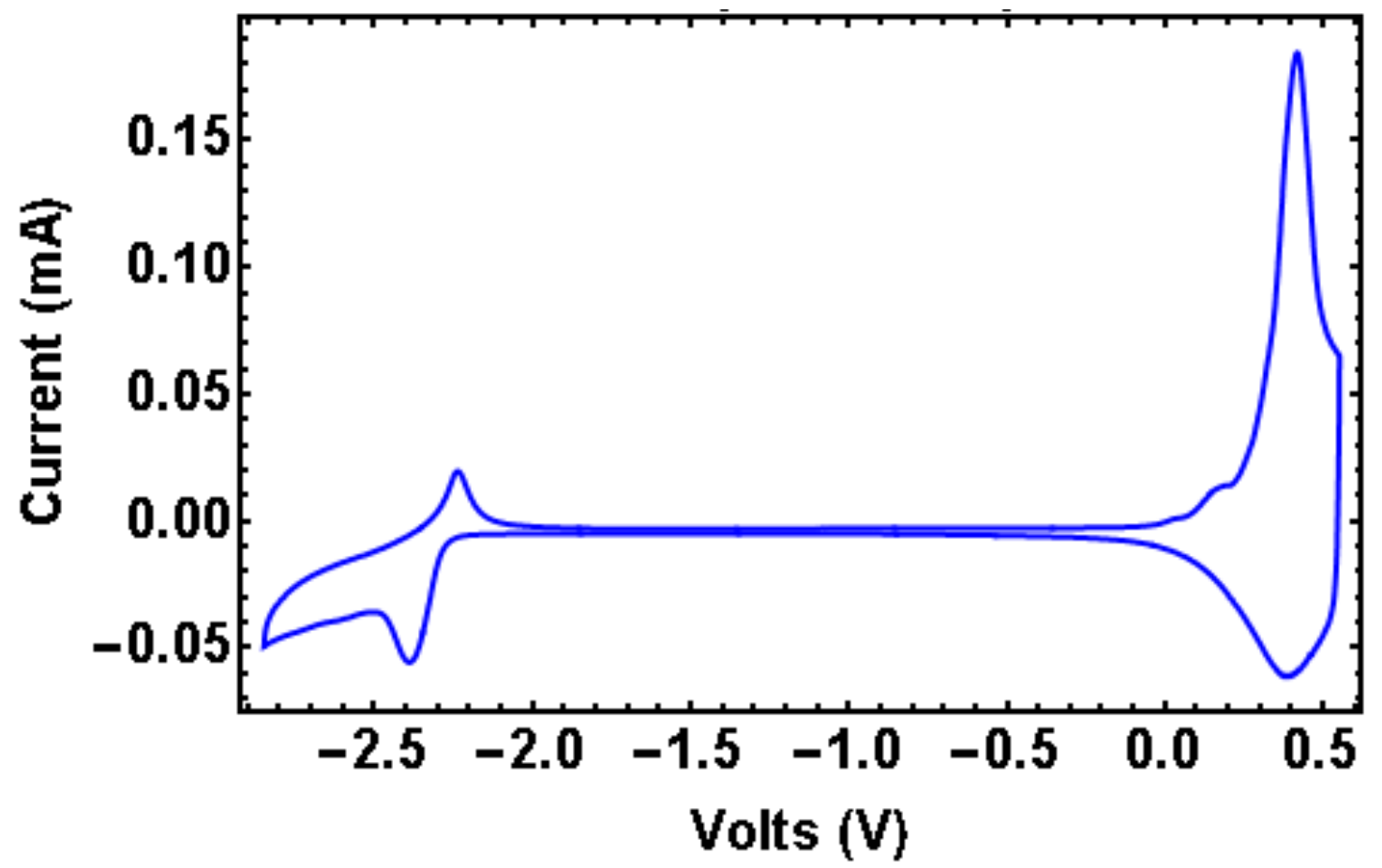

Figure S47. Cyclic Voltammogram for T-T-Se.

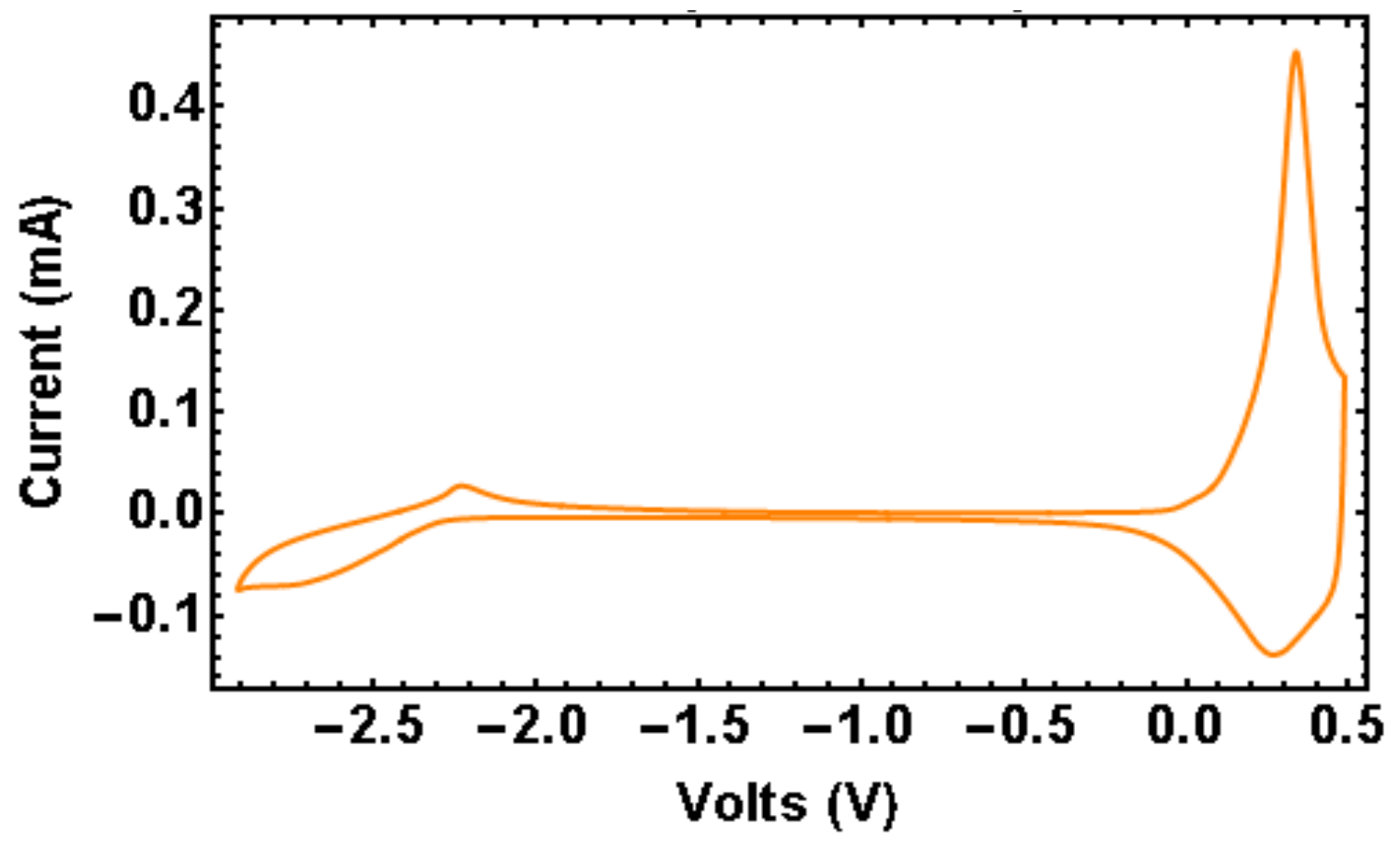

Figure S48. Cyclic Voltammogram for T-Se-Se. 


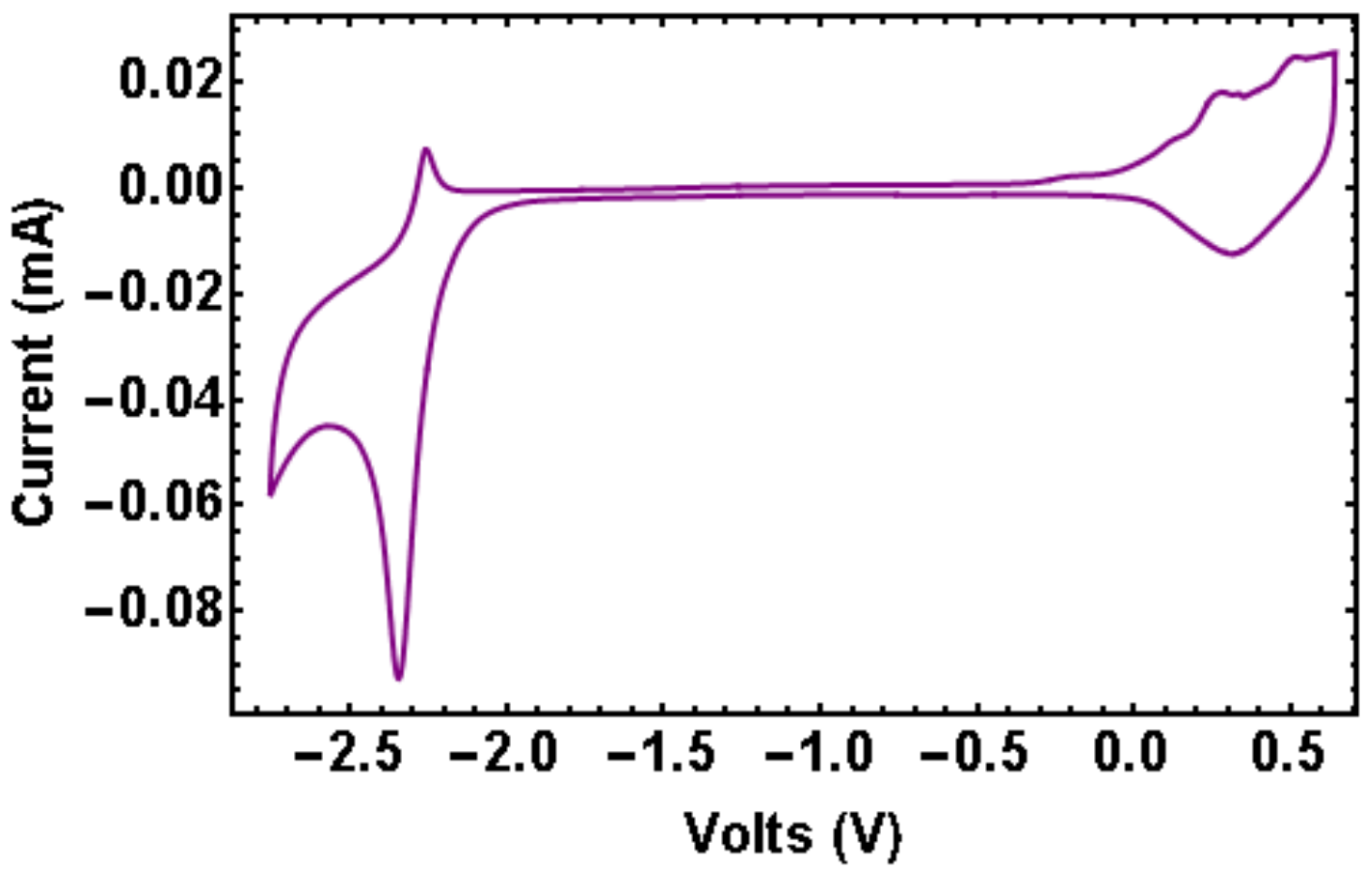

Figure S49. Cyclic Voltammogram for F-T-Se. 


\section{DFT Computation and Analysis}

Time-dependent density-functional theory (TDDFT) calculations were used to model the sequence dependence of the experimentally observed excitation energies of the copolymers. Although the TDDFT calculations are performed on oligomers, our primary interest is in the long-chain, polymer limit. We would therefore like to limit the influence of finite-size, or chain-end effects, on the computations. Calculations on thiophene and selenophene oligomers have found substantial effects from chain ends, with both the bond-lengths and torsional angles varying along the length of the oligomer. ${ }^{12}$ To reduce such effects, the geometry optimizations reported below enforce identical structures for each repeat unit in the oligomer. TDDFT computations on oligomers of varying lengths are then used to derive an exciton model, whose parameters give insight into the sequence dependence of the optical excitation energies of polymers.

Geometry optimizations. To obtain structures that are reflective of those long chains, the geometries are optimized in a manner that enforces each repeat unit to have identical structures. Note that, because some sequences lead to curvature in the polymer backbone, one-dimensional periodic boundary conditions are not applicable. Instead, we construct zmatrices in which the internal coordinates (bond lengths, angles and dihedrals) are shared between repeat units. The investigated repeat units are: [S], [Se], [O], [S Se], [S O], [Se O], [S S Se], and [S Se Se], where S, Se and O indicate thiophene, selenophene and furan heterocycles. Each heterocycle has a single methyl group, to model the effects of the alkyl chain, with all head-to-tail couplings. The twist angle between heterocycles is defined through the $\mathrm{X}-\mathrm{C}-\mathrm{C}-\mathrm{X}$ dihedral angle in the $\mathrm{z}$-matrix (X being the heteroatom), with alternating positive and negative signs such that twisted structures adopt an up- 
down, as opposed to helical structure. Optimizations are performed on oligomers with 6 and 12 heterocycles, because these lengths can accommodate integral numbers of each of the investigated sequences. Although the equivalence of the repeat units is enforced in the computations, end effects may still influence the computed geometries since these are obtained from minimizing the energy of the oligomers. Comparison of the repeat-unit geometries obtained from oligomers of length 6 with those from oligomers of length 12 show only small differences (changes in bond lengths $<0.008 \mathrm{~A}$, bond angles $<0.6^{\circ}$ and dihedrals $<0.06^{\circ}$ ), suggesting that end effects have minimal impacts on the computed geometries.

A complicating issue in the geometry optimizations is the low energy associated with twisted structures, and the strong dependence of the potential energy associated with twisting on the details of the computational methods. ${ }^{12}$ Here, we use the B3LYP functional and compared results obtained with the double-zeta $6-31 \mathrm{G}(\mathrm{d}, \mathrm{p})$ basis set and those obtained with the triple-zeta $6-311 \mathrm{G}(\mathrm{d}, \mathrm{p})$ basis set. Figure S50 shows the torsional potential obtained on oligomers of length 6 . The computations are for uniform twisting of the oligomer, with the reported values corresponding to the energy per dihedral angle. Similar to past work, the twisting energy is found to change substantially with basis set. ${ }^{12 a}$ Although these changes are large in a relative sense, the disagreements are small in an absolute sense, with differences in predicted energies being below $1 \mathrm{kcal} / \mathrm{mol}$. The results from both basis sets agree that, at room temperature, the structure is highly fluxional and that the fluctuations occur about an essentially planar structure. The precise location of the minimum may, for some oligomers, be non-planar. However, we chose to focus on the planar structure since, in the solid state, the structures will be strongly 
influenced by packing forces, and the experimental results in the solid-state suggest that $\pi$-stacking will favor planar structures. Inclusions of the effects of twisting fluctuations on the solution spectra and other photophysical properties is left for future work. ${ }^{13}$

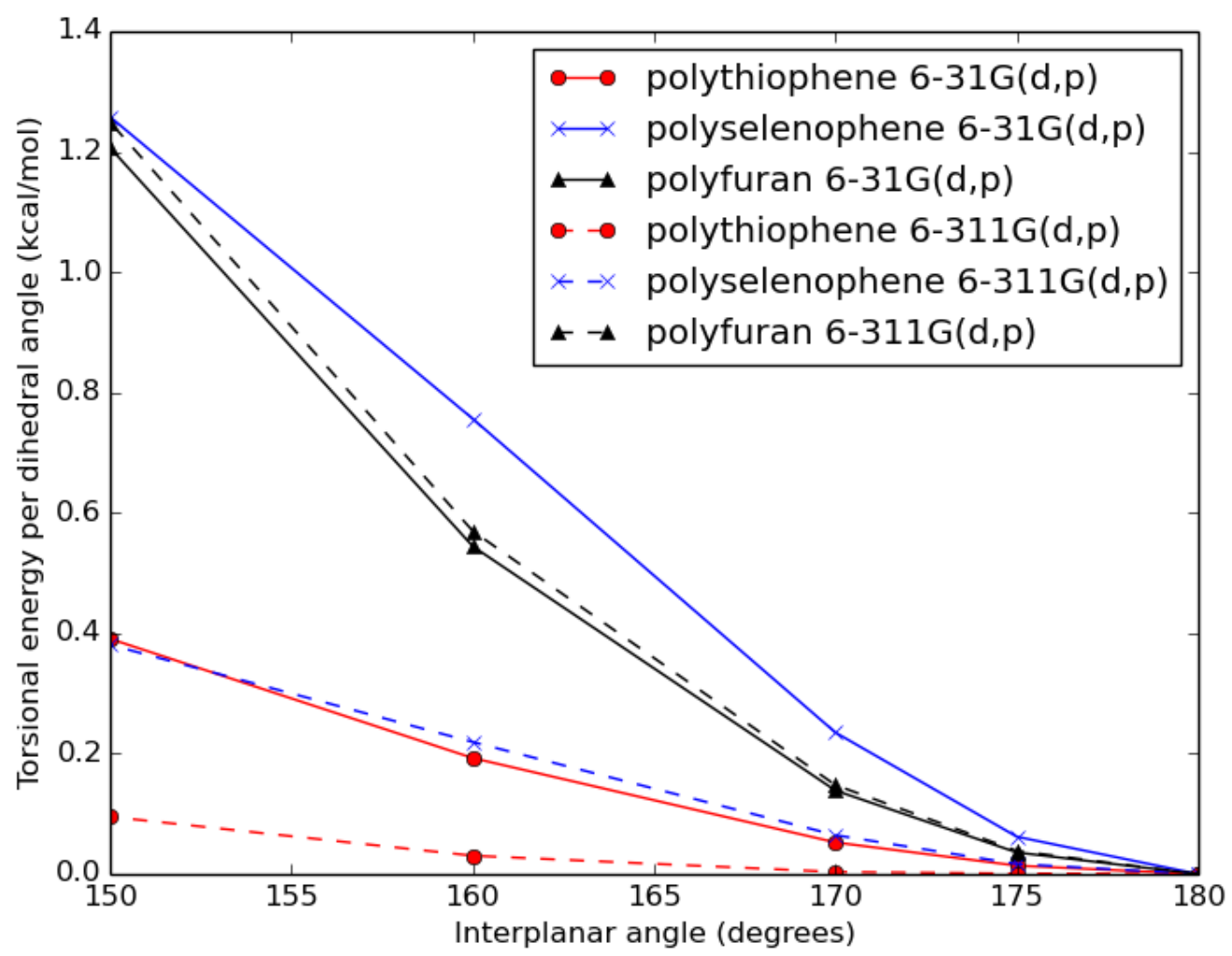

Figure S50. Energy associated with uniform up-down (as opposed to helical) twisting of oligomers with size heterocycles.

For the sequences [ $\mathrm{S} \mathrm{Se}],[\mathrm{S} \mathrm{O}]$, and [Se O], asymmetry in the structure of the repeat unit is expected to lead to curvature in the polymer backbone (Figure 5 in the main text). Table S5 shows the predicted curvature in units of degrees per repeat unit. These curvatures are obtained by measuring the angle between identical, sequential heteroatoms (S-S-S, Se-Se-Se, or O-O-O) along the polymer. The predicted curvatures are substantially larger for sequences incorporating furan units, as expected from the substantially shorter bond length of the C-O bond in furan relative to the C-Se and C-S 
bonds in selenophene and thiophene. The predicted curvatures vary somewhat with basis set, especially for the [S Se] copolymer, where the curvature is relatively modest. In addition, inclusion of the methyl group reduces the predicted curvature, as may be expected due to steric interactions between the side chains and the heterocycles of the polymer backbone.

Table S5. Predicted curvature in alternating copolymers of thiophene, selenophene and furan, in units of degrees per repeat unit.

\begin{tabular}{lllll}
\hline Copolymer & \multicolumn{2}{l}{ With methyl group } & \multicolumn{2}{c}{ Without methyl group } \\
sequence & $6-31 \mathrm{G}(\mathrm{d}, \mathrm{p})$ & $6-311 \mathrm{G}(\mathrm{d}, \mathrm{p})$ & $6-31 \mathrm{G}(\mathrm{d}, \mathrm{p})$ & $6-311 \mathrm{G}(\mathrm{d}, \mathrm{p})$ \\
\hline $\mathrm{S} \mathrm{Se}$ & 3.1 & 4.9 & 5.0 & 5.5 \\
$\mathrm{O} \mathrm{S}$ & 23.0 & 22.9 & 25.0 & 24.9 \\
$\mathrm{O} \mathrm{Se}$ & 26.3 & 27.8 & 29.1 & 30.0 \\
\hline
\end{tabular}

Excited-State calculations. TDDFT calculations were performed using the $6-31 \mathrm{G}(\mathrm{d}, \mathrm{p})$ basis set and a functional, CAMB3LYP, that corrects for long-range charge transfer. Because solvent can have a substantial effect on the predicted excitation energies, selfconsistent reaction field (SCRF) within the Gaussian $09^{14}$ software package is used to include the effects of chloroform solvent in the TDDFT calculations. Results are obtained for all oligomers with between 2 and 12 heterocycles, constructed with integral number of repeat units ([S], [Se], [O], [S Se], [S O], [Se O], [S S Se], and [S Se Se]). Calculations are performed at fixed geometries, constructed using the repeat units optimized as discussed above. The optimized molecular geometries and predicted excitation energies are included in a separate text file available free of charge at pubs.acs.org (geometries.txt).

An exciton model is used to gain insight into the TDDFT results. The exciton model views the excited state as containing an effective particle, an exciton, which is coherently delocalized along the oligomer. Each heterocycle is treated as a single site, 
with the exciton having energy $\alpha_{\mathrm{Se}}, \alpha_{\mathrm{S}}$, or $\alpha_{O}$ when it resides on a selenophene, thiophene or furan site, respectively. Coherent delocalization is due to coupling between sites with magnitude $\beta$. This leads to the following Hamiltonian matrix for the exciton,

$$
H=\left(\begin{array}{cccc}
\alpha_{1} & \beta & & \\
\beta & \alpha_{2} & \ddots & \\
& \ddots & \ddots & \beta \\
& & \beta & \alpha_{N}
\end{array}\right)
$$

where the exciton energy for site $i, \alpha_{\mathrm{i}}$, has values $\alpha_{\mathrm{Se}}, \alpha_{\mathrm{S}}$, or $\alpha_{\mathrm{O}}$ for selenophene, thiophene and furan, respectively. These parameters establish the one-dimensional effective energy landscape along which the exciton is coherently delocalized in the polymer. The coupling between adjacent rings, $\beta$, sets the effective mass of the exciton or, equivalently, the energy stabilization due to exciton delocalization. The lowest-energy state arising from the above Hamiltonian matrix corresponds to the lowest-energy singlet excited state, $S_{1}$, of the oligomer. The parameters are obtained from least squares fits to the results from TDDFT calculations described above, corresponding to all oligomers with between 2 to 12 heterocycles, constructed with integral number of repeat units ([S], [Se], [O], [S Se], [S O], [Se O], [S S Se], and [S Se Se]). Somewhat improved results were obtained by allowing the coupling, $\beta$, between heterocycles where one or both is a furan, $\beta_{\mathrm{O}}$, to have a different magnitude from the other couplings. The fitted model parameters are $\left(\alpha_{\mathrm{Se}}: 5.615 \mathrm{eV}, \alpha_{\mathrm{S}}: 5.777 \mathrm{eV}, \alpha_{\mathrm{O}}: 6.356 \mathrm{eV}, \beta:-1.715 \mathrm{eV}, \beta_{\mathrm{O}}:-1.819 \mathrm{eV}\right)$. Figure S51 shows the correlation between the excitation energy from TDDFT and that predicted from the model. The predicted values have a root mean square (RMS) error of $0.015 \mathrm{eV}$, a mean absolute error (MAE) of $0.013 \mathrm{eV}$, and a maximum error of $0.048 \mathrm{eV}$. 
The disagreement between the model and the TDDFT results are sufficiently low that the model parameters may be taken as a concise summary of the TDDFT results.

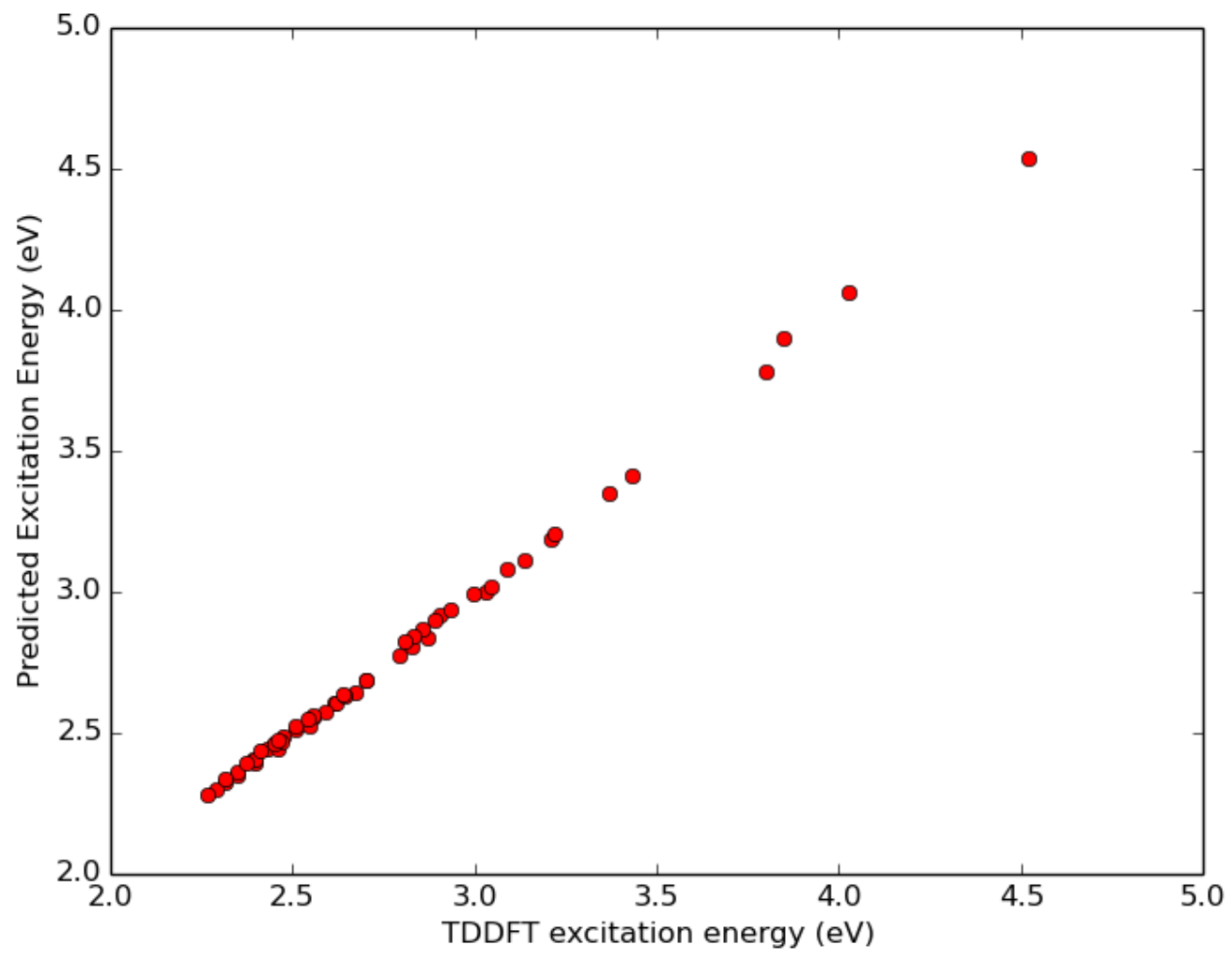

Figure S51. Correlation between the predictions of the exciton model and the energy of the lowest excited state $\left(\mathrm{S}_{1}\right)$ computed from TDDFT.

The experimental results indicate that the excitation energy depends linearly on the $\% \mathrm{Se}$ in the polymer. This linear dependence on $\% \mathrm{Se}$ is consistent with the exciton model derived above. The exciton present in the excited state will be uniformly delocalized over the polymer, provided the coupling between rings, $|\beta|$, is substantially larger than the difference in energy between the rings, $\left|\alpha_{S e}-\alpha_{S}\right|$. The parameters obtained from fitting the exciton model to TDDFT indicate that the coupling is an order magnitude larger than the differences in the site energies for thiophene-selenophene copolymers. The observed 
linear dependence of excitation energy on $\%$ Se composition is therefore consistent with the results of the exciton model. 


\section{References}

(1) Hollinger, J.; Jahnke, A. A.; Coombs, N.; Seferos, D. S. J. Am. Chem. Soc. 2010, 132, 8546-8547.

(2) Qiu, Y.; Fortney, A.; Tsai, C.-H.; Baker, M. A.; Gil, R. R.; Kowalewski, T.; Noonan, K. J. T. ACS Macro Lett. 2016, 5, 332-336.

(3) Castañar, L.; Sistaré, E.; Virgili, A.; Williamson, R. T.; Parella, T. Magn. Reson. Chem. 2015, 53, 115-119.

(4) Bard, A. J.; Faulkner, L. R. Electrochemical Methods: Fundamentals and Applications; John Wiley and Sons, Inc.: New York, 2001.

(5) Renaud, G.; Lazzari, R.; Leroy, F. Surf. Sci. Rep. 2009, 64, 255-380.

(6) (a) Hagemann, O.; Jørgensen, M.; Krebs, F. C. J. Org. Chem. 2006, 71, 5546-5559.

(b) Krebs, F. C.; Spanggaard, H. Sol. Energy Mater. Sol. Cells 2005, 88, 363-375.

(7) Li, W.; Maddux, T.; Yu, L. Macromolecules 1996, 29, 7329-7334.

(8) Yagai, S.; Suzuki, M.; Lin, X.; Gushiken, M.; Noguchi, T.; Karatsu, T.; Kitamura, A.; Saeki, A.; Seki, S.; Kikkawa, Y.; Tani, Y.; Nakayama, K.-i. Chem.-Eur.J. 2014, 20, $16128-16137$.

(9) Qiu, Y.; Mohin, J.; Tsai, C.-H.; Tristram-Nagle, S.; Gil, R. R.; Kowalewski, T.; Noonan, K. J. T. Macromol. Rapid Commun. 2015, 36, 840-844.

(10) Lai, Y.-Y.; Tung, T.-C.; Liang, W.-W.; Cheng, Y.-J. Macromolecules 2015, 48, 2978-2988.

(11) Heeney, M.; Zhang, W.; Crouch, D. J.; Chabinyc, M. L.; Gordeyev, S.; Hamilton, R.; Higgins, S. J.; McCulloch, I.; Skabara, P. J.; Sparrowe, D.; Tierney, S. Chem. Commun. 2007, 5061-5063.

(12) (a) Zade, S. S.; Bendikov, M. Chem.-Eur. J. 2007, 13, 3688-3700. (b) Zade, S. S.; Zamoshchik, N.; Bendikov, M. Chem.-Eur. J. 2009, 15, 8613-8624. (c) Tsoi, W. C.; James, D. T.; Domingo, E. B.; Kim, J. S.; Al-Hashimi, M.; Murphy, C. E.; Stingelin, N.; Heeney, M.; Kim, J.-S. ACS Nano 2012, 6, 9646-9656.

(13) Liu, L. T.; Yaron, D.; Berg, M. A. J. Phys. Chem. C. 2007, 111, 5770-5782.

(14) Gaussian 09, Revision E.01, Frisch, M. J.; Trucks, G. W.; Schlegel, H. B.; Scuseria, G. E.; Robb, M. A.; Cheeseman, J. R.; Scalmani, G.; Barone, V.; Mennucci, B.; Petersson, G. A.; Nakatsuji, H.; Caricato, M.; Li, X.; Hratchian, H. P.; Izmaylov, A. F.; Bloino, J.; Zheng, G.; Sonnenberg, J. L.; Hada, M.; Ehara, M.; Toyota, K.; Fukuda, R.; Hasegawa, J.; Ishida, M.; Nakajima, T.; Honda, Y.; Kitao, O.; Nakai, H.; Vreven, T.; Montgomery, J. A., Jr.; Peralta, J. E.; Ogliaro, F.; Bearpark, M.; Heyd, J. J.; Brothers, E.; Kudin, K. N.; Staroverov, V. N.; Kobayashi, R.; Normand, J.; Raghavachari, K.; Rendell, A.; Burant, J. C.; Iyengar, S. S.; Tomasi, J.; Cossi, M.; Rega, N.; Millam, J. M.; Klene, M.; Knox, J. E.; Cross, J. B.; Bakken, V.; Adamo, C.; Jaramillo, J.; Gomperts, R.; Stratmann, R. E.; Yazyev, O.; Austin, A. J.; Cammi, R.; Pomelli, C.; Ochterski, J. W.; Martin, R. L.; Morokuma, K.; Zakrzewski, V. G.; Voth, G. A.; Salvador, P.; Dannenberg, J. J.;

Dapprich, S.; Daniels, A. D.; Farkas, Ö.; Foresman, J. B.; Ortiz, J. V.; Cioslowski, J.; Fox, D. J. Gaussian, Inc., Wallingford CT, 2009. 